Aus der Abteilung Klinische Pharmakologie

(Prof. Dr. med. J. Brockmöller)

im Zentrum Pharmakologie und Toxikologie

der Medizinischen Fakultät der Universität Göttingen

\title{
Auswirkungen von CYP2D6-, CYP2C9- und CYP2C19- Polymorphismen auf Pharmakokinetik und Wirkungen von Carvedilol
}

\author{
INAUGURAL-DISSERTATION \\ zur Erlangung des Doktorgrades \\ der Medizinischen Fakultät \\ der Georg-August-Universität zu Göttingen
}

vorgelegt von

Şenol Gültepe

aus

Goslar

Göttingen 2011 
Dekan:

I. Berichterstatter:

II. Berichterstatter/in:

III. Berichterstatter/ in:

Tag der mündlichen Prüfung:
Prof Dr. med. C. Frömmel

Prof. Dr. med. J. Brockmöller

Frau Prof. Dr. med. Virsik-Köpp

PD Dr. med. Vollmann

18.10.2011 


\section{Inhaltsverzeichnis}

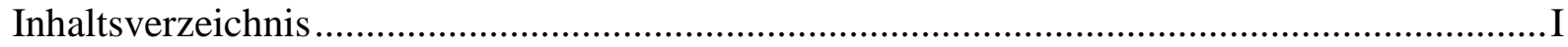

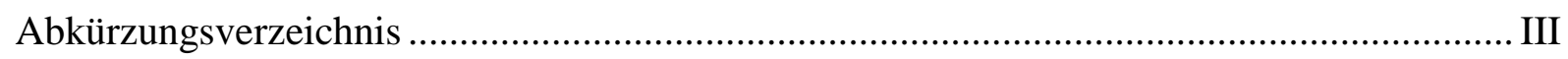

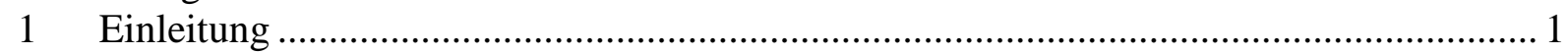

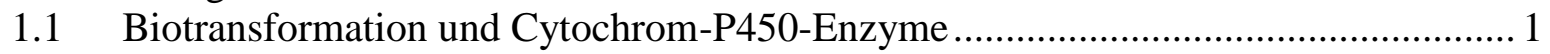

1.1.1 Arzneistoffmetabolismus oder Biotransformation ........................................ 2

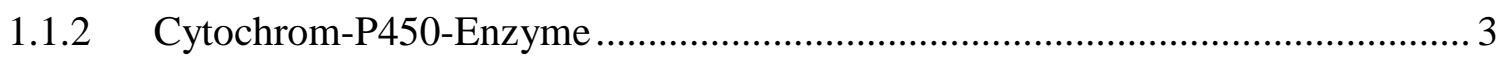

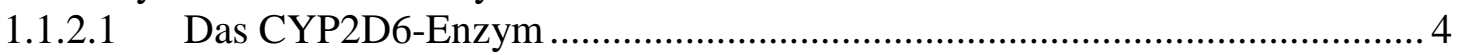

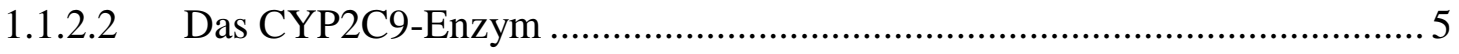

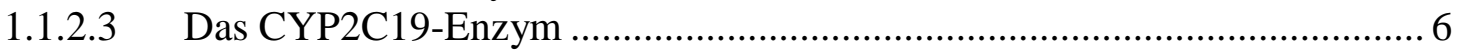

1.2 Genetischer Polymorphismus in der Medizin .................................................... 7

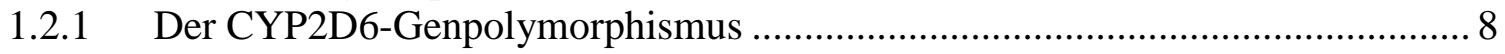

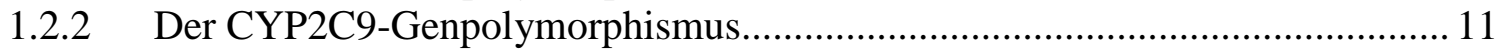

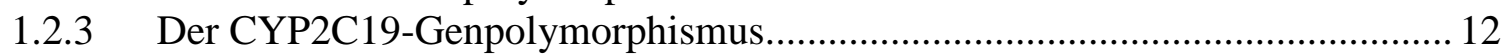

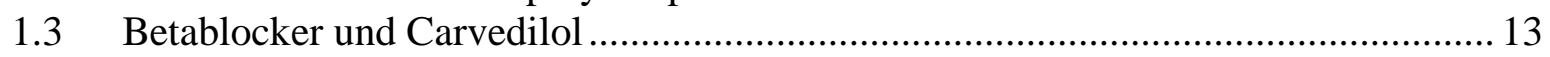

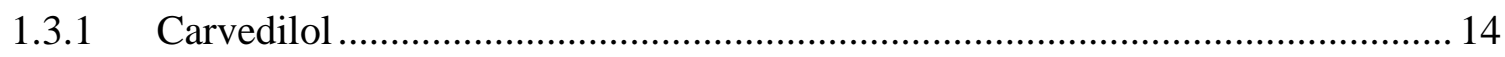

1.3.1.1 Chemie und Wirkungsweise des Carvedilol .......................................... 14

1.3.1.2 Indikation, Kontraindikation und Nebenwirkung ................................... 15

1.3.1.4 Pharmakokinetische Parameter ............................................................ 17

1.3.1.5 Metabolisierung von Carvedilol durch Cytochrom-Enzyme ..................... 18

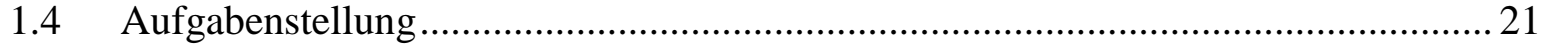

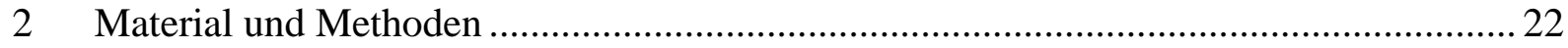

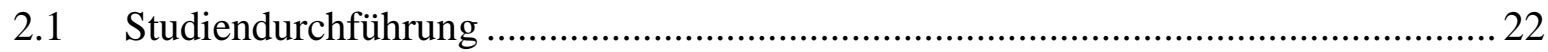

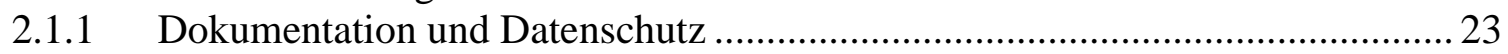

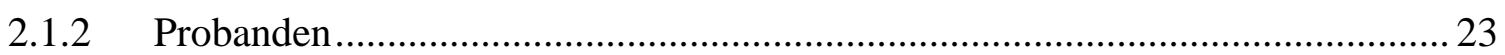

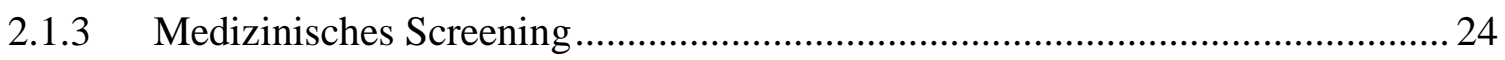

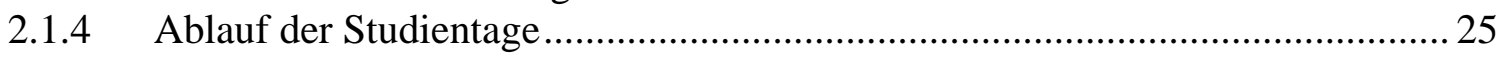

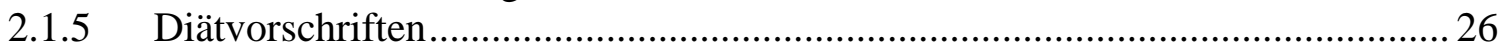

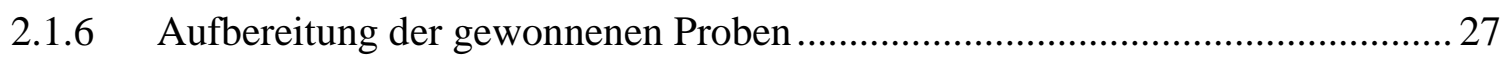

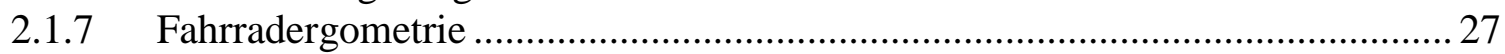

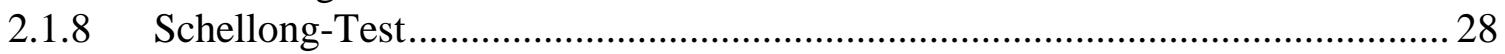

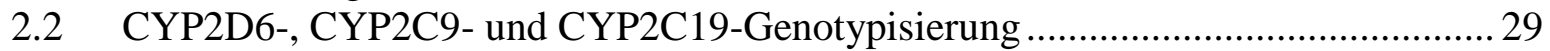

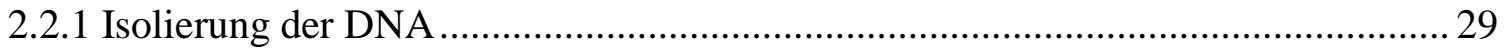

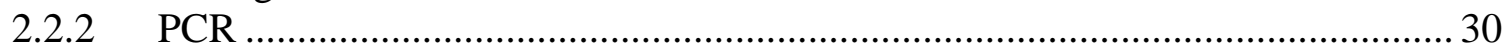

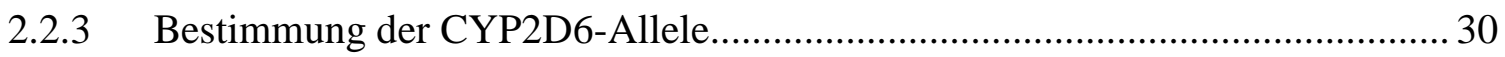

2.2.3.1 Identifizierung der Allele $* 2, * 3, * 4, * 6, * 9, * 10, * 17$ und $* 41$............... 31

2.2.3.2. Identifizierung der CYP2D6-Gendeletion (Allel *5) und der CYP2D6-

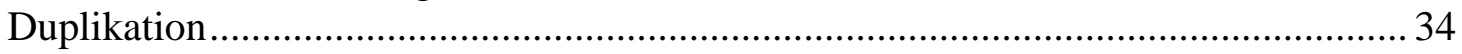

2.2.4 Bestimmung der CYP2C9- und CYP2C19-Allele ......................................... 37

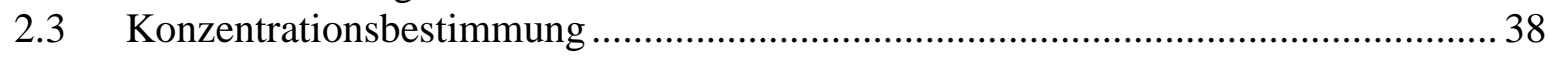

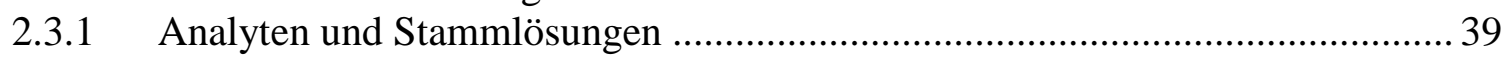

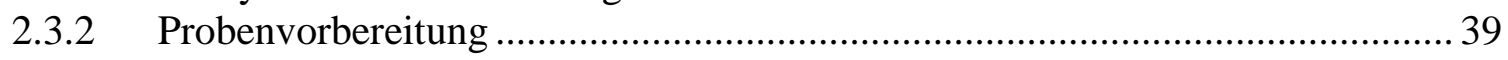

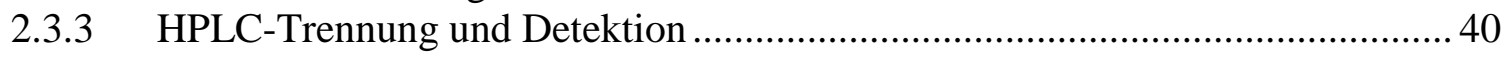

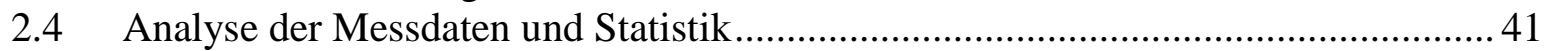

2.4.1 Pharmakokinetische Begriffe und Parameter.................................................. 41

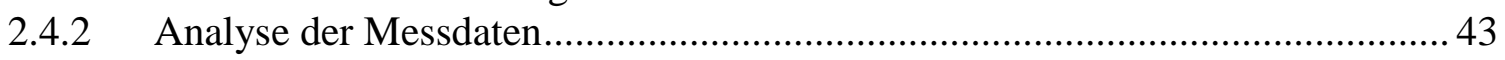

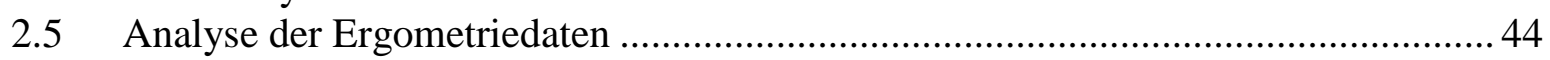

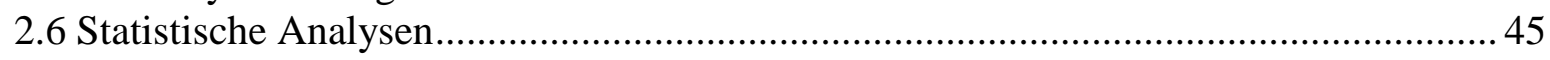

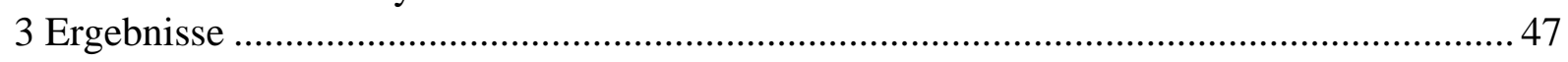


Inhaltsverzeichnis

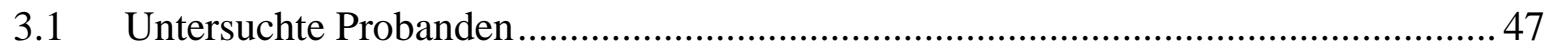

3.2 Art und Häufigkeit der genetischen Polymorphismen ........................................ 47

3.3. Darstellung der pharmakokinetischen Ergebnisse............................................... 49

3.3.1 Pharmakokinetik von R- und S-Carvedilol in Relation zum CYP2D6-Genotyp50

3.3.1.1 Carvedilol-Metaboliten in Relation zum CYP2D6-Genotyp....................... 53

3.3.2 Carvedilol-Enantiomere und -Metaboliten in Relation zum CYP2C9- und

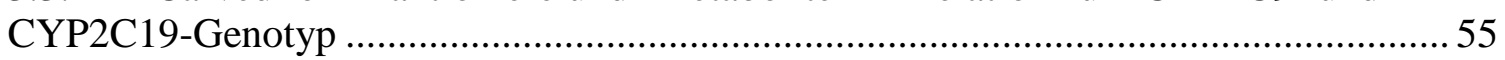

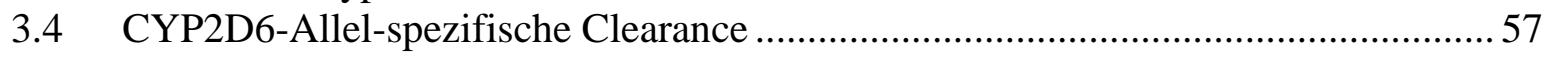

3.5 Wirkungen von Carvedilol auf Herzfrequenz und Blutdruck in der Ergometrie ...... 59

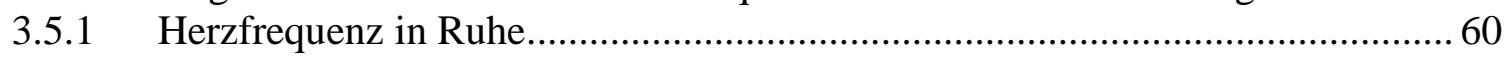

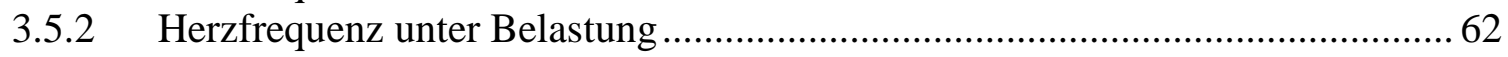

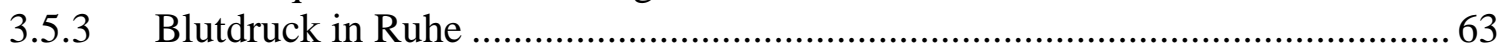

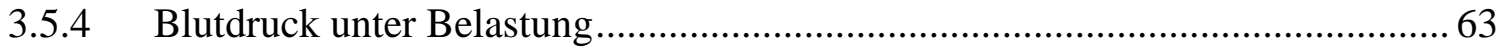

3.6 Herzfrequenz- und Blutdruck-Wirkungen von Carvedilol in der Ergometrie in

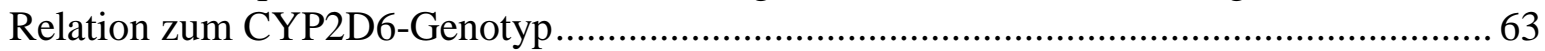

3.6.1 Herzfrequenz-Wirkungen von Carvedilol in Relation zum CYP2D6-Genotyp. 64

3.6.2 Blutdruck-Wirkungen von Carvedilol in Relation zum CYP2D6-Genotyp ...... 66

3.7 Wirkungen von Carvedilol auf Herzfrequenz und Blutdruck im Schellong-Test in

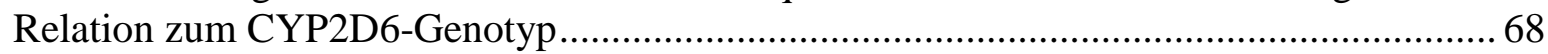

3.7.1 Herzfrequenz im Liegen und Stehen in Relation zum CYP2D6-Genotyp......... 68

3.7.2 Systolischer Blutdruck im Liegen und Stehen in Relation zum CYP2D6-

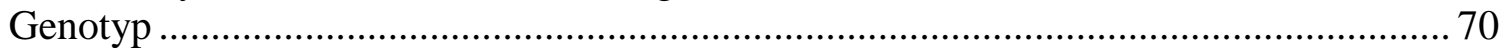

3.7.3 Diastolischer Blutdruck im Liegen und Stehen in Relation zum CYP2D6-

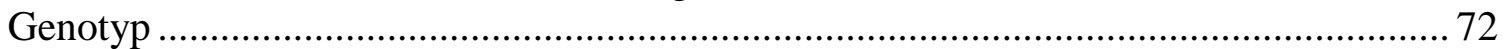

3.8 Carvedilol-Wirkungen in Relation zum CYP2C9- und CYP2C19-Genotyp ............. 73

3.9 Nebenwirkungen in Relation zum CYP2D6-Genotyp .......................................... 74

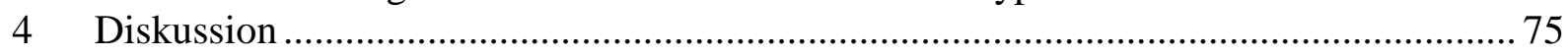

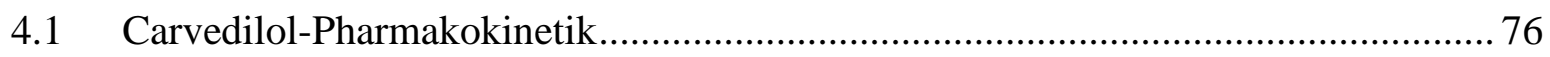

4.1.1 Pharmakokinetik der Carvedilol-Enantiomere in Relation zum CYP2D6-

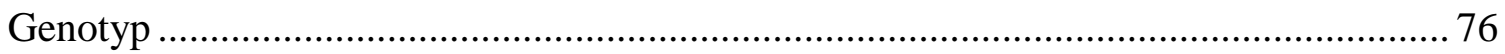

4.1.2 CYP2D6-Allel-spezifische Clearance ......................................................... 79

4.1.3 Pharmakokinetik der Carvedilol-Metaboliten in Relation zum CYP2D6-

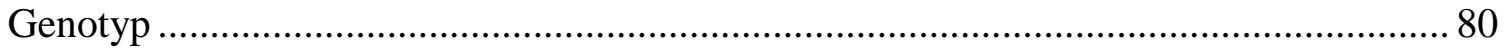

4.1.4 Pharmakokinetik von Carvedilol und seiner Metaboliten in Relation zum

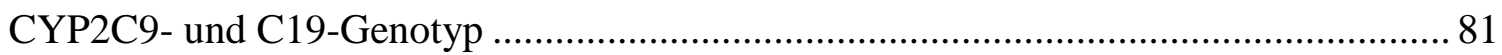

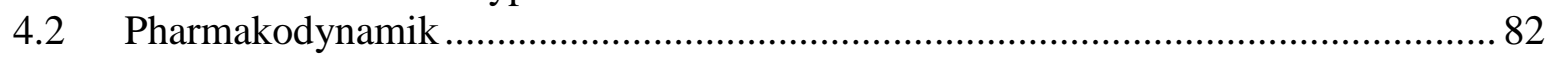

4.2.1 Pharmakodynamische Daten von Carvedilol im Vergleich zur Literatur .......... 83

4.2.2 Pharmakodynamische Daten in Relation zum CYP2D6-Genotyp...................... 85

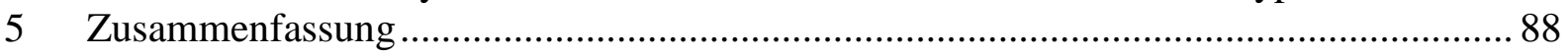

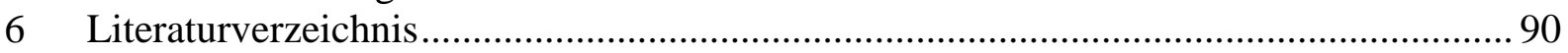




\section{Abkürzungsverzeichnis}

AUC

bp

${ }^{\circ} \mathrm{C}$

ca.

$\mathrm{Cl}$

$\mathrm{C}_{\max }$

CRF

CYP

ddNTP

DNA

dNTP

$\mathrm{EC}_{50}$

EDTA

EKG

EM

$\mathrm{E}_{\max }$

et al.

$\mathrm{F}$

GITC

$\mathrm{h}$

$\mathrm{HF}$

HPLC

IM

JTTT

Kap.

$\mathrm{kb}$

$\mathrm{kg}$

$\mathrm{L}$

$\mathrm{m}^{2}$

MBI

mg

$\mathrm{Mg}^{2+}$ area under the curve (Fläche unter der Konzentrations-Zeit-Kurve)

Base pair, Basenpaare

Grad Celsius

circa

Clearance

maximale Konzentration

Case report form (,Dokumentations-Vorlage“)

Cytochrom-P450

Didesoxynucleosidtriphosphat

desoxyribonucleic acid

Desoxynukleosidtriphosphat

Michaelis-Menten-Konstante

Ethylendiamintetraacetat

Elektrokardiogramm

Exstensive metabolizer

maximaler Effekt

et alii (und andere)

Bioverfügbarkeit

Glucopyranosyl-isothiocyanat

Stunde

Herzfrequenz

High performance liquid chromatography

Intermediate metabolizer

Jonckheere-Terpstra-Trend-Test

Kapitel

Kilobasenpaare

Kilogramm

Liter

Quadratmeter

Methylbenzylisocyanat

Milligramm

Magnesium 
Abkürzungsverzeichnis

\begin{tabular}{|c|c|}
\hline $\min$ & Minute \\
\hline $\mathrm{ml}$ & Milliliter \\
\hline $\mathrm{mM}$ & Millimolar \\
\hline mmol & Millimol \\
\hline MRT & Mean residence time (mittlere Verweildauer) \\
\hline$\mu \mathrm{L}$ & Mikroliter \\
\hline$\mu \mathrm{M}$ & Mikromolar \\
\hline ng & Nanogramm \\
\hline $\mathrm{nm}$ & Nanometer \\
\hline $\mathrm{nM}$ & Nanomolar \\
\hline nmol & Nanomol \\
\hline Nr. & Nummer \\
\hline $\mathrm{OH}$ & Hydroxyl-Gruppe \\
\hline $\mathrm{P}$ & P-Wert \\
\hline PCR & Polymerase Chain Reaction \\
\hline PIT & Point of time (Untersuchungsabschnitt) \\
\hline PM & Poor metabolizer \\
\hline S. & Seite \\
\hline SBPE & Single Base Primer Extension \\
\hline sek & Sekunde \\
\hline SNP & Single nucleotide Polymorphism \\
\hline $\mathrm{t}_{1 / 2}$ & Halbwertszeit \\
\hline Tab. & Tabelle \\
\hline Taq & Thermus aquaticus \\
\hline$t_{\max }$ & Zeitpunkt der maximalen Plasmakonzentration \\
\hline $\mathrm{U}$ & Unit \\
\hline UM & Ultrarapid metabolizer \\
\hline V & Verteilungsvolumen \\
\hline z. B. & zum Beispiel \\
\hline
\end{tabular}


Einleitung

\section{$1 \quad$ Einleitung}

Mehr als $40 \%$ aller Medikamente, unter diesen auch Carvedilol, werden beim Menschen durch die drei Enzyme Cytochrom-P450-2D6 (CYP2D6), Cytochrom-P450-2C9 (CYP2C9) und Cytochrom-P450-2C19 (CYP2C19) metabolisiert. Dabei existieren in der Aktivität dieser drei Enzyme außerordentlich große interindividuelle Unterschiede. Diese Unterschiede können entweder angeboren (Genpolymorphismus) oder aber erworben (Enzyminduktion oder Enzyminhibition) sein. Der Schwerpunkt der vorliegenden Arbeit soll auf der Bedeutung der angeborenen Varianten der Enzyme CYP2D6, CYP2C9 und CYP2C19 für die Pharmakokinetik und die Wirkungen des Betablockers Carvedilol liegen.

Es ist bereits seit mehreren Jahrzehnten bekannt, dass es für Substrate dieser Enzyme Gruppen von Menschen gibt, die keine Aktivität haben (poor metabolizer), sowie solche mit erniedrigter Aktivität (intermediate metabolizer) und mit normal hoher Aktivität (extensive metabolizer). Zumindest für das Enzym CYP2D6 sind darüber hinaus auch Personen mit weit überdurchschnittlich hoher Aktivität bekannt (ultrarapid metabolizer). Diese Genpolymorphismen können prinzipiell sowohl die Metabolisierung (Pharmakokinetik) als auch die Wirkung (Pharmakodynamik) eines Medikamentes beeinflussen. In der hier beschriebenen klinischen Studie wurde gesunden weiblichen und männlichen Probanden einmalig $25 \mathrm{mg}$ Carvedilol verabreicht und dessen Pharmakokinetik, Wirkungen und Nebenwirkungen untersucht und schließlich in Relation zur genetischen Variabilität der Cytochrom-P450-Enzyme CYP2D6, CYP2C9 und CYP2C19 analysiert.

Im Folgenden soll zunächst auf die Biotransformation und die Rolle, die das CytochromP450-System dabei spielt, eingegangen werden. Danach erfolgt eine Darstellung der Enzyme CYP2D6, CYP2C9 und CYP2C19 mit einer detaillierten Darstellung der bei diesen Enzymen bereits bekannten häufigen Genpolymorphismen. Zuletzt soll die Pharmakologie und Pharmakokinetik von Carvedilol näher behandelt werden.

\subsection{Biotransformation und Cytochrom-P450-Enzyme}

Wird ein Arzneimittel eingenommen, so durchläuft es im Körper mehrere pharmakokinetische Teilprozesse. Zunächst wird es aus der Darreichungsform freigesetzt (Liberation), dann resorbiert (Absorption), anschließend kommt es zur Verteilung 
Einleitung

(Distribution) in die unterschiedlichen Gewebe des menschlichen Körpers. Darauf erfolgt der Metabolismus, bei der Cytochrom-P450-Enzyme beteiligt sind, als ein sehr bedeutender Teilschritt in der Pharmakokinetik (Biotransformation) und schließlich die Ausscheidung (Exkretion) von der unveränderten Substanz oder von deren Stoffwechselprodukten (Metaboliten). Diese 5 Teilprozesse werden in der Arzneimittelforschung mit dem Akronym LADME zusammengefasst.

\subsubsection{Arzneistoffmetabolismus oder Biotransformation}

Bei vielen Arzneimitteln hat nicht nur die Muttersubstanz selbst, sondern auch ein oder mehrere ihrer Metaboliten pharmakologische Wirkungen. Falls es zu Störungen innerhalb des Metabolismus von der Muttersubstanz über die Metabolitenbildung bis zur Metabolitenausscheidung kommt, hat dies klinische Auswirkungen durch eine Verstärkung oder Verminderung der Wirksamkeit des Medikaments oder seiner Metaboliten. Entsprechend wichtig ist es, die Prinzipien der Biotransformation in diese Metaboliten zu kennen. Die große Familie der Cytochrom-P450-Enzyme ist dabei an der Biotransformation von etwa $3 / 4$ aller Medikamente beteiligt (Zanger et al. 2008). Die prinzipiellen Reaktionen und Konsequenzen des Arzneimittel-Stoffwechsels sollen im Folgenden beschrieben werden.

Für den Fall, dass ein Medikament oder eine andere chemische Substanz (Xenobiotika) aufgenommen werden, haben alle tierischen Organismen Mechanismen entwickelt diese Fremdstoffe so zu metabolisieren, dass sie in der Regel ohne zu akkumulieren aus dem Organismus eliminiert werden können. Ist die Substanz hydrophil, so kann sie leicht renal ausgeschieden werden. Die renale Elimination von hydrophoben Molekülen dagegen ist erschwert. Dies gilt auch für die Elimination über die Leber (biliäre Elimination), da sehr hydrophobe Substanzen zwar über die Galle mittels Gallensäuren sezerniert werden können, dann aber wieder rückresorbiert werden. Damit aber auch lipophile Stoffe aus dem Körper eliminiert werden können, müssen diese zunächst zu inaktiven polareren Substanzen verstoffwechselt werden. Dies geschieht in der Phase-I- und Phase-II-Reaktion, wobei die entsprechenden Enzyme sich im endoplasmatischen Retikulum in der Leber, aber auch im Darm befinden (Boelsterli 2002). Nur wenige Substanzen wie einige Schwermetalle und einige nicht metabolisierbare organische Verbindungen (persistent organic polutants) können nicht metabolisiert und eliminiert werden und stellen entsprechend eine hohe Belastung für Mensch und Umwelt dar. 
Einleitung

In Phase-I-Reaktionen kommt es z. B. durch Oxidation, Reduktion und Hydrolyse zur Veränderung der Molekülstruktur. Da hierbei eine funktionelle Gruppe eingeführt wird, bezeichnet man die Phase-I-Reaktionen auch als Funktionalisierungsreaktionen. Die Enzyme der Cytochrom-P450-Superfamilie haben eine wichtige Rolle bei der Oxidation und Reduktion der meisten Arzneistoffe (siehe unten). Andere Enzyme der Phase-I-Reaktion sind z. B. Flavin-haltige Monooxygenasen, Alkoholdehydrogenasen, Aldehyddehydrogenasen, Epoxidhydrolasen und Esterasen.

Phase-II-Reaktionen stellen Kopplungsreaktionen (Konjugationsreaktionen) dar, die zu einer besseren Wasserlöslichkeit und somit auch zu einer besseren Elimination über Nieren oder Faeces führen. Konjugiert werden die Phase-I-Produkte z. B. mit Glucuronsäure, Schwefelsäure, Glutathion oder Acetat mit Hilfe der entsprechenden Enzyme UDP-Glucuronosyltransferase, Sulfotransferase, Glutathion-S-Transferase oder N-Acetyltransferase (Boelsterli 2002). Da Cytochrom-P450-Enzyme für die Biotransformation von großer Wichtigkeit sind, soll im Folgenden darauf näher eingegangen werden

\subsubsection{Cytochrom-P450-Enzyme}

Cytochrom-P450-Enzyme kommen in einigen Prokaryonten und in allen Eukaryonten vor. Ihre Nomenklatur erfolgt nicht nach ihrer katalytischen Funktion, sondern entsprechend der genetischen Beziehung dieser Enzyme zueinander. Diese wird aus der Ähnlichkeit der Aminosäuresequenzen beziehungsweise der DNA-Sequenzen hergeleitet. Die Nomenklatur setzt sich aus dem Wortstamm CYP (Cytochrom-P450), gefolgt von einer arabischen Ziffer, die die Familie angibt, gefolgt von einem Buchstaben, der die Unter(Sub)-Familie angibt und einer weiteren arabischen Ziffer für Isoformen in einer Unterfamilie, zusammen. So bedeutet CYP2D6, dass dieses Enzym in die Familie 2 und in die Subfamilie D mit der Isoform Nummer 6 gehört. In eine Familie werden alle Enzyme subsumiert, deren Aminosäuresequenzen zu mehr als $40 \%$ übereinstimmen. Stimmt die Aminosäuresequenz innerhalb einer Familie zu mehr als 55\% überein, so sind diese Enzyme Teil einer Subfamilie (van der Weide und Hinrichs 2006).

Die Mehrheit (ca. 78\%) der hepatisch metabolisierten Medikamente wird durch CytochromP450-Enzyme der Familien 1, 2 und 3 verstoffwechselt, wobei CYP3A4/5 37\%, CYP2C9 17\%, CYP2D6 15\%, CYP2C19 10\%, CYP1A2 9\%, CYP2C8 6\% und CYP2B6 4\% der 
Einleitung

Metabolisierung übernehmen (Zanger et al. 2008). Dementsprechend haben CYP3A4/5, CYP2C9, CYP2D6 und CYP2C19 die größte Bedeutung im Arzneimittelmetabolismus.

CYPs sind Hämoproteine, die durch den Besitz eines Eisen-Ions molekularen Sauerstoff oder Kohlenmonoxid (CO) binden können. Da Cytochrom-P450-Enzyme nach Reduktion mit Natriumdithionit und Äquilibrierung mit Kohlenmonoxid Licht der Wellenlänge $450 \mathrm{~nm}$ stark absorbieren, wurde die Zahl 450 in der Bezeichnung Cytochrom-P450 verwandt (Mutschler et al. 2001). Für die Oxidationsreaktion des Substrates benötigt das CYP-Enzym den Kofaktor $\mathrm{NADPH}+\mathrm{H}^{+}$sowie das Enzym Cytochrom-P450-Reduktase. Dabei entstehen das hydroxylierte Substrat und Wasser (Boelsterli 2002).

CYP-Enzyme werden zum größten Teil in der Leber, aber auch im Darm, Nasenepithel, in der Lunge und in der Haut gefunden (Boelsterli 2002). Da die CYP-Enzyme CYP2D6, CYP2C9 und CYP2C19 für den Metabolismus von Carvedilol entscheidend sein sollen, soll in den folgenden Kapiteln näher auf diese eingegangen werden.

\subsubsection{Das CYP2D6-Enzym}

Das CYP2D6-Gen befindet sich auf Chromosom 22 (Gough et al. 1993) und bildet mit den Pseudogenen CYP2D7P und CYP2D8P ein Gencluster (Kimura et al. 1989). Das aus neun Exons bestehende Gen kodiert für ein Protein aus 497 Aminosäuren (Kimura et al. 1989; Ingelman-Sundberg 2005). Obwohl dieses Enzym mit ca. 2\% nur einen kleinen Teil der hepatischen CYP-Enzyme ausmacht (Shimada et al. 1994), ist seine Rolle in der Arzneimittelmetabolisierung von immenser Bedeutung, da ca. 15 - 20\% aller Arzneimittel durch dieses Enzym verstoffwechselt werden (Zanger et al. 2004; Zanger et al. 2008).

CYP2D6-Substrate sind gemeinhin lipophile Basen, häufig mit einem quartären und somit positiv geladenen Stickstoffatom in einer Entfernung von etwa 5 bis 7 Angstrøm zum Kohlenstoffatom, welches vom CYP2D6-Enzym oxidiert wird (Ingelman-Sundberg 2005). Alle Substrate von CYP2D6 sind zugleich kompetitive Hemmstoffe dieses Enzyms. Einige Medikamente wie z. B. Chinidin binden aber darüber hinaus mit sehr hoher Affinität an das Enzym und bewirken eine starke Hemmung. 
Einleitung

Tab. 1 CYP2D6-Substrate

\begin{tabular}{ll}
\hline Indikationsgruppe & Beispiele für Medikamente \\
\hline Antidepressiva & Amitriptylin, Clomipramin, Desipramin, Fluoxetin, Imipramin, \\
& Nortriptylin, Paroxetin \\
Neuroleptika & Haloperidol, Perphenazin, Risperidon, Thioridazin, Zuclopenthixol \\
Betablocker & Carvedilol, Metoprolol, Nebivolol, Propranolol, Timolol \\
Antiarrhythmika & Encainid, Flecainid, Lidocain, Mexiletin, Propafenon, Spartein* \\
Opioide & Codein, Tramadol \\
Weitere & Amphetamine, Donepezil, Metoclopramid, Ondansetron, Debrisoquin* \\
\hline
\end{tabular}

*Substrate werden heutzutage nicht mehr verwendet, sind jedoch wichtig bei der Entdeckung der CYP2D6Polymorphismen gewesen. Zusammengestellt aus www.medicine.iupui.edu/clinpharm/ddis/Table.asp.

Die CYP2D6-Enzymexpression ist nach gegenwärtigem Wissen im Gegensatz zu anderen CYP-Enzymen weder durch natürliche Substanzen noch durch Hormone induzierbar (Ingelman-Sundberg 2005). Auf die vielfältigen und klinisch relevanten Genpolymorphismen von CYP2D6 wird im Kapitel 1.2.1 eingegangen.

\subsubsection{Das CYP2C9-Enzym}

Das CYP2C9-Enzym bildet zusammen mit den Isoenzymen CYP2C8, 2C18 und 2C19 die CYP2C-Subfamilie (Gray et al. 1995), die beim Menschen bezogen auf die Proteinmenge etwa 20\% des Gesamtanteils an Cytochrom-P450-Enzymen in der Leber ausmacht (Shimada et al. 1994). Das CYP2C9-Enzym wiederum macht mit 30\% den Hauptanteil der CYP2CIsoenzyme in der menschlichen Leber aus (Schwab et al. 2002) und beteiligt sich an der Metabolisierung von etwa 17\% aller Arzneimittel (Zanger et al. 2008). Das kodierende Gen der CYP2C-Enzyme befindet sich auf Chromosom 10 (Schwab et al. 2002) und besteht aus 9 Exons. Als Genprodukt entsteht ein Hämoprotein aus 490 Aminosäuren (Miners und Birkett 1998). Die Aminosäurensequenz der vier Isoenzyme weist eine über 82\%ige Homologie auf (Goldstein und de Morais 1994), dennoch gibt es nur wenige Überschneidungen in ihrer Substratspezifität (Wrighton und Stevens 1992).

Typische CYP2C9-Substrate sind schwache Säuren mit einer anionischen Gruppe etwa 7 Angstrøm entfernt von dem Kohlenstoffatom, welches in der Phase-I-Reaktion oxidiert wird (Miners und Birkett 1998). Das CYP2C9-Enzym ist neben der Metabolisierung von Carvedilol hauptsächlich bei der Metabolisierung der in Tab.2 aufgelisteten Substrate beteiligt. 
Einleitung

Tab. 2 CYP2C9-Substrate

\begin{tabular}{ll}
\hline Indikationsgruppe & Beispiele für Medikamente \\
\hline Nichtsteroidale Antiphlogistika & Diclofenac, Ibuprofen, Meloxicam, Piroxicam, Indometacin, S- \\
& Naproxen \\
Cumarine & S-Warfarin, Phenprocoumon \\
Antiepileptika & Phenytoin, Phenobarbital, Temazepam, Valproinsäure, Zopiclon, \\
& Zolpidem \\
Antidepressiva & Amitriptylin, Fluoxetin, Moclobemid, Sertralin, Perphenazin \\
Orale Antidiabetika/Insulinsensitizer & Tolbutamid, Glibenclamid, Glimepirid, Rosiglitazon \\
Angiotensin-2-Rezeptorantagonisten & Losartan, Irbesartan, Candesartan \\
HMG-CoA-Reduktasehemmer & Fluvastatin \\
Schleifendiuretika & Torasemid \\
Weitere & Carvedilol, Sildenafil \\
\hline Daten nach Brockmöller et al. (2000); Kirchheiner et al. (2004) und Arzneimittelfachinformation Querto ${ }^{\circledR}$ \\
(2009).
\end{tabular}

Unter den vielen Inhibitoren dieses Enzyms sind neben dem heute nicht mehr angewendeten Sulfonamid Sulfaphenazol vor allem die Medikamente Fluconazol und Amiodaron klinisch relevant (Miners und Birkett 1998). Diese Kenntnis ist in klinischen Studien von großer Wichtigkeit, da in Anwesenheit dieser Inhibitoren das CYP2C9-Substrat nicht verstoffwechselt wird. Rifampizin und Secobarbital induzieren beide die Bildung des CYP2C9-Enzyms. Auch dieses Enzym weist Polymorphismen auf, diese werden in dem jeweiligen Kapitel besprochen.

\subsubsection{Das CYP2C19-Enzym}

Wie das CYP2C9-Enzym ist auch das CYP2C19-Enzym Mitglied der CYP2C-Subfamilie (Goldstein und de Morais 1994). Dieses Enzym ist bei der Metabolisierung von ca. 10\% der klinisch wichtigen Medikamente beteiligt (siehe Tab. 3) (Zanger et al. 2008) und soll ebenfalls eine Rolle bei der Carvedilol-Metabolisierung spielen (Arzneimittelfachinformation Querto ${ }^{\circledR} 2009$ ). 
Einleitung

Tab 3 CYP2C19-Substrate

\begin{tabular}{ll}
\hline Indikationsgruppe & Beispiele für Medikamente \\
\hline Protonenpumpenhemmer & Omeprazol, Lansoprazol, Pantoprazol, Rabeprazol \\
Antikonvulsiva/Sedativa & S-Mephenytoin, Diazepam, Primidon, Flunitrazepam, Phenobarbital \\
Antidepressiva & Amitriptylin, Imipramin, Clomipramin, Citalopram, Sertralin, \\
& Moclobemid \\
Zytostatika & Cyclophosphamid \\
Antimalariamittel & Proguanil \\
Betablocker & Carvedilol, Propranolol \\
\hline
\end{tabular}

Daten nach Brockmöller et al. (2000); Schwab et al. (2002); www.medicine.iupui.edu/flockhart/; Arzneimittelfachinformation Querto® (2009).

Wie bei den Enzymen CYP2D6 und CYP2C9 gibt es auch beim CYP2C19-Enzym Polymorphismen, worauf im jeweiligen Kapitel eingegangen wird.

\subsection{Genetischer Polymorphismus in der Medizin}

Der Großteil der Medikamente wird durch das Cytochrom-System verstoffwechselt und dann aus dem Körper eliminiert. Hierbei bestimmen unter anderem die Enzymaktivitäten die Eliminierungsgeschwindigkeit der Arzneimittel. Es ist bekannt, dass es bei gleicher Dosierung eines Arzneimittels interindividuelle Unterschiede in der Intensität, der Wirkungsdauer und der Nebenwirkungen gibt. Für diese Beobachtungen werden Enzymvariabilitäten, die durch sogenannte genetische Polymorphismen entstehen, verantwortlich gemacht (Schwab et al. 2002). Durch die Kenntnis dieser Polymorphismen können Arzneimittelwirkungen und - nebenwirkungen durch Anwendung pharmakogenetisch basierter Dosierungen optimiert werden.

Unter Polymorphismus versteht man das Auftreten einer Genvariante (Allel) in einer Population. Die Häufigkeit der Genvariante (Allelfrequenz) muss größer als ein Prozent sein, andernfalls wird von seltenen genetischen Varianten gesprochen (Hardman et al. 2001). Den größten Teil dieser genetischen Polymorphismen machen neben Deletion, Insertion sowie Duplikation die sogenannten SNPs (single nucleotid polymorphism) aus. Bei einem SNP kommt es zu einer Punktmutation, die zu einem Nukleinsäureaustausch führt und entsprechend einen Aminosäureaustausch zur Folge haben kann. Da aber viele Aminosäuren 
Einleitung

von mehreren Basentripletts kodiert werden, hat nicht jeder Basenaustausch innerhalb der DNA zwingend einen Aminosäureaustausch im Protein zur Folge (Hardman et al. 2001).

Die Aktivität der betroffenen Enzyme kann so beeinflusst werden, dass es zu aufgehobenen (poor metabolizer, PM), verminderten (intermediate metabolizer, IM), normal schnellen (extensive metabolizer, EM) oder sehr schnellen (ultrarapid metabolizer, UM) Metabolisierungen kommen kann. Eine zum Funktionsverlust führende Mutation eines medikamentenabbauenden Enzyms kann somit zur Akkumulation eines Medikamentes im Organismus und daraus folgend zu verstärkten Wirkungen und Nebenwirkungen führen.

\subsubsection{Der CYP2D6-Genpolymorphismus}

Klinische Beobachtungen besonderer Nebenwirkungen und besonderer Variabilität in der Pharmakokinetik der Medikamente Spartein (Antiarrythmikum) und Debrisoquin (Antihypertensivum) führten erstmals Mitte der 70er-Jahre zur Entdeckung des CYP2D6Polymorphismus (Eichelbaum 1975; Mahgoub et al. 1977). Dabei wurden Probanden, die diese Medikamente gar nicht verstoffwechselten (poor metabolizer) von Probanden, die diese Medikamente schnell verstoffwechselten (extensive metabolizer) durch Phänotypisierung unterschieden. Erst 15 Jahre später, nach Identifizierung des für die Debrisoquin-SparteinHydroxylase kodierenden Gens, konnten diese individuellen Unterschiede molekulargenetisch identifiziert (genotypisiert) werden (Gonzalez et al. 1988; Kimura et al. 1989).

Je nachdem welche Mutation die einzelnen Allele aufweisen, können Träger von 0, 1, 2 und $\geq 3$ aktiven Allelen identifiziert und aufgrund ihrer Enzymaktivität in defiziente (PM), verminderte (IM), schnelle (EM) und ultraschnelle (UM) Metabolisierer eingeordnet werden (siehe oben) (Brockmöller et al. 2000). Dabei wurde einzelnen CYP2D6-Allelen eine Gendosis wie folgt zugeordnet: Die Gendosis 0 entspricht inaktiven Allelen, eine Gendosis von 0,5 vermindert aktiven Allelen und eine Gendosis von 1 normal aktiven Allelen (Kirchheiner et al. 2004; Steimer et al. 2004). Bei Allel-Duplikationen geht man von einer Verdopplung der Aktivitätszahl des dupliziert vorliegenden Allels aus (Kirchheiner et al. 2004). Häufige der heute bekannten CYP2D6-Varianten sind in der folgenden Tabelle zusammengefasst. 
Einleitung

Tab. 4 Häufige CYP2D6-Allele bei Kaukasiern

\begin{tabular}{|c|c|c|c|}
\hline Allel-Typ & Bekannte Allele & Schlüssel-Mutation $^{\text {** }}$ & Allelfrequenz in $\%$ \\
\hline \multirow[t]{4}{*}{$\mathrm{PM}$} & $* 4$ & 1846G>A (splicing defect) & $12-22$ \\
\hline & $* 3$ & 2549delA (frameshift) & 2 \\
\hline & $* 5$ & Gendeletion & $2-7$ \\
\hline & $* 6$ & 1707delT (frameshift) & 1 \\
\hline \multirow[t]{4}{*}{$\mathrm{IM}$} & $* 41$ & $2988 \mathrm{G}>\mathrm{A}$ & 8 \\
\hline & $* 9$ & 2613-2615delAGA & 2 \\
\hline & $* 10$ & P34S & $1-2$ \\
\hline & $* 17$ & T107I, R296C, S486T & $0-2$ \\
\hline \multirow[t]{2}{*}{$\mathrm{EM}$} & $* 1$ & Keine Mutation & 36 \\
\hline & $* 2$ & Mehrere Substitutionen & 33 \\
\hline UM & $\begin{array}{l}\text { Genduplikation/ Genamplifikation } \\
2 \text { (n) } x * 1,2 \text { (n) } x * 2,2 \text { (n) } x * 35\end{array}$ & Mehrere Genkopien & $2-5$ \\
\hline
\end{tabular}

Bei den defizienten Metabolisierern (PM), die ca. 5 - 10\% der kaukasischen Bevölkerung ausmachen (Sakuyama et al. 2008), sind zwei inaktive Alle (Nullallele) vorhanden. Die häufigsten dieser Nullallele sind CYP2D6*3, *4, *5, und *6 (Sachse et al. 1997). Dabei stellt das CYP2D6*4-Allel mit einer Häufigkeit von 12\% - 22\% in der kaukasischen Bevölkerung den größten Anteil der Nullallele dar. Bei dem CYP2D6*4 führt ein Basenaustausch von Guanin zu Adenin an der Position 1846 zu einem falschen Splicing mit fehlender Expression von aktivem Protein (Gough et al. 1990; Hanioka et al. 1990; Kagimoto et al. 1990). Die Mutationen in CYP2D6*3 und CYP2D6*6 werden durch Basendeletion erklärt, wodurch der Leserahmen verschoben wird (frameshift). Hierbei geht dem CYP2D6*3 an Position 2549 Adenin (Kagimoto et al. 1990) und dem CYP2D6*6 an Position 1707 Thymin verloren (Saxena et al. 1994). Schließlich besteht die Veränderung bei CYP2D6*5 in einem vollständigen Fehlen des CYP2D6-Gens (Deletion) (Gaedigk et al. 1991; Steen et al. 1995).

Für die Häufigkeit des Auftretens der intermediate metabolizer bei Kaukasiern werden Angaben zwischen 10 - 15\% (Steimer et al. 2004) und 32\% (van der Weide und Hinrichs 2006) gefunden. Beispiele für IM-Allele mit verminderter CYP2D6-Aktivität sind CYP2D6*9, *10, *17 und *41. Dabei bestehen in der Literatur keine einheitlichen Auffassungen, ob jeder heterozygote Genotyp aus einem aktiven und einem defizienten Allel als intermediate metabolizer klassifiziert werden soll oder nur die Genotypen, bei denen ein 
Einleitung

defizientes Allel (z. B. *3 bis *6) mit einem schwach aktiven Allel (z. B. *9, *10, *17 oder *41) kombiniert ist.

Mit 1\% - 2\% ist das CYP2D6*10 in der kaukasischen Bevölkerung vorhanden (siehe Tab. 4). Dieser genetische Polymorphismus wird durch einen Aminosäureaustausch an Position 34 (Prolin34Serin) charakterisiert, bedingt durch den Basenaustausch 100Cytosin $>$ Thymin (Yokota et al. 1993; Johansson et al. 1994; Sakuyama et al. 2008). Im Gegensatz zu den Kaukasiern kommt das CYP2D6*10 jedoch bei > 50\% der Asiaten vor (Ingelman-Sundberg 2005).

Das CYP2D6*9 wird durch die Deletion eines Basentripletts und damit durch Verlust einer Aminosäure beschrieben (AGAdel (Deletion) $\rightarrow \mathrm{K}($ Lysin)281del) (Broly und Meyer 1993).

Das CYP2D6*41 ist eine Variante des CYP2D6*2 und kommt bei ca. 8,4\% der Kaukasier vor (Raimundo et al. 2004). Es unterscheidet sich vom CYP2D6*2 durch das Fehlen der Mutation an Position 1584C $>\mathrm{G}$ (Raimundo et al. 2000; Raimundo et al. 2004). Ein weiterer Polymorphismus wurde bei CYP2D6*41 entdeckt, wo es zu einem Basenaustausch in Position 2988 G>A kommt (Raimundo et al. 2004).

Bei CYP2D6*17 führen Basenaustausche von Cytosin zu Thymin in Position 1111 und 2938, sowie eine Guanin-Cytosin-Transversion in Position $4268 \mathrm{zu}$ den Aminosäureaustauschen T107I (Threonin107Isoleucin), R296C (Arginin296Cystein) und S486T (Serin486Threonin) und entsprechend $\mathrm{zu}$ einer herabgesetzten Aktivität mit veränderter Substratspezifität (Masimirembwa et al. 1996; Oscarson et al. 1997).

Mit ca. 55\% gehört die Mehrheit der europäischen Bevölkerung der EM-Gruppe mit normaler Enzymaktivität an (van der Weide und Hinrichs 2006). Beispiele für EM-Allele sind CYP2D6*1, welches dem Wildtyp entspricht und CYP2D6*2. CYP2D6*2 weist normale Aktivität auf, unterscheidet sich jedoch vom Wildtyp CYP2D6*1 durch zwei AminosäureSubstitutionen (Arginin296Cystein und Serin486Threonin) und zusätzliche SNPs in der 5 Region (www.cypalleles.ki.se/cyp2d6.htm).

Genduplikationen oder -amplifikationen des CYP2D6-Gens charakterisieren den ultrarapid metabolizer (UM), welcher in der kaukasischen Bevölkerung in Häufigkeiten zwischen 1 und 10\% (in Südeuropa häufiger) vorkommt. Dagegen sind UM in der äthiopischen Bevölkerung mit ca. 30\% vertreten (Aklillu et al. 1996). Bei diesem Metabolisierungstyp kann es durch beschleunigte Verstoffwechselung zu einer fehlenden therapeutischen Wirksamkeit kommen (Ingelmann-Sundberg 2005). Neben dem Allel *2 existieren auch Duplikationen der Allele $* 1, * 4, * 6, * 10, * 17$ und *35 (Sachse et al. 1997; Gaedigk et al. 2007). 
Einleitung

In vorangehenden Studien wie z. B der von Honda et al. (2006) wurden unter anderem Effekte der CYP2D6*10-Allelvariante auf die Carvedilol-Pharmakokinetik untersucht. Allerdings sind viele der oben dargestellten Genotypen bezüglich der CarvedilolPharmakokinetik noch wenig erforscht.

\subsubsection{Der CYP2C9-Genpolymorphismus}

Bekannt wurde der CYP2C9-Polymorphismus durch klinische Studien einerseits mit dem Antiepileptikum Phenytoin (Kutt et al. 1964) und andererseits mit dem Sulfonylharnstoff Tolbutamid (Scott und Poffenbarger 1979), bei denen unerwünschte Nebenwirkungen auftraten. Es konnte dann gezeigt werden, dass CYP2C9 die Verstoffwechslung beider oben genannter Medikamente vornimmt und dass ein Funktionsverlust des CYP2C9-Enzyms durch zwei zum Aminosäureaustausch führende Mutationen für die Nebenwirkungen verantwortlich war (siehe unten).

Neben dem Wildtyp CYP2C9*1, der die Aminosäure Arginin an Position 144 und Isoleucin an Position 359 (Arginin144/Isoleucin359) enthält, sind zwei weitere Allele CYP2C9*2 und CYP2C9*3 bekannt (Yasar et al. 1999). Bei diesen letztgenannten Allel-Varianten kommt es im Vergleich zum Wild-Typ substratabhängig zur unterschiedlichen Abnahme der Enzymaktivitäten (Kirchheiner und Brockmöller 2005). Der Wildtyp liegt mit einer Häufigkeit von 79\% bis 86\% in der kaukasischen Population vor (Miners und Birkett 1998). Die Allelvariante CYP2C9*2 mit Cystein statt Arginin in Position 144 (Cystein144/Isoleucin359), bedingt durch Cytosin statt Thymin bei Basenpaar 430 (www.cypalleles.ki.se/cyp2c9.htm), tritt bei 11\% der weißen Bevölkerung auf (Kirchheiner und Brockmöller 2005). Die dritte Variante CYP2C9*3 kommt mit 7\% in der weißen Bevölkerung vor (Kirchheiner und Brockmöller 2005). Hier kommt es bei Basenpaar $1075 \mathrm{zu}$ einem Basenaustausch von Adenin zu Cytosin (www.cypalleles.ki.se/cyp2c9.htm), daraus resultierend wird Isoleucin in Position 359 der Aminosäurenkette durch Leucin ersetzt (Arginin144/Leucin359) (Miners und Birkett 1998). Homozygote CYP2C9*3-Träger sind mit ca. $0,4 \%$ sehr selten in der weißen Bevölkerung vertreten (Kirchheiner und Brockmöller 2005). 
Einleitung

Tab. 5 CYP2C9-Polymorphismen

\begin{tabular}{llll}
\hline Allel & Basenaustausch & Effekt & Enzymaktivität \\
CYP2C $9 * 1$ & & & Normal \\
$\mathrm{CYP} 2 \mathrm{C} 9 * 2$ & $430 \mathrm{C}>\mathrm{T}$ & Arg144Cys & Vermindert \\
$\mathrm{CYP} 2 \mathrm{C} 9 * 3$ & $1075 \mathrm{~A}>\mathrm{C}$ & Ile359Leu & Vermindert \\
\hline
\end{tabular}

A, Adenin; Arg, Arginin;C, Cytosin; Cys, Cystein; Ile, Isoleucin; Leu, Leucin; T, Thymin. Daten aus Miners und Birkett (1998), van der Weide und Hinrichs (2006), www.cypalleles.ki.se/cyp2c9.htm.

Kirchheiner und Brockmöller (2005) stellten in ihrer Arbeit Studien vor, in denen die Varianten CYP2C9*2 und *3 und deren Einfluss auf verschiedene Medikamente untersucht wurden. Über den Zusammenhang von CYP2C9-Polymorphismen und Carvedilol existieren bislang aber nur wenige in-vivo-Studien (Giessmann et al. 2004; Honda et al. 2006).

\subsubsection{Der CYP2C19-Genpolymorphismus}

Anfang der 80er-Jahre wurde der CYP2C19-Polymorphismus zunächst als S-Mephenytoin 4'Hydroxylase-Polymorphismus beschrieben (Kupfer und Preisig 1984). Dieser genetische Defekt wurde durch die zwei mutierten Allelvarianten CYP2C19*2 (De Morais et al. 1994 a) und CYP2C19*3 verursacht (De Morais et al. 1994 b). Neben diesen und dem normal aktiven Allel *1 konnten bisher weitere Allele nachgewiesen werden. In der vorliegenden Arbeit werden die Varianten $* 1, * 2$ und $* 17$ untersucht und im Folgenden dargestellt.

Bei der Genvariante *2 führt eine Punktmutation (Guanin $\rightarrow$ Adenin) des Basenpaares 681 in Exon $5 \mathrm{zu}$ einem frühzeitigen Stopcodon, wodurch ein verkürztes und inaktives Protein entsteht (De Morais et al. 1994 a). Von dieser Genvariante sind ca. 13\% der Kaukasier betroffen (van der Weide und Hinrichs 2006). Eine neu beschriebene Genvariante ist das CYP2C19*17, das überdurchschnittlich aktiv (UM) zu sein scheint (Sim et al. 2006). Diese Allelvariante wird durch eine Mutation an der 5'-flankierenden Region des Gens verursacht, was zu einer erhöhten Transkriptionsrate und somit zu einer erhöhten metabolischen Aktivität führt (Sim et al. 2006). In der klinischen Studie von Sim et al. wurde das CYP2C19*17 mit einer Allelfrequenz von $18 \%$ bei Schweden und Äthiopiern, sowie $4 \%$ bei Chinesen gesehen (Sim et al. 2006). Während 19\% - 23\% der Japaner, $15 \%$ der Chinesen, sowie $13 \%$ der Koreaner zur Gruppe der PM gehören, sind nur 3 - 5 \% der Kaukasier PM (Wang et al. 2009).

Es existieren bisher wenige in-vivo-Studien (z. B Honda et al. 2006) zu Auswirkungen des CYP2C19-Polymorphismus auf die Metabolisierung von Carvedilol. 
Einleitung

\subsection{Betablocker und Carvedilol}

Reizung von sympathischen Nerven oder Injektion von Noradrenalin oder Adrenalin führt zu einer großen Zahl von teils hemmenden, teils stimulierenden Effekten an nahezu allen peripheren Organen. Diese Effekte werden hauptsächlich durch drei AdrenoRezeptorgruppen, nämlich die $\alpha_{1^{-}}, \alpha_{2^{-}}$und $\beta$ - Rezeptoren vermittelt. Alpha $1^{-}$Rezeptoren werden vorwiegend in Blutgefäßen, Alpha 2 -Rezeptoren hauptsächlich prä- und postsynaptisch auf Neuronen des vegetativen und zentralen Nervensystems gefunden. Die Beta-Rezeptoren werden in 3 Untergruppen unterteilt: $\beta_{1}$-Rezeptoren werden vorwiegend am Herzen gefunden, $\beta_{2}$-Rezeptoren in peripheren Gefäßen und Bronchien und $\beta_{3}$-Rezeptoren im Fettgewebe. Die folgende Tabelle ordnet den einzelnen Adrenozeptoren ihre klinisch relevantesten Wirkungen nach Stimulierung mit Sympathomimetika zu.

Tab 6 Adrenozeptoren und Wirkung

\begin{tabular}{|c|c|c|c|}
\hline Gruppe & Rezeptor & Vorkommen & Wirkung \\
\hline Alpha 1 & Alpha 1 & $\begin{array}{l}\text { Auge; Arteriolen; Niere; } \\
\text { Harnblase; Uterus; Speicheldrüse; } \\
\text { Leber }\end{array}$ & $\begin{array}{l}\text { Mydriasis; Vasokonstriktion; Reninsekretions- } \\
\text { hemmung; Uteruskontraktion; } \\
\text { Speicheldrüsensekretion; Glycogenolyse }\end{array}$ \\
\hline Alpha 2 & Alpha 2 & $\begin{array}{l}\text { Fettgewebe und Pankreas; } \\
\text { präsynaptisch an noradrenergen } \\
\text { Nervenendigungen }\end{array}$ & $\begin{array}{l}\text { Hemmung der Lipolyse und der } \\
\text { Insulinsekretion; } \\
\text { Reduktion der Adrenalinausschüttung }\end{array}$ \\
\hline \multirow[t]{3}{*}{ Beta } & Beta 1 & $\begin{array}{l}\text { Herz (Sinus-/AV-Knoten, Atrium, } \\
\text { Ventrikel und His-Purkinje- } \\
\text { System); Niere }\end{array}$ & $\begin{array}{l}\text { positiv chrono-, ino-, dromo-, bathmotrop; } \\
\text { Stimulierung der Reninsekretion }\end{array}$ \\
\hline & Beta 2 & $\begin{array}{l}\text { Herz; Arteriolen; Bronchien; } \\
\text { Uterus; Leber; Fettgewebe }\end{array}$ & $\begin{array}{l}\text { Positiv ino- und chronotrop; Vaso- und } \\
\text { Bronchodilatation; Uterusrelaxation; } \\
\text { Steigerung der Glycogenolyse der Leber } \\
\text { Steigerung der Lipolyse des Fettgewebes }\end{array}$ \\
\hline & Beta 3 & Fettgewebe & $\begin{array}{l}\text { Steigerung der Lipolyse und Thermogenese im } \\
\text { braunen Fettgewebe }\end{array}$ \\
\hline
\end{tabular}

Daten nach Estler (2000), S. 48 - 49 und Brodde et al. (2006), S. 117.

Adrenozeptoren werden nicht nur durch Adrenalin und Noradrenalin sowie Derivate dieser Stresshormone aktiviert, sondern durch strukturell ähnliche Moleküle wie Betablocker - und damit auch durch Carvedilol - blockiert. Der Blutdruck, der eine Resultante aus 2 Größen ist, kann durch Manipulierung dieser 2 Größen gesenkt werden. Bei diesen 2 Größen handelt es sich einerseits um das Herz-Zeit-Volumen, das sich als Produkt aus Herzfrequenz und Schlagvolumen zusammensetzt, und andererseits den peripheren Gefäßwiderstand. Während eine Veränderung im Herz-Zeit-Volumen sich im systolischen Blutdruck reflektiert, drückt sich eine Veränderung im peripheren Gefäßwiderstand eher im diastolischen Blutdruck aus (Böhm et al. 2001). Betablocker werden einerseits in $\beta_{1^{-}}$selektive (z. B Atenolol, Metoprolol) und nicht- selektive $\beta_{1}$ - und $\beta_{2^{-}}$Blocker (z. B Propranolol, Carvedilol) und andererseits in $\beta$ - 
Einleitung

Blocker mit und ohne ISA (intrinsische sympathomimetische Aktivität) unterteilt. Die Wirkung der $\beta$-Blocker ergibt sich aus der kompetitiven Hemmung der Katecholaminwirkung an $\beta_{1}$ - und $\beta_{2}$-Rezeptoren (Brodde et al. 2006). Es kommt dadurch zu einer negativen Chrono-, Ino- und Dromotropie und zu einer Bathmotropie, folglich sinkt der myokardiale Sauerstoffverbrauch. Je größer der Sympathikotonus ist, desto größer ist der Effekt der oben geschilderten $\beta$-Blockade (Estler 2000). Meistens entstehen Nebenwirkungen durch Antagonisierung der glattmuskulären $\beta_{2}$-Rezeptoren der Bronchien und der Widerstandsgefäße.

\subsubsection{Carvedilol}

Wie oben bereits gesagt, gehört Carvedilol zur Gruppe der Betablocker. Nachfolgend werden die chemische Struktur, die Indikationen und Kontraindikationen, sowie die Nebenwirkungen von Carvedilol dargestellt und dann die Carvedilol-Pharmakokinetik in Abhängigkeit von CYP450-Enzymen erläutert.

\subsubsection{Chemie und Wirkungsweise des Carvedilol}

Carvedilol, mit der chemischen Bezeichnung 1-(carbazol-4-yloxy-3-[[2-(O-methoxyphenoxy) ethyl]amino]-2-propranol, wird als Razemat von 50\% R-Carvedilol und 50\% S-Carvedilol verabreicht. Die beiden Konfigurationen des Moleküls sind nicht deckungsgleich und werden deshalb als chiral bezeichnet. Ursache dafür ist ein so genanntes asymmetrisches Kohlenstoffatom (in der Abbildung unten das Kohlenstoffatom mit der Hydroxylgruppe (OHGruppe)), das das Stereozentrum (Chiralitätszentrum) mit 4 unterschiedlichen Liganden bildet.

Abb. 1 Strukturformel von Carvedilol

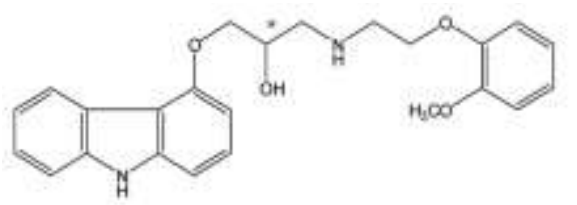

* Chiralitätszentrum; Entnommen aus You et al. (2007), S. 757.

Hinsichtlich der pharmakologischen Rezeptorwirkungen ist Carvedilol sowohl ein nichtselektiver $\beta_{1}$ - und $\beta_{2}$-Blocker (ohne intrinsische sympathomimetische Aktivität) (Estler 2000) 
Einleitung

als auch ein $\alpha_{1}$-Blocker, wobei die Blockade der $\alpha_{1}$-Rezeptoren zu einer Vasodilatation führt (Bartsch et al. 1990). Die Beta-Selektivität von Carvedilol am Herzen wird unterschiedlich bewertet. Im Gegensatz zu Estler (2000) soll nach Molenaar et al. (2006) Carvedilol die kardialen $\beta_{2}$-Rezeptoren stärker blockieren als die $\beta_{1}$-Rezeptoren. Das Verhältnis von $\alpha_{1}$ - zu $\beta$-Blockade soll für Carvedilol 1:10 sein (Frishman 1998). Bei hohen Konzentrationen soll es ebenfalls Calcium-Kanal blockierende Wirkung besitzen (Frishman 1998) und es soll eine antiproliferative und antioxidative Wirkung aufweisen (Moser und Frishman 1998). Die Wirkung von Carvedilol ähnelt deren der anderen Betablocker (siehe Kapitel 1.3), wobei die schon beschriebene Vasodilatation ein wichtiger Unterschied ist. Das S-Enantiomer ist für die Betablockade verantwortlich, wohingegen die $\alpha_{1}$-Blockade gleichartig durch beide Enantiomere vermittelt wird (Tenero et al. 2000; Bartsch et al. 1990). In der folgenden Tabelle sind lediglich die wichtigsten Wirkungen der Carvedilol-Enantiomere zusammengefasst.

Tab. 7 Wirkung von R- und S-Carvedilol

\begin{tabular}{llll}
\hline Carvedilol-Enantiomer & Alpha $_{1}$-Blockade & Beta $_{1}$-Blockade & Beta $_{2}$ Blockade $^{\text {R-Carvedilol }}$ \\
S-Carvedilol & Vasodilatation & & \\
& Vasodilatation & negativ chrono-, ino-, \\
dromo- und bathmotrop & $\begin{array}{l}\text { negativ chrono- und ino- } \\
\text { trop; periphere Vasokon- } \\
\text { striktion, Bronchokon- } \\
\text { striktion }\end{array}$ \\
\hline
\end{tabular}

\subsubsection{Indikation, Kontraindikation und Nebenwirkung}

In Deutschland ist das Medikament Carvedilol (Arzneimittelfachinformation Querto® 2009) zur Behandlung der essentiellen Hypertonie, der chronisch stabilen Angina pectoris sowie der chronisch stabilen Herzinsuffizienz zusätzlich zu Diuretika, ACE-Hemmer und Digitalis zugelassen. Der Wert von Carvedilol für die oben genannten Indikationen ist durch eine Reihe von Studien belegt.

Die essentielle Hypertonie ist eine Erkrankung mit komplexer Ätiologie. Der erhöhte Blutdruck kann sowohl durch Zunahme des Herzzeitvolumens als auch durch Anstieg des peripheren Gefäßwiderstandes entstehen. Im Gegensatz zu den meist üblichen $\beta$-Blockern wie. z. B Metoprolol soll laut vorangehender Studien Carvedilol bei Bluthochdruck den erhöhten Blutdruck unter anderem durch Erniedrigen des peripheren Gefäßwiderstandes ohne großartige Veränderung des Herzzeitvolumens senken (Weber et al. 1998; Stafylas und Sarafidis 2008; Arzneimittelfachinformation Querto ${ }^{\circledR}$ 2009). Die Senkung des Blutdruckes 


\section{Einleitung}

wird nicht so stark von einer Reflextachykardie begleitet wie bei vielen reinen $\alpha_{1}$-Blockern, da Carvedilol auch die $\beta_{1}$-Rezeptoren, die in den Pathomechanismus der Reflextachykardie involviert sind, blockiert (Estler 2000). In klinischen Studien beobachtete man sowohl bei Gesunden nach mehrmaliger Carvedilol-Applikation eine signifikante Senkung des systolischen Blutdruckes und der Herzfrequenz (Giessmann et al. 2004) als auch bei Hypertonikern in Ruhe und unter Belastung eine signifikante Senkung des systolischen und des diastolischen Blutdruckes sowie eine leichte Herzfrequenzsenkung (Leonetti et al. 1987; Omvik und Lund-Johansen 1991; Why and Richardson 1992). Es konnte auch nachgewiesen werden, dass sich bei Hypertonikern die linksventrikuläre Herzmasse unter Carvedilol verringert (Why and Richardson 1992).

Bei Patienten mit Herzinsuffizienz führt die Aktivierung des sympathischen Nervensystems und des Renin-Angiotensin-Aldosteron-Systems $\mathrm{zu}$ einer negativen Beeinflussung des klinischen Verlaufs (Frishman 1998). Hier erzielt Carvedilol seine besondere Wirkung durch Blockade des sympathischen Nervensystems ( $\alpha$ - und - $\beta$-Blockade) und des Renin-Systems ( $\beta$-Blockade) (Estler 2000; Arzneimittelfachinformation Querto $\left.{ }^{\circledR} 2009\right)$. Bei der CopernicusStudie (Carvedilol Prospective Randomized Cumulative Survival-Trial) zeigte sich der mortalitäts- und morbiditätssenkende Effekt von Carvedilol gegen Placebo bei schwerer, symptomatischer Herzinsuffizienz (Packer et al. 2001). Im Vergleich zu Metoprolol zeigte sich in der COMET-Studie (Carvedilol Or Metoprolol European Trial) unter Carvedilol eine geringere Mortalität bei Patienten mit chronischer Herzinsuffzienz (Poole-Wilson et al. 2003). In der CAPRICORN-Studie konnte die Senkung der kardiovaskulären Mortalität, der nichtfatalen Rezidiv-Infarkte und der Kombination der beiden Ereignisse unter Carvedilol im Vergleich zu Placebo bei Patienten mit linksventrikulärer Dysfunktion nach akutem Myokardinfarkt nachgewiesen werden (Dargie 2001).

Der positive Effekt von Carvedilol auf die Nierenfunktion konnte in einer Studie von Dupont (1990) demonstriert werden. In einer weiteren Studie wurde der positive Einfluss von Carvedilol im Vergleich zu Placebo und Atenolol sowohl auf den Lipid- als auch auf den Kohlenhydratstoffwechsel bei hypertonen Probanden mit nicht-insulinpflichtigem Diabetes mellitus dargestellt (Giugliano et al. 1997). Verglichen mit Metoprolol kann Carvedilol besser bei Patienten mit metabolischem Syndrom verwendet werden, da Carvedilol einen positiven Effekt auf die Insulinsensitivität hat und neutral auf den Lipidstoffwechsel zu wirken scheint (Jacob et al. 1996). In der folgenden Tabelle werden neben Indikationen die wichtigsten Kontraindikationen, sowie Nebenwirkungen von Carvedilol zusammenfassend dargestellt. 
Einleitung

Tab. 8 Indikation, Kontraindikation und Nebenwirkung von Carvedilol

\begin{tabular}{|c|c|c|}
\hline Indikation & Kontraindikation & Nebenwirkung \\
\hline $\begin{array}{ll}\text { - } & \text { Essentielle } \\
\text { Hypertonie } \\
\text { - } & \text { Chronisch } \\
\text { stabile } \\
\text { Angina } \\
\text { pectoris } \\
\text { - Stabile, } \\
\text { symptoma- } \\
\text { tische, } \\
\text { chronische } \\
\text { Herzinsuf- } \\
\text { fizienz } \\
\text { aller } \\
\text { Schwere- } \\
\text { grade }\end{array}$ & $\begin{array}{l}\text { - } \text { Überempfindlichkeit gegen Carvedilol } \\
\text { - } \quad \text { dekompensierte Herzinsuffizienz } \\
\text { - } \quad \text { Klinisch relevante } \\
\text { - } \quad \text { AVberfunktionsstörungen } \\
\text { Sinusknotensyndrom, sinuatrialer Block } \\
\text { (Ausnahme: Schrittmacher-Therapie) } \\
\text { - Hypotonie (systolischer RR < 85mm } \\
\text { Hg), kardiogener Schock } \\
\text { - } \quad \text { Prinzmetal-Angina } \\
\text { Veichzeitige i.v. Therapie mit } \\
\text { - Antiarryhthmika } \\
\text { Asthma bronchiale, sonstige } \\
\text { Atemwegserkrankungen mit } \\
\text { brocnchospastischer Komponente } \\
\text { - Cor pulmonale, akute Lungenembolie } \\
\text { - } \quad \text { Stillzeit }\end{array}$ & $\begin{array}{ll}\text { - } & \text { Schwindel } \\
\text { - } & \text { Kopfschmerzen } \\
\text { - } & \text { Müdigkeit } \\
\text { - } & \text { Schlafstörungen } \\
\text { - } & \text { Hypotonie } \\
\text { - } & \text { Selten Synkope } \\
\text { - } & \text { Bradykardie } \\
\text { - } & \text { Symptomverstärkung bei } \\
& \text { Claudicatio intermittens, } \\
& \text { Raynaud, Angina } \\
\text { - } & \text { Dectoris } \\
\text { - Nyspnoe } & \text { Nausea, Diarrhoe, } \\
\text { - } \text { Mmesis } & \text { Maskierung einer } \\
\text { Hypoglykämie bei } \\
\text { insulinpflichtigem } \\
\text { Diabetes } \\
\text { Psoriasis }\end{array}$ \\
\hline
\end{tabular}

Daten aus Arzneimittelfachinformation Querto ${ }^{\circledR}$ (2009).

\subsubsection{Pharmakokinetische Parameter}

Carvedilol wird nach oraler Applikation bei Hypertonikern und Gesunden schnell absorbiert, die maximale Plasmakonzentration $\left(\mathrm{C}_{\max }\right)$ wird nach 1 bis 2 Stunden $\left(\mathrm{t}_{\max }\right)$ erreicht (Morgan 1994). Die $C_{\max }$-Werte verhalten sich linear zu der applizierten Arzneimitteldosis und die Pharmakokinetik ändert sich nicht nach mehrmaligem Applizieren von Carvedilol (McPhillips et al. 1988). Allerdings ist die $t_{\max }$ nach Nahrungsaufnahme verlängert (Morgan 1994), wobei die Bioverfügbarkeit von Carvedilol wenig beeinflusst wird. Aufgrund der Lipophilie verteilt sich Carvedilol sehr gut im Organismus und weist ein Verteilungsvolumen von ca. 2 1/kg auf (Arzneimittelfachinformation Querto ${ }^{\circledR}$ 2009). Im Plasma werden 98\% des Medikamentes an Proteine, v.a. an Albumin gebunden. Die Halbwertszeit $\left(\mathrm{t}_{1 / 2}\right)$ liegt zwischen 4 und 7 Stunden (Morgan 1994). Nach oraler Gabe bertägt der First-pass-Metabolismus bei Carvedilol $60 \%$ bis $75 \%$. Es resultiert eine absolute Bioverfügbarkeit von ungefähr $25 \%$ (Arzneimittelfachinformation Querto ${ }^{\circledR}$ ), wohingegen die absolute Bioverfügbarkeit bei oraler Medikamenteneinnahme für das R- sowie für das S-Carvedilol-Enantiomer bei ca. 31,1\% sowie 15,1\% liegt (Neugebauer et al. 1990). Das S-Enantiomer wird schneller metabolisiert als das R-Enantiomer (Oldham und Clarke 1997). Beim Carvedilol-Metabolismus entstehen durch Demethylierung und Hydroxylierung mit Hilfe der Cytochrom-Enzyme aktive Metaboliten mit $\beta$-blockierenden Wirkungen (siehe folgendes Kapitel) (Arzneimittelfachinformation Querto ${ }^{\circledR}$ 2009). Neben den CYP-Enzymen sollen auch das P-Glycoprotein und das 
Einleitung

Multidrug-Resistance-Protein 2 beim Carvedilol-Stoffwechsel beteiligt sein, dabei fungiert das P-Glycoprotein als ein intestinaler Efflux-Transporter und sekretiert aufgenommenes Carvedilol (Giessmann et al. 2004).

Die Plasmaclearance beträgt $590 \mathrm{ml} / \mathrm{min}$. Die Hauptausscheidung von Carvedilol erfolgt bis zu 60\% biliär über die Faeces, wobei 23\% der applizierten Dosis unverändert ausgeschieden werden (Neugebauer et al. 1987; You et al. 2007; Arzneimittelfachinformation Querto ${ }^{\circledR}$ 2009). Nur etwa $16 \%$ des Medikaments werden in Form von Metaboliten und nur 0,3\% der applizierten Dosis unverändert renal eliminiert (Neugebauer et al. 1987; You et al. 2007; Arzneimittelfachinformation Querto ${ }^{\circledR}$ 2009). Patienten mit Lebererkrankungen wie. z. B Leberzirrhose müssen mit starker Erhöhung der Bioverfügbarkeit und somit großen Nebenwirkungen rechnen, wohingegen renale Funktionsstörungen geringe Auswirkungen zeigen (Arzneimittelfachinformation Querto ${ }^{\circledR} 2009$ ).

\subsubsection{Metabolisierung von Carvedilol durch Cytochrom-Enzyme}

Die Metabolisierung von Carvedilol wurde unter anderem von Oldham und Clarke (1997) untersucht. Einige der Cytochrom-P450-Enzyme (CYP2D6, 2C9 und 1A2), die im Carvedilol-Metabolismus eine besondere Rolle spielen, sind in der folgenden Abbildung zusammengefasst. Auch CYP2C19, CYP2E1 sowie CYP3A4 sollen am Metabolismus beteiligt sein (Oldham und Clarke 1997; Arzneimittelfachinformation Querto ${ }^{\circledR}$ 2009).

Abb. 2 Biotransformation von Carvedilol durch Cytochrom-Enzyme

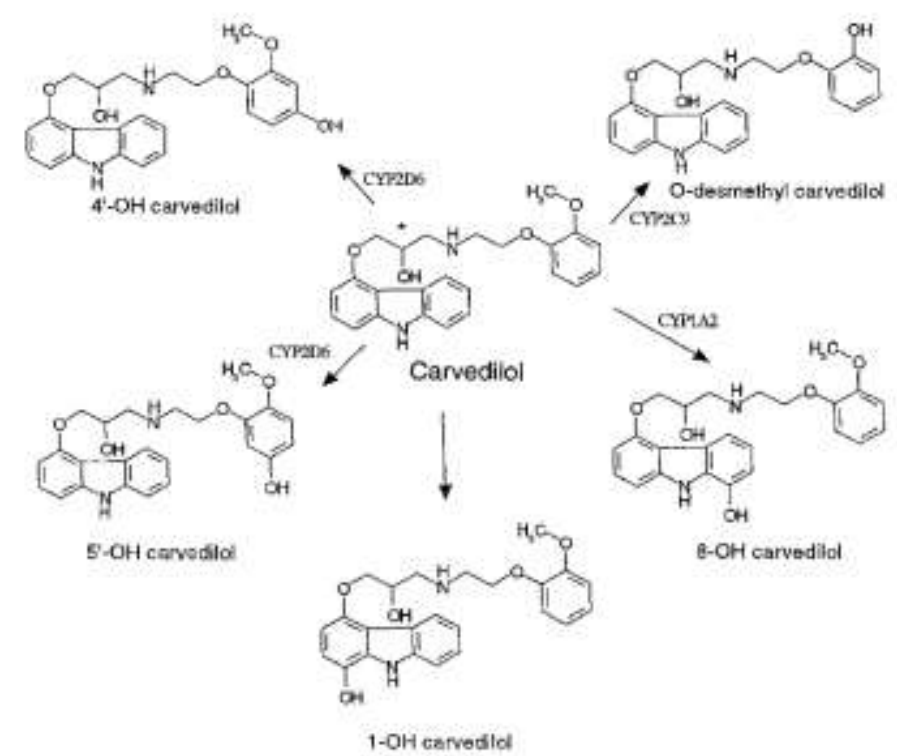

Entnommen aus Oldham und Clarke (1997), S. 971. 
Einleitung

Carvedilol wird sowohl durch Cytochrom-Enzyme in der Oxidations- als auch durch Glucuronosyltransferasen in der Konjugationsreaktion in der Leber metabolisiert und aus dem Körper eliminiert. Die direkte Glucuronidierung soll neben der Oxidation eine große Bedeutung beim Carvedilol-Metabolismus haben (Ohno et al. 2004; Takekuma et al. 2006).

Carvedilol weist einen stereoselektiven First-pass-Metabolismus auf, wobei S-Carvedilol schneller metabolisiert wird als das R-Enantiomer (Neugebauer et al. 1990; Tenero et al. 2000; Honda et al. 2006). Sowohl das R- als auch das S-Enantiomer des Carvedilol werden in der Phase-I-Reaktion hepatisch zu hydroxylierten und demethylierten Metaboliten verstoffwechselt und eliminiert. Hierbei ist das CYP2D6 hauptsächlich für die Produktion von 4 - und 5'-Hydroxyphenyl (OH)-Carvedilol verantwortlich. Für die O-Desmethyl-Carvedilol Bildung ist neben anderen metabolisierenden Enzymen vor allem das CYP2C9 zuständig (Oldham und Clarke 1997). Da es im Gegensatz zu den Enzymen CYP2D6, CYP2C9 und CYP2C19 im Gen der Enzyme CYP1A2, CYP3A4 und CYP2E1 in Bezug auf den Carvedilol-Metabolismus keine funktionell bedeutenden Genvarianten gibt, werden diese nicht weiter analysiert. Die wichtigen Metaboliten und die jeweiligen Enzyme sind in den folgenden Tabellen zusammengefasst.

Tab. 9 R-Carvedilol Metaboliten und CYP-Enzyme

\begin{tabular}{ll}
\hline Cytochrom-Enzym & Metabolit \\
\hline CYP2D6 & 4- und 5-Hydroxyphenyl-Carvedilol, partiell O-Desmethyl- \\
& Carevdilol \\
CYP2C9 & O-Desmethyl-Carvedilol \\
CYP2E1 $^{*}$ & 5-Hydroxyphenyl-Carvedilol, O-Desmethyl-Carvedilol \\
CYP3A4 & 8-Hydroxycarbazolyl-Carvedilol \\
\hline
\end{tabular}

${ }^{*}$ Werden in der vorliegenden Arbeit nicht weiter untersucht. Daten nach Oldham und Clarke (1997).

\begin{tabular}{ll}
\hline \multicolumn{2}{l}{ Tab. 10 S-Carvedilol Metaboliten und CYP-Enzyme } \\
\hline Cytochrom-Enzym & Metabolit \\
\hline CYP2D6 & 4`- und 5`-Hydroxyphenyl-Carvedilol, partiell O-Desmethyl- \\
& Carvedilol \\
CYP2C9 & O-Desmethyl-Carvedilo, 4-Hydroxyphenyl-Carvedilol \\
CYP2E1 & 5-Hydroxyphenyl-Carvedilol \\
CYP1A2* ${ }^{*}$ und CYP3A4* & 8-Hydroxycarbazolyl-Carvedilol \\
\hline
\end{tabular}

*Werden in der vorliegenden Arbeit nicht weiter untersucht. Daten nach Oldham und Clarke (1997).

Einige der in den Tabellen 9 und 10 dargestellten Metaboliten sollen auch pharmakologisch wirksam sein. Dabei spielen das 4-Hydroxyphenyl- und das Desmethyl-carvedilol eine besondere Rolle, jedoch soll die Konzentration dieser Metaboliten im Verhältnis zur 
Einleitung

Ausgangssubstanz Carvedilol bis zu 10-fach niedriger sein (Tenero et al. 2000). Die Zusammenhänge zwischen Metabolit und Wirkung sollen in der folgenden Tabelle zusammengefasst werden.

Tab. 11 Aktivität der Carvedilol-Metaboliten im Vergleich zur Carvedilol-Aktivität

\begin{tabular}{lll}
\hline Metabolit & Betablocker-Aktivität & Alphablocker-Aktivität \\
\hline 4-Hydroxyphenyl-Carvedilol & $13 \mathrm{x}$ & - \\
5-Hydroxyphenyl-Carvedilol & $0,6 \mathrm{x}$ & - \\
Desmethyl-Carvedilol $^{-}$ & $2,5 \mathrm{x}$ & - \\
1-Hydroxycarbazolyl-Carvedilol* & $0,125 \mathrm{x}$ & $<0,1 \mathrm{x}$ \\
8-Hydroxycarbazolyl-Carvedilol* & $0,5 \mathrm{x}$ & 1 \\
\hline
\end{tabular}

* Diese Metaboliten wurden in dieser Arbeit nicht weiter untersucht. Daten nach Tenero et al. (2000).

Der Zusammenhang zwischen CYP2D6 und dem Carvedilol-Metabolismus wurde zunächst von Zhou und Wood (1995) untersucht, später konnten Honda et al. (2006) die Beziehung der CYP2D6*10-Enzymvariante zum Carvedilol-Stoffwechsel darstellen. Die Relation einiger CYP2C9- und CYP2C19-Genotypen zum Carvedilol-Stoffwechsel wurden unter anderem von Honda et al (2006) und Giessmann et al (2004) untersucht. Es fehlen jedoch Studien über die Beziehung weiterer CYP2D6-, CYP2C9- und -C19-Genotypen zur CarvedilolPharmakokinetik und-dynamik. 
Aufgabenstellung

\section{$1.4 \quad$ Aufgabenstellung}

Wie in den vorangehenden Kapiteln dargestellt, ist Carvedilol aufgrund seiner speziellen Wirkweise im Kreise der Betablocker eine besondere Substanz, deren Metabolisierung nicht zuletzt durch die genetisch sehr variablen Cytochrom-P450-Enzyme 2D6, 2C9 und 2C19 vermittelt wird. Noch wenig bekannt ist, wie die unterschiedlichen Genvarianten der genannten Enzyme sich im Einzelnen auswirken. Ziel dieser Arbeit war es, die Auswirkungen der Genvarianten CYP2D6*1, *2, *3, *4, *5, *6, *9, *10, *17, *41, *2x1 und *2x2, sowie CYP2C9*1, *2 und *3 und CYP2C19*1, *2 und *17 auf die Pharmakokinetik von Carvedilol und seinen Metaboliten zu untersuchen. Daneben sollte auch die Bedeutung der Genvarianten für die Wirkungen von Carvedilol unter Ruhe und bei körperlicher Belastung analysiert werden.

Daraus ergab sich die Aufgabe, gesunden männlichen und weiblichen Probanden Carvedilol zu verabreichen und anschließend die Blutabnahmen für die Pharmakokinetik durchzuführen sowie Ergometrien und Schellong-Tests zur Messung der Wirkungen durchzuführen. Die daraus resultierenden Daten sollten hier in Relation zu den Genvarianten von CYP2D6, CYP2C9 und CYP2C19 untersucht werden. 


\section{Material und Methoden}

\subsection{Studiendurchführung}

Die Metoprolol-Carvedilol-CYP2D6-based-Dosage (MCCD)-Studie ist eine offene, nichtrandomisierte, pharmakokinetische und pharmakogenetische Arzneimittelstudie. Da das applizierte Medikament schon zugelassen ist, handelt es sich bei der vorliegenden Studie um eine Phase-IV-Studie. Die Studie war in eine Metoprolol- und eine Carvedilol-Phase aufgeteilt, die vorliegende Arbeit befasst sich lediglich mit dem Carvedilol Teil.

In dieser Studie wurde die genetische Variabilität in den Cytochrom-P450-Enzymen CYP2D6 sowie CYP2C9 und CYP2C19 und ihre Folgen für die Pharmakokinetik und die Wirkungen von Carvedilol untersucht. Freiwillige männliche und weibliche Probanden wurden folgendermaßen rekrutiert mittels:

- $\quad$ Kontaktieren von Probanden von vorhergehenden Studien

- $\quad$ Werbung (Inserate) in der Zitty- und TIP-Zeitschrift in Berlin

- $\quad$ Werbung (Inserate) in der lokalen Göttinger Zeitung

- $\quad$ Aushänge in Universitätsgebäuden.

Die Ein- und Ausschlusskriterien werden in der Tabelle 13 (Kap. 2.1.2) dargestellt.

Die Vorraussetzungen zur Studienteilnahme und Studiendurchführung waren eine Aufklärung, schriftliche Einverständniserklärung, körperliche Untersuchung sowie Genotypisierung des Probanden. Die Studienteilnehmer absolvierten einen Baseline-Tag und 3 Studientage. Es wurde lediglich am 1. Studientag $25 \mathrm{mg}$ Carvedilol (Tab. 2.1) einmalig verabreicht. Weiterhin wurden an allen Studientagen Blutabnahmen, Ergometrien und Schellong-Tests durchgeführt (siehe Kap. 2.1.4). Aus einer Stichprobe von mehr als 700 Probanden wurden Probanden so selektiert, dass möglichst viele Träger der CYP2D6Genvarianten $(* 3, * 4, * 5, * 6, * 9, * 10, * 17$, sowie *41) in die Studie eingeschlossen werden konnten. In der vorliegenden Studie wurden die Daten von 74 gesunden männlichen und 36 gesunden weiblichen Probanden ausgewertet.

Der Studienleiter war Daniel Sehrt von der Abteilung Klinische Pharmakologie der Universität Göttingen. Die Studie wurde durch die Ethikkommission der Georg-AugustUniversität Göttingen genehmigt. Sie wurde einerseits auf der Probandenstation der Göttinger Universität und andererseits später aufgrund von Rekrutierungsproblemen in Göttingen auf der Probandenstation der Universitätsklinik Charité Campus Mitte in Berlin durchgeführt. 
Material und Methoden

Tab. 12 Studienmedikation

\begin{tabular}{ll}
\hline Medikament & Querto \\
Wirkstoff & Carvedilol \\
Dosierung & $25 \mathrm{mg}$ \\
Hersteller & Altana Konstanz Deutschland \\
\hline
\end{tabular}

\subsubsection{Dokumentation und Datenschutz}

Alle Befunde der Voruntersuchungen, sowohl alle Daten und Ergebnisse, die an den Studientagen erhoben wurden, als auch jede Intervention an den Studientagen wurden in für diese Studie entworfenen Dokumentationsbögen (Case Report Form; CRF) festgehalten. Diese CRFs wurden mit Hilfe eines fünfstelligen individuellen Codes aus Zahlen und der Initialen aus Vor- und Nachnamen des Probanden zugeordnet. Mit diesem Codeschlüssel wurden ebenfalls die Blut- und Urinproben der Probanden zugeordnet. Der Codeschlüssel war nur dem Doktoranden und dem Studienleiter bekannt. Während der Studie wurden die CRFs in den Abteilungen für Klinische Pharmakologie der Universität Göttingen und der Charité Campus Mitte in Berlin aufbewahrt. Nach Abschluss der Studie wurden alle CRFs in nicht frei zugängliche Schränke der Abteilung für Klinische Pharmakologie der Universität Göttingen aufbewahrt. Weiterhin ist für die Weitergabe der Daten an Dritte eine Zustimmung des Probanden obligatorisch.

\subsubsection{Probanden}

Als Studienteilnehmer wurden männliche und weibliche Nichtraucher rekrutiert. Im Studienprotokoll waren die Ein- und Ausschlusskriterien vorgegeben (Tab. 13). In einem Vorgespräch wurden die potentiellen Probanden über die Studieninhalte und den Studienablauf aufgeklärt. Des Weiteren mussten die Probanden vor Studienbeginn eine Einverständniserklärung unterschreiben. Allerdings musste zunächst eine Genotypisierung mittels Blutentnahme vorgenommen werden, um zu klären, inwieweit die Probanden für die Studie geeignet waren. Die Probanden hatten die Möglichkeit, die Studie jederzeit abzubrechen. 
Material und Methoden

Tab. 13 Ein- und Ausschlusskriterien für potentielle Probanden



^ Um Aussagen über die CYP2D6-*17- sowie -*10 Varianten machen zu können, wurden 4 Probanden afrikanischer und 5 asiatischer Abstammung in die Studie aufgenommen.

\subsubsection{Medizinisches Screening}

Die Probanden, die durch Genotypisierung (siehe Kap. 2.2) geklärt für die Studie genotypisch geeignet waren, wurden in einem folgenden Termin körperlich und labormedizinisch untersucht. Die Bestimmung der Herzfrequenz, des Blutdruckes und der Temperatur sowie die Ableitung eines Elektrokardiogramms gehörten zur Untersuchung. Wenn die Zeitspanne zwischen dem körperlichen und labormedizinischen Screening und dem Studienbeginn (Baseline-Tag) mehr als 28 Tage betrug, mussten diese Untersuchungen wiederholt werden.

Bei der labormedizinischen Untersuchung wurden vor dem Studieneinschluss am AufnahmeUntersuchungstag folgende Laborparameter bestimmt:

- Klinisch chemische Parameter: Kalium, Natrium, Calcium, Glucose (nüchtern), Aspartataminotransferase, Kreatinin, Bilirubin und Quick/INR.

- Kleines Blutbild: Hämoglobin, Hämatokrit, Erythrozyten- und Granulozytenanzahl.

- Urinuntersuchung: pH, Leukozyten, Nitrit, Proteine, Glucose, Ketonkörper, Urobilinogen, Bilirubin, Erythrozyten und Hämoglobin. 
Material und Methoden

Die Laboruntersuchungen wurden durch die Abteilungen der Klinischen Chemie des Universitätsklinikums Göttingen und der Charité Campus Mitte (Berlin) durchgeführt.

\subsubsection{Ablauf der Studientage}

Die Studie gliederte sich in einen Baseline-Tag und in weitere 3 Studientage auf. Erst wenn der Baseline-Tag komplikationslos durchführbar war, konnten die Probanden die folgenden drei Studientage absolvieren. Die Zeitspanne zwischen Baseline-Tag und 1. Studientag sollte 14 Tage nicht überschreiten. Sowohl der Baseline-Tag als auch die 3 Studientage wurden weiter in sogenannte Untersuchungsabschnitte (PIT, points of time) untergliedert. Die Carvedilol-Dosis wurde lediglich einmal am 1. Studientag verabreicht. Am Baseline-Tag und 1. Studientag mussten die Probanden bis zum PIT2 (Baseline-Tag) sowie PIT3 (1. Studientag) nüchtern sein und auf der Probandenstation bleiben, des Weiteren musste ab den oben genannten PITs ein Ernährungsplan eingehalten werden (siehe Kap. 2.1.5). Zur Erfassung von spezifischen unerwünschten Arzneimittelnebenwirkungen wurde am Morgen, am Mittag sowie am Nachmittag des Baseline-Tages und am Morgen des 1. Studientages vor der Carvedilol-Mediaktion sowie 3, 6, 9, 24, 33 und 48 h nach der Carvedilol-Medikation der Fragebogen 1 abgefragt. Im Fragebogen 1 wurde nach Schwindel, Müdigkeit, Konzentrationsstörungen, Herzrrythmusstörungen, Brustschmerzen, Kopfschmerzen, Luftnot, Übelkeit sowie Bauchschmerzen gefragt. Von den Probanden musste die Intensität der Nebenwirkungen von 1 (überhaupt nicht) bis 6 (sehr stark) angegeben werden. Im Gegensatz zum Fragebogen 1 wurde der Fragebogen 2 nur am Morgen jedes Studientages einmal ausgehändigt und vom Probanden ausgefüllt. Im Fragebogen 2 wurde nach folgenden Symptomen und deren Intensitäten (1 (überhaupt nicht) bis 6 (sehr stark)) gefragt: Depression, Alpträume, Schlafstörungen, Halluzinationen, Vergesslichkeit, kalte Hände und/ oder Füße, Schwindel beim Aufstehen, Übelkeit und Erbrechen, Muskelkrämpfe, Ängstlichkeit, Sehprobleme, Hörprobleme, Geschmacksveränderungen, Fußschwellung, Mundtrockenheit, Verstopfung, Durchfall, Hautirritationen, Muskelschwäche, Augenirritationen, Potenzstörungen, verstopfte Nase und Aggravierung einer bekannten Allergie.

Die Tabelle 14 zeigt den genaueren Plan der Studie. Dabei galt im Allgemeinen für alle Studientage folgendes Prozedere: An jedem Studientag mussten die Probanden den Fragebogen 2 einmalig ausfüllen. Danach musste der Proband für fünf Minuten auf einer 
Material und Methoden

Liege liegen, während der Fragebogen 1 mündlich abgefragt wurde. Der Fragebogen 1 wurde vor jedem PIT abgefragt. Anschließend wurden Blutdruck und Puls gemessen.

Am Baseline-Tag wurden die Ergometrien um 9:00 Uhr, 12:00 Uhr, sowie 18:00 Uhr und ab dem 1. Studientag wurden die Ergometrien um 8:30 vor der einmaligen Carvedilol-Dosis, dann 2,5 h, 6 h, 9 h, 24 h, 33 h, sowie 48 h nach Medikamentengabe durchgeführt. Vor jeder Ergometrie erfolgte die Blutentnahme in $9 \mathrm{ml}$ EDTA-Röhrchen durch Punktieren einer Armvene (Aufbereitung und Analyse der Blutproben siehe unten). Am 1. Studientag, an dem mehrere Blutentnahmen erfolgten, wurde je nach Wunsch des Probanden wahlweise auch eine Venenverweilkanüle (Braunüle) gelegt. Vor, während und nach der Ergometrie diente ein 12Kanal-EKG zur Aufzeichnung der elektrischen Herzaktivität. Die Schellong-Tests erfolgten am Baseline-Tag um 11:00 Uhr und 17:00 Uhr, sowie am 1. Studientag 3 h, 6 h und 9 h nach Medikamentengabe. Am Ende des PIT2 und PIT3 des Baseline-Tages, sowie am Ende des PIT3 und PIT5 des 1. Studientages wurde aus dem Urinbehälter nach gründlichem Schütteln und Abwiegen eine Urinprobe von $10 \mathrm{ml}$ entnommen und bis zur Analyse im Tiefkühlfach bei $-18^{\circ} \mathrm{C}$ aufbewahrt.

\begin{tabular}{|c|c|c|c|c|c|c|c|c|}
\hline Studientag & Zeitpunkt & $\begin{array}{c}\text { Schellong- } \\
\text { Test }\end{array}$ & $\begin{array}{c}\text { Blutab- } \\
\text { nahme }\end{array}$ & $\begin{array}{c}\text { BZ- } \\
\text { Messung }\end{array}$ & $\begin{array}{l}\text { Ergo- } \\
\text { metrie }\end{array}$ & $\begin{array}{c}\text { BZ- } \\
\text { Messung }\end{array}$ & $\begin{array}{l}25 \mathrm{mg} \\
\text { Carv. }\end{array}$ & $\begin{array}{l}\text { Urin- } \\
\text { probe }\end{array}$ \\
\hline \multirow[t]{3}{*}{ Baseline } & PIT 1 & & $\bullet$ & & $\bullet$ & & & \\
\hline & PIT2 & $\bullet$ & $\bullet$ & $\bullet$ & $\bullet$ & $\bullet$ & & $\bullet$ \\
\hline & PIT3 & • & & - & - & $\bullet$ & & - \\
\hline \multirow[t]{5}{*}{1} & PIT1 & & • & & - & & $\bullet$ & \\
\hline & PIT2 & & - & & & & & \\
\hline & PIT3 & $\bullet$ & $\bullet$ & $\bullet$ & $\bullet$ & $\bullet$ & & $\bullet$ \\
\hline & PIT4 & $\bullet$ & $\bullet$ & $\bullet$ & $\bullet$ & $\bullet$ & & \\
\hline & PIT5 & $\bullet$ & $\bullet$ & $\bullet$ & $\bullet$ & $\bullet$ & & $\bullet$ \\
\hline \multirow[t]{2}{*}{2} & PIT1 & & $\bullet$ & & $\bullet$ & & & \\
\hline & PIT2 & & $\bullet$ & & $\bullet$ & & & \\
\hline 3 & PIT1 & & $\bullet$ & & $\bullet$ & & & \\
\hline
\end{tabular}

PIT, point of time (Untersuchungsabschnitt); BZ, Blutzucker; Carv., Carvedilol.

\subsubsection{Diätvorschriften}

Vor Beginn der Studie wurden die Probanden ebenfalls über eine Diät während der Studie aufgeklärt. Die Einhaltung dieser Diät war Voraussetzung zur Teilnahme an der Studie. Da einige Nahrungsbestandteile wie Medikamente Enzymaktivitäten beeinflussen und stören 
Material und Methoden

können, sollten diese Störfaktoren weitgehend durch die Einhaltung dieser Diät minimiert werden.

Am Baseline-Tag, 1. Studientag und 24 Stunden vor Beginn der Studie sollten vor allem die in Tab. 15 aufgelisteten Ernährungsvorgaben eingehalten werden. Zur Lebensmitteldokumentation wurde den Probanden am Baseline-Tag und am 1. Studientag ein Plan ausgehändigt, der am Ende des Studientages wieder abgegeben werden musste. Hinzu kommt, dass die Probanden in der Zeit der Medikamenteneinnahme auf eine eingeschränkte körperliche Belastung achten sollten.

Tab. 15 Ernährungsvorgaben

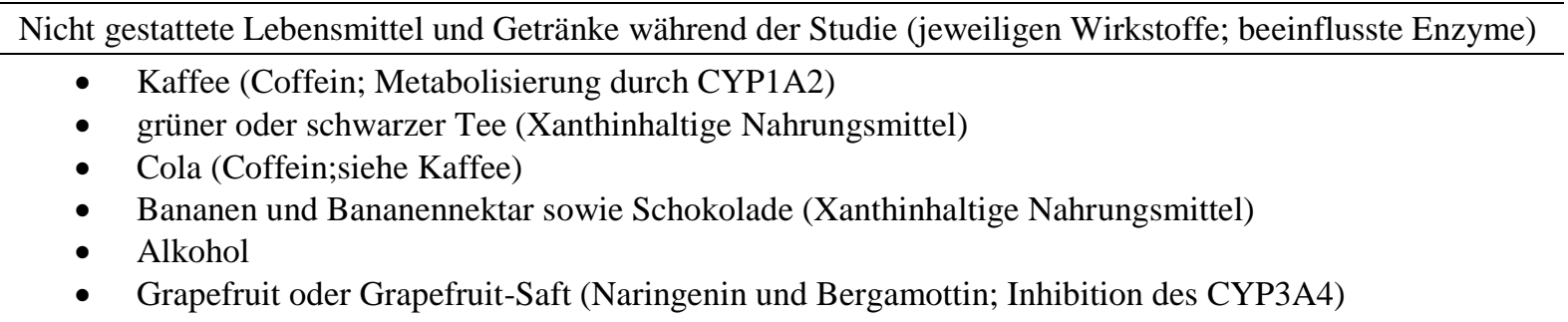

\subsubsection{Aufbereitung der gewonnenen Proben}

Die zur Konzentrationsbestimmung abgenommenen Blut- und Urinproben wurden mit den Probandendaten (Initialen und Probandennummer des Probanden) versehen. Die 9-ml-EDTABlutproben wurden 10 Minuten lang bei $4^{\circ} \mathrm{C}$ bei $>1000$ Umdrehungen/min zentrifugiert. Danach wurde das Blutplasma in 2 mit Probandendaten (Codeschlüssel) versehene Polypropylen-Greiner Röhrchen zu gleichen Teilen pipettiert, anschließend wurden die Proben bis zur Konzentrations- und Analytikbestimmung im Tiefkühlfach bei $-18^{\circ} \mathrm{C}$ aufbewahrt (siehe Kap. 2.3). Ebenfalls wurde die zur Genotypisierung bestimmte 9-mlEDTA-Blutprobe mit den Probandendaten versehen und bei $-18^{\circ} \mathrm{C}$ bis zur Analyse tiefgefroren (siehe Kap. 2.2). Wie im Vorhergehenden schon erwähnt, wurde auch der Urin auf Röhrchen aufgezogen und bei $-18^{\circ} \mathrm{C}$ bis zur Analyse aufbewahrt.

\subsubsection{Fahrradergometrie}

Die Ergometrie ist eine Methode, mit der die Belastung eines Patienten gemessen werden kann, indem während des Belastungsvorganges simultan ein 12-Kanal-EKG abgeleitet und der Blutdruck gemessen wird. In unserer Studie erfolgte die Ergometrie auf einem EKGErgometrie-System mit automatischer Blutdruck- und Herzfrequenzmessung von der Firma 
Material und Methoden

Schiller (Modell AT 104 PC; Schiller, Riemerling, Deutschland). Bevor die Belastung begann, wurde drei Minuten lang ein Ruhe-EKG abgeleitet und der Ruheblutdruck gemessen. Die Belastung wurde sowohl bei weiblichen als auch bei männlichen Probanden bei 100 Watt gestartet. Die Belastungsstufe wurde jede Minute um 25 Watt gesteigert, bis die maximale Herzfrequenz (maximale Herzfrequenz $=220-$ Lebensalter) erreicht wurde. Anschließend wurde die Belastung auf 25 Watt reduziert und die Normalisierung des Blutdruckes sowie der Herzfrequenz in den folgenden 5 Minuten wurden registriert. Während der Ergometrie wurde die Herzfrequenz automatisch in 10 Sekunden Abständen und der Blutdruck minütlich gemessen und aufgezeichnet.

In der vorliegenden Studie wurden die Ergometriedaten, die nach Medikamenten-Einnahme erhoben wurden, mit den Ergometriedaten der 1. Ergometrie-Sequenz vom 1. Studientag verglichen.

\subsubsection{Schellong-Test}

Orthostatische Veränderungen sowohl in der Herzfrequenz als auch im Blutdruck wurden durch den Schellong-Test erfasst. Der Schellong-Test ist ein Kreislauffunktionstest, bei dem der Proband nach einer Liegezeit von 5 Minuten 10 Minuten steht und anschließend wiederum 5 Minuten liegt. Während des Tests wurden in der vorliegenden Studie der Blutdruck im Minutentakt und die Herzfrequenz in 10 Sekunden Abständen gemessen und aufgezeichnet.

Ein Abfall des systolischen Blutdruckwertes von $\geq 20 \mathrm{~mm} \mathrm{Hg}$ in der Stehphase deutet auf eine Kreislauffunktionsstörung hin. Wohingegen bei Gesunden in der Stehphase eine leichte Pulsfrequenzzunahme und ein Abfall des systolischen Blutdruckwertes zwischen 10-15 mm $\mathrm{Hg}$ noch als normal anzusehen sind. Bei Auftreten von gravierenden Nebenwirkungen wurde der Test abgebrochen und Gegenmaßnahmen wurden durchgeführt.

In der vorliegenden Studie wurden die Daten der Schellong-Tests, die nach MedikamentenEinnahme erhoben wurden, mit den Daten der Schellong-Tests vom Baseline-Tag verglichen. 
Material und Methoden

\subsection{CYP2D6-, CYP2C9- und CYP2C19-Genotypisierung}

Vor Studienbeginn wurde jedem Probanden in einem 9-ml-EDTA-Röhrchen Blut zur Genotypisierung der polymorphen Cytochrom-P450-Enzyme 2D6, 2C9 und 2C19 abgenommen. Nachdem die genomische DNA durch Extraktion gewonnen worden war, erfolgte die DNA-Amplifikation durch PCR (Polymerase-Kettenreaktion). Dann folgte die Bestimmung der CYP2D6-Allele, der CYP2C9*2- und *3-Allele sowie der CYP2C19*2- und *17-Allele. Die CYP2D6-Ergebnisse wurden mit der Gene Mapper v3.7 Software ${ }^{\circledR}$ (Applied Biosystems) und die Ergebnisse des CYP2C9 und des CYP2C19 mit dem 7900HT Sequence Detection System (Applied Biosystems, Carlsbad, USA) analysiert. Die Genotypisierung fand in der Abteilung für Klinische Pharmakologie der Universität Göttingen statt.

\subsubsection{Isolierung der DNA}

Die Gewinnung qualitativ hochwertiger genomischer DNA aus EDTA-Blut erfolgte mit Hilfe des EZ1 DNA Blood Kit der Firma Qiagen. Dieser basiert auf einer Festphasenextraktion mit Hilfe von Siliziumdioxid beschichteten Magnetpartikeln (Sorbens) (EZ1 DNA Blood Handbook 04/2009). Diese DNA-Extraktion läuft vollautomatisiert im BioRobot EZ1 ab (Firma Qiagen).

Dabei werden folgende Schritte durchlaufen: Durch Zugabe von Lösungs-/Bindungspuffern kommt es zu einer kompletten Zellyse, diese Lösung wird durch das Sorbens geleitet. Durch chaotropische Salze der Bindungspuffer induziert bindet die DNA durch Wechselwirkungen an die mit Siliziumdioxid beschichteten Magnetpartikel. Nachdem die mit DNA beladenen Magnetpartikel mit Hilfe eines Magneten aus der Lösung separiert sind, wird die DNA durch bestimmte Pufferlösungen aufgereinigt. Schließlich wird die noch gebundene DNA durch ein geeignetes Lösungsmittel von den Magnetpartikeln abgelöst (eluiert). Der komplette Versuchsablauf dauert ca. 20 min, hierbei können bei einer Ausgangsmenge von $350 \mu \mathrm{l}$ Vollblut $200 \mu \mathrm{l}$ DNA-Lösung mit Konzentrationen von 10 bis $200 \mathrm{ng} / \mu 1$ gewonnen werden. 
Material und Methoden

\subsubsection{PCR}

Bei der Polymerase-Kettenreaktion (englisch: Polymerase Chain Reaction, PCR) werden in vitro DNA-Sequenzen durch DNA-Polymerasen amplifiziert. Produkte vorheriger Zyklen dienen als Ausgangsstoffe für den nächsten Zyklus, dies wird als Kettenreaktion bezeichnet.

Im Allgemeinen besteht ein PCR-Zyklus aus drei Schritten und läuft vollautomatisiert im Thermozykler ab. Um eine ausreichende DNA-Menge zu amplifizieren, müssen jedoch mehrere Zyklen durchlaufen werden. Erstens wird die doppelsträngige DNA durch Erhitzen auf ca. $95^{\circ} \mathrm{C}$ denaturiert, sodass sie in zwei Einzelsträngen vorliegt. Im zweiten Schritt, der sogenannten Primerhybridisierung (primer annealing), kommt es durch Absenken der Temperatur auf ca. $60^{\circ} \mathrm{C}$ zur Anlagerung der Primer an die beiden DNA-Einzelstränge. Als Primer werden einsträngige Oligonukleotide aus 20 bis 30 Basen bezeichnet, die komplementär zum Randbereich des zu amplifizierenden Genabschnitts sind. Der VorwärtsPrimer läuft vom 5'-Ende in Richtung 3'-Endes des ersten Stranges, wohingegen der Rückwärts-Primer vom 5'-Ende in Richtung des 3'-Endes des Gegenstranges läuft. Die Primer dienen im dritten Schritt der PCR als Starthilfe für die thermostabile DNAPolymerase, die bei $72^{\circ} \mathrm{C}$ ihr Optimum besitzt. Diese Polymerase verlängert die Primer am 3'-Ende, hierbei werden die im Reaktionsgemisch vorhandenen Desoxyribonukleosidtriphosphate verwendet. Durch die PCR kommt es somit zu einer exponentiellen, selektiven Amplifizierung der ursprünglichen DNA-Sequenz.

\subsubsection{Bestimmung der CYP2D6-Allele}

Zur Bestimmung der in dieser Arbeit untersuchten CYP2D6-Allele wurde eine PCR (LongPCR, Expand Long Template PCR Systems ${ }^{\circledR}$ (Roche, Mannheim, Deutschland)) und eine Einzel-Basen-Primerverlängerungstechnik (Single Base Primer Extension (SBPE); SNaPShotKits ${ }^{\circledR}$ von Roche) verwendet. Diese Genotypisierungsmethode, die auf Publikationen von Fuselli et al. (2004), Johansson et al. (1996) und Sachse et al. (1997) basiert, wurde von Dr. M. Tzvetkov aus der Abteilung der Klinischen Pharmakologie der Universität Göttingen optimiert. In den folgenden Kapiteln werden die Verfahren zur Identifizierung sowohl der CYP2D6-Allele $* 2, * 3, * 4, * 6, * 9, * 10, * 17$ und *41 als auch der CYP2D6-Gendeletion (Allel *5) und der CYP2D6-Duplikation beschrieben. 
Material und Methoden

\subsubsection{Identifizierung der Allele $* 2, * 3, * 4, * 6, * 9, * 10, * 17$ und $* 41$}

Zunächst musste das CYP2D6-Gen mit Hilfe des Expand Long Template PCR Systems ${ }^{\circledR}$, welches Taq (aus Thermus aquaticus isoliert)- und Tgo (aus Thermococcus gorgonarius isoliert)-DNA-Polymerase enthält (Handbook Roche Version 09/2005), selektiv aus dem CYP2D-Genlocus amplifiziert (Reaktion Nr.1) werden. Im Gegensatz zu der Taq-DNAPolymerase verfügt die Tgo (aus Thermococcus gorgonarius isoliert)-DNA-Polymerase über eine Exonukleaseaktivität, die in $3^{\prime}-5^{\prime}$-Richtung falsch eingebaute Basen entfernt und somit Fehler korrigiert. Die für diesen Reaktionsschritt verwendeten Primer und die Reaktionsbedingungen sind in Tabelle 16 bis 18 dargestellt.

Die Long-PCR wurde im Thermal Zykler PTC-200 (Bio-Rad, München, Deutschland) mit geheiztem Deckel durchgeführt. Die Proben wurden erst in den Zykler hineingestellt, nachdem die Blocktemperatur $85^{\circ} \mathrm{C}$ erreicht hatte (so genannter Hot Start).

Tab. 16 PCR-Mix (Reaktion Nr. 1)

\begin{tabular}{lll}
\hline Reagenz & Volumen $[\boldsymbol{\mu l}]$ & Endkonzentration \\
$\mathrm{H}_{2} \mathrm{O}$ & 15,9 & \\
10 -facher Expand-Long Puffer 1 & 2,8 & 1 -fach \\
$\mathrm{Mg}^{2+}(25 \mathrm{mM})$ & 0,8 & $0,7 \mathrm{mM}$ \\
$\mathrm{dNTPs}(2 \mathrm{mM})$ & 4,5 & $0,32 \mathrm{mM}$ \\
Primer $(10 \mu \mathrm{M}):$ CYP2D6-F & 0,5 & $0,18 \mu \mathrm{M}$ \\
Primer $(10 \mu \mathrm{M}): \mathrm{CYP} 2 \mathrm{D} 6-\mathrm{R}$ & 0,5 & $0,18 \mu \mathrm{M}$ \\
Expand Long DNA Polymerase Mix & 0,3 & $1,5 \mathrm{U}$ \\
Genomische DANN & 3,0 & \\
\hline
\end{tabular}

Tab. 17 PCR-Primer (Reaktion Nr. 1)

\begin{tabular}{ll}
\hline Name & Sequenz \\
CYP2D6-F & 5'- CCAGAAGGCTTTGCAGGCTTCA -3' \\
CYP2D6-R & 5'- ACTGAGCCCTGGGAGGTAGGTA -3' \\
Lx2F & 5'- GCCACCATGGTGTCTTTGCTTTC -3' \\
Lx2R & 5'- ACCGGATTCCAGCTGGGAAATG -3' \\
P13 & 5'- ACCGGGCACCTGTCATCCTCA -3' \\
P24 & 5'- GCATGAGCTAAGGCACCCAGAC -3' \\
P81 & 5'- CGTCTAGTGGGGAGACAAAC -3' \\
CYP17 & 5'- TCCCCCACTGACCCAACTCT -3' \\
CYP32 & 5'- CACGTGCAGGGCACCTAGAT -3' \\
\hline
\end{tabular}


Material und Methoden

Tab. 18 Zyklerprogramm (Reaktion Nr. 1)

\begin{tabular}{llll}
\hline PCR-Stufe & Temperatur & Zeit & Zyklen \\
Initiale Denaturierung & $94^{\circ} \mathrm{C}$ & $2 \mathrm{~min}$ & \\
& & & \\
Denaturierung & $96^{\circ} \mathrm{C}$ & $10 \mathrm{sek}$ & $35 \mathrm{x}$ \\
Anlagerung & $60^{\circ} \mathrm{C}$ & $20 \mathrm{sek}$ & \\
Verlängerung & $68^{\circ} \mathrm{C}$ & $5 \mathrm{~min}$ & \\
Finale Verlängerung & & $7 \mathrm{~min}$ & \\
\hline
\end{tabular}

In der folgenden Reaktion Nr.2 wurden $13 \mu$ PCR-Produkt (aus der Reaktion Nr. 1) bei $37^{\circ} \mathrm{C}$ durch Zugabe von $5 \mu \mathrm{l}(1 \mathrm{U} / \mu \mathrm{l})$ Shrimp alkalische Phosphatase (SAP, USB, Staufen, Deutschland), 0,2 $\mu \mathrm{l}$ (10 U/ $\mu \mathrm{l})$ Exonuklease I aus E. coli (ExoI, USB, Staufen, Deutschland) und $2 \mu 1$ 10-fach Shrimp alkalische Phosphatase Puffer gereinigt. Diese Reaktion wurde durch eine 15 minütige Erhitzung auf $80^{\circ} \mathrm{C}$ gestoppt. Zusätzlich wurden durch diese Reinigung auch die Desoxyribonukleosidtriphosphate (dNTPs), die die folgende Einzel-BasenPrimerverlängerungsmethode stören würden, entfernt. Die Qualität des PCR-Produktes wurde auf 0,8\% Agarose-Gel kontrolliert, wobei die Ampliconlänge bei 5092 bp liegen sollte. Das Ergebnis der Reaktion Nr. 1 und Nr. 2 war das aus dem CYP2D-Genlocus amplifizierte CYP2D6-Gen.

Zur Identifizierung der oben genannten häufigsten Polymorphismen des CYP2D6-Allels bei Kaukasiern wurde die Einzel-Basen-Primerverlängerungsreaktion (SBPE) (SNaPshot ${ }^{\circledR}$ Kit der Firma Applied Biosystems) (Reaktion Nr. 3) angewandt. Es wurden $2 \mu 1$ des aufgereinigten PCR-Produktes (aus der Reaktion Nr. 2) zu $3 \mu 1$ des Master-Mix (Tab. 19) zugegeben. Die Primer der SBPE wurden so gewählt, dass die erste folgende Base am 3`Ende des Primers die Position des SNP ist. Bei der SBPE werden die Primer lediglich um eine einzige Base verlängert, da das Reaktionsgemisch nur fluorenszenmarkierte Didesoxynukleosidtriphosphate (ddNTPs) beinhaltet. Im Gegensatz zu den dNTPs, die in der Reaktion Nr. 2 durch Reinigung entfernt wurden, kann an die ddNTPs aufgrund ihrer biochemischen Struktur keine weitere Base durch die DNA-Polymerase angelagert werden. Die Reagenzien, fluoreszenzmarkierten Primer und die Reaktionsbedingungen der Reaktion Nr.3 werden in den Tabellen 19, 20 und 21 dargestellt. 
Material und Methoden

Tab. 19 Master-Mix (Reaktion Nr.3)

\begin{tabular}{ll}
\hline Reagenz & Volumen $[\boldsymbol{\mu l}]$ \\
2-fach SNaPshot Reaction Mix & 2,5 \\
10-fach Primer-Mix & 0,5 \\
\hline
\end{tabular}

Tab. 20 Zyklerprogramm (Reaktion Nr. 3)

\begin{tabular}{llll}
\hline PCR-Stufe & Temperatur & Zeit & Zyklen \\
Denaturierung & $96^{\circ} \mathrm{C}$ & $10 \mathrm{sek}$ & \\
Anlagerung & $50^{\circ} \mathrm{C}$ & $5 \mathrm{sek}$ & $25 \mathrm{x}$ \\
Verlängerung & $60^{\circ} \mathrm{C}$ & $30 \mathrm{sek}$ & \\
\hline
\end{tabular}

Tab. 21 Primer für Primerverlängerungsreaktion (Reaktion Nr. 3)

\begin{tabular}{|c|c|c|c|}
\hline Name & Sequenz & $\begin{array}{l}\text { Länge } \\
\text { [bp] }\end{array}$ & $\begin{array}{c}\text { End- } \\
\text { konzentration }\end{array}$ \\
\hline $2850 \mathrm{C}>\mathrm{T}$ & $5^{\prime}-(\mathrm{A})_{7} \mathrm{CAGGTCAGCCACCACTATGC-3^{ \prime }}$ & 27 & $250 \mathrm{nM}$ \\
\hline $1846 \mathrm{G}>\mathrm{A}$ & $5^{\prime}-(\mathrm{A})_{16} \mathrm{TACCCGCATCTCCCACCCCCA} \mathrm{-3'}$ & 37 & $250 \mathrm{nM}$ \\
\hline $1707 \mathrm{~T}>\mathrm{del}$ & $5^{\prime}-(\mathrm{A})_{21}$ GGCAAGAAGTCGCTGGAGCAG -3' & 42 & $500 \mathrm{nM}$ \\
\hline $\begin{array}{l}2613- \\
15 \mathrm{AGA}>\mathrm{del}\end{array}$ & $5^{\prime}-(\mathrm{A})_{26} \mathrm{GCCTTCCTGGCAGAGATGGAG-3'}$ & 47 & $500 \mathrm{nM}$ \\
\hline $100 \mathrm{C}>\mathrm{T}$ & $5^{\prime}-(\mathrm{A})_{31} \mathrm{CAACGCTGGGCTGCACGCTAC-3'}$ & 52 & $1,5 \mu \mathrm{M}$ \\
\hline $4180 \mathrm{G}>\mathrm{C}$ & $5^{\prime}-(\mathrm{A})_{37} \mathrm{CAAAGCTCATAGGGGGATGGG-3'}$ & 58 & $1,5 \mu \mathrm{M}$ \\
\hline $1023 \mathrm{C}>\mathrm{T}$ & $5^{\prime}-(\mathrm{A})_{42} \mathrm{CCGCCCGCCTGTGCCCATCA-3^{ \prime }}$ & 62 & $1,5 \mu \mathrm{M}$ \\
\hline $2988 \mathrm{G}>\mathrm{A}$ & $5^{\prime}-(\mathrm{A})_{45} \mathrm{AACAGTGCAGGGGCCGAGGGAG-3'}$ & 67 & $1 \mu \mathrm{M}$ \\
\hline $31 \mathrm{G}>\mathrm{A}$ & $\begin{array}{l}5^{\prime}-(\mathrm{A})_{43} \mathrm{CCAGGAGCAGGAAGATGGCCACTATCA-} \\
3^{\prime}\end{array}$ & 70 & $2,5 \mu \mathrm{M}$ \\
\hline $\begin{array}{l}2549 \mathrm{~A}>\mathrm{del} \\
\operatorname{var} 3\end{array}$ & $5^{\prime}-(\mathrm{A}){ }_{54} \mathrm{GGGCTGGGTCCCAGGTCATCC-3'}$ & 75 & $5 \mu \mathrm{M}$ \\
\hline
\end{tabular}

Die in der Reaktion Nr.3 entstandenen fluoreszenzmarkierten PCR-Produkte, wurden in der anschließenden Reaktion Nr.4 vor der Kapillargelelektrophorese von den nicht-integrierten ddNTPs gereinigt. Dafür wurden 0,5 $\mu 1$ Kälber alkalische Phosphatase (Fermentas, St. LeonRot, Deutschland) zu dem Reaktionsprodukt hinzugegeben und für eine Stunde bei $37^{\circ} \mathrm{C}$ inkubiert. Die alkalische Phosphatase wurde für 15 Minuten bei $75^{\circ} \mathrm{C}$ hitzeinaktiviert. Ein $\mu 1$ des aufgereinigten PCR-Produktes der Reaktion Nr.4 wurde mit $9 \mu$ Formamid $\left(\mathrm{Hi}-\mathrm{Di}{ }^{\mathrm{TM}}\right.$ Formamide, Applied Biosystems) gemischt und denaturiert. Somit erhält man einzelsträngige DNA, die keine Sekundärstrukturen ausbildet, wodurch die Fragmente ausschließlich nach ihrem Molekulargewicht aufgetrennt werden. Diesem denaturierten Gemisch wurde zusätzlich $0.5 \mu$ l Molekulargewichtsmarker (Längenstandard) GeneScan-120LIZ® (Applied Biosystems), welcher als Kontrollstandard in der Kapillarelektrophorese mitläuft, hinzugefügt.

Bei der Kapillarelektrophorese sind die Kapillaren mit einem Polymer gefüllt, in denen sich die Amplifikate nach Anlegen einer Spannung im elektrischen Feld zur Anode bewegen (3130 xl 
Material und Methoden

Genetic Analyser, Applied Biosystems, USA). Beim Durchlaufen wird ein Argonlaser, dessen Hauptemissionen bei einer Wellenlänge von $488 \mathrm{~nm}$ und 514,5 nm liegen, passiert. Hierdurch kommt es zur Anregung der fluoreszenzmarkierten Amplifikate, wobei diese Licht emittieren und es auf einen Charge Coupled Device-Chip projizieren. Dieser Charge Coupled Device-Chip dient zur Detektion der Intensität von vier nicht überlappenden Wellenlängen-Bereichen. Die Bestimmung des Genotyps der einzelnen Varianten wurde auf Grund der Retentionszeit und Farbe der Signale mit Hilf der Gene Mapper v3.7 Software ${ }^{\circledR}$ (Applied Biosystems) durchgeführt. Basierend auf der Kombination der einzelnen Varianten wurden die CYP2D6Allele bestimmt (Tabelle 22). Die Resultate der Elektrophorese konnten dann in Elektrophoregrammen gezeigt werden.

Tab. 22 Zuordnung der CYP2D6-Allele basierend auf den SNPs bzw. Insertion Deleletion-Varianten

\begin{tabular}{llllllllllll}
$\begin{array}{l}\text { Position im } \\
\text { pherogramm }\end{array}$ & Electro- & 27 & 37 & 42 & 47 & 52 & 57 & 62 & 67 & 70 & 22 \\
\hline $\begin{array}{l}\text { Position im } \\
\text { Gen }\end{array}$ & CYP2D6- & 2850 & 1846 & 1707 & 2613 & 100 & 4180 & 1023 & 2988 & 31 & 2549 \\
\hline $\begin{array}{l}\text { Austausch } \\
\text { Allel }\end{array}$ & G/A & G/A & T/G & A/G & C/T & G/C & C/T & G/A & C/T & T/G \\
$* 1$ & & & & & & & & & & \\
$* 2$ & & G & G & T & A & C & C & C & G & C & T \\
$* 3$ & A & G & T & A & C & G & C & G & C & T \\
$* 4$ & G & G & T & A & C & C & C & G & C & G \\
$* 6$ & G & A & T & A & T & G & C & G & C & T \\
$* 9$ & G & G & G & A & C & C & C & G & C & T \\
$* 10$ & G & G & T & G & C & C & C & G & C & T \\
$* 17$ & G & G & T & A & T & G & C & G & C & T \\
$* 41$ & A & G & T & A & C & G & T & G & C & T \\
\hline
\end{tabular}

Die zur Allel-Klassifikation verwendeten Substitutionen sind gelb hinterlegt.

\subsubsection{Identifizierung der CYP2D6-Gendeletion (Allel *5) und der CYP2D6-Duplikation}

Die PCR wurde ebenfalls bei der Bestimmung von Gesamtgendeletion oder Duplikation von CYP2D6 angewandt. Dabei wurden zwei separate Reaktionen, die Primerpaare spezifisch für das duplizierte und das deletierte Allel enthalten, angewandt. Die in Tabelle 23 dargestellten Primer P13, P24 und P81, die in der PCR Reaktion in einem Volumen von $26 \mu 1$ verwendet wurden, dienten für die Identifizierung der CYP2D6-Gesamtgendeletion (Allel *5). 
Material und Methoden

Tab. 23 PCR-Mix bei der Gesamtgendeletion

\begin{tabular}{lll}
\hline Reagenz & Volumen [ $\mu \mathrm{l}]$ & Endkonzentration \\
$\mathrm{H}_{2} \mathrm{O}$ & 14,45 & \\
10 -facher Expand-Long Puffer 1 & 2,60 & 1 -fach \\
$\mathrm{Mg}^{2+}(25 \mathrm{mM})$ & 0,80 & $0,77 \mathrm{mM}$ \\
$\mathrm{dNTPs}(2 \mathrm{mM})$ & 4,50 & $0,35 \mathrm{mM}$ \\
Primer $(10 \mu \mathrm{M}): \mathrm{P} 13$ & 0,50 & $0,19 \mu \mathrm{M}$ \\
Primer $(10 \mu \mathrm{M}): \mathrm{P} 24$ & 0,50 & $0,19 \mu \mathrm{M}$ \\
Primer $(10 \mu \mathrm{M}):$ P81 & 0,50 & $0,19 \mu \mathrm{M}$ \\
Expand Long DNA Polymerase Mix & 0,25 & $1,25 \mathrm{U}$ \\
Genomische DNA & 2,00 & \\
\hline
\end{tabular}

Die Primer CYP17 und CYP32 in der PCR (Tab. 24) wurden bei der Identifizierung der CYP2D6-Gesamtgenduplikation benutzt.

Tab. 24 PCR-Mix bei der Gesamtgenduplikation

\begin{tabular}{lll}
\hline Reagenz & Volumen $[\boldsymbol{\mu l}]$ & Endkonzentration \\
$\mathrm{H}_{2} \mathrm{O}$ & 14,95 & \\
10 -facher Expand-Long Puffer 1 & 2,60 & 1 -fach \\
$\mathrm{Mg}^{2+}(25 \mathrm{mM})$ & 0,80 & $0,77 \mathrm{mM}$ \\
$\mathrm{dNTPs}(2 \mathrm{mM})$ & 4,50 & $0,35 \mathrm{mM}$ \\
Primer $(10 \mu \mathrm{M}):$ CYP17 & 0,50 & $0,19 \mu \mathrm{M}$ \\
Primer $(10 \mu \mathrm{M}):$ CYPP32 & 0,50 & $0,19 \mu \mathrm{M}$ \\
Expand Long DNA Polymerase Mix & 0,25 & $1,25 \mathrm{U}$ \\
Genomische DNA & 2,00 & \\
\hline
\end{tabular}

Sowohl die PCR zur Bestimmung der Gesamtgendeletion, als auch die PCR zur Gesamtgenduplikation erfolgten unter den gleichen Reaktionsbedingungen (Tab. 25).

Tab. 25 Zyklerprogramm für CYP2D6-Duplikation und CYP2D6-Deletion

\begin{tabular}{llll}
\hline PCR-Stufe & Temperatur & Zeit & Zyklen \\
Initiale Denaturierung & $94^{\circ} \mathrm{C}$ & $2 \mathrm{~min}$ & \\
& & & \\
Denaturierung & $96{ }^{\circ} \mathrm{C}$ & $10 \mathrm{sek}$ & $35 \mathrm{x}$ \\
Anlagerung & $57^{\circ} \mathrm{C}$ & $20 \mathrm{sek}$ & \\
Verlängerung & $68^{\circ} \mathrm{C}$ & $5 \mathrm{~min}$ & \\
& & $7 \mathrm{~min}$ & \\
Finale Verlängerung & $68^{\circ} \mathrm{C}$ &
\end{tabular}

Die Analyse der PCR Produkte erfolgte auf einem 0,8 \% Agarosegel. Aufgrund der Längenunterschiede der PCR Produkte in der Elektrophorese zeigte das *5-Allel ein PCRSignal bei 3,5 kb, wobei das nicht deletierte CYP2D6-Gen ein PCR-Signal bei 4,5 kb aufwies. 
Material und Methoden

In der Duplikations-spezifischen Reaktion zeigte das duplizierte CYP2D6-Gen ein Signal bei 3,6 $\mathrm{kb}$ und das nicht duplizierte bei 4,5 kb.

Um die duplizierten Allele genau zu identifizieren, wurde ein modifiziertes SNaPshot Verfahren verwendet. Hierbei wurde nur das duplizierte Allel in einer typischerweise heterozygoten Probe mit Hilfe einer spezifischen PCR unter den in Tab. 27 genannten Bedingungen in einem Volumen von $27 \mu 1$ voramplifiziert (Tab. 26).

Sowohl die Reinigung der PCR-Produkte, als auch die weitere Analyse der gewonnenen PCR-Produkte in der SNaPshot-Reaktion wurden dann, wie unter Kapitel 2.2.3.1 ab der Reaktion Nr. 2 beschrieben, durchgeführt. Im Unterschied $\mathrm{zu}$ der in Kapitel 2.2.3.1 beschriebenen SNaPshot-Reaktion, wurden bei dieser reduzierten SNapshot-Reaktion nur die 4 in Tab. 28 aufgeführten Primer verwendet. Dieses Verfahren konnte zeigen, ob die Allele $* 1, * 2, * 4, * 10$, oder $* 41$ in einer heterozygoten Probe dupliziert vorlagen. Im Gegensatz zu einer Duplikation eines aktiven Allels wie *1 oder *2 führt eine Duplikation eines vermindert aktiven Allels wie $* 10$ oder $* 41$ nur zu einer begrenzten Steigerung der Enzymaktivität und eine Duplikation eines inaktiven Allels *4 führt zu keiner Erhöhung der Enzymaktivität.

Tab. 26 PCR-Mix bei der Snapshot-Gesamtgenduplikation

\begin{tabular}{lll}
\hline Reagenz & Volumen $[\boldsymbol{\mu l}]$ & Endkonzentration \\
$\mathrm{H}_{2} \mathrm{O}$ & 15,9 & \\
10 -facher Expand-Long Puffer 1 & 2,7 & 1 -fach \\
$\mathrm{Mg}^{2+}(25 \mathrm{mM})$ & 0,80 & $0,74 \mathrm{mM}$ \\
$\mathrm{dNTPs}(2 \mathrm{mM})$ & 4,50 & $0,33 \mathrm{mM}$ \\
Primer $(10 \mu \mathrm{M}):$ Lx2F & 0,50 & $0,18 \mu \mathrm{M}$ \\
Primer $(10 \mu \mathrm{M}):$ Lx2R & 0,50 & $0,18 \mu \mathrm{M}$ \\
Expand Long DNA Polymerase Mix & 0,3 & $1,5 \mathrm{U}$ \\
Genomische DANN & 2,00 & \\
\hline
\end{tabular}

Tab. 27 Zyklerprogramm

\begin{tabular}{llll}
\hline PCR-Stufe & Temperatur & Zeit & Zyklen \\
Initiale Denaturierung & $94^{\circ} \mathrm{C}$ & $2 \mathrm{~min}$ & \\
& & & \\
Denaturierung & $96^{\circ} \mathrm{C}$ & $10 \mathrm{sek}$ & $35 \mathrm{x}$ \\
Anlagerung & $60^{\circ} \mathrm{C}$ & $20 \mathrm{sek}$ & $7 \mathrm{~min}$ \\
Verlängerung & $68^{\circ} \mathrm{C}$ & & \\
Finale Verlängerung & $68^{\circ} \mathrm{C}$ & $7 \mathrm{~min}$ & \\
\hline
\end{tabular}


Material und Methoden

Tab. 28 Primer für die SNapshot-Gesamtgenduplikation-PCR

\begin{tabular}{|c|c|c|c|}
\hline Name & Sequenz & $\begin{array}{l}\text { Länge } \\
\text { [bp] }\end{array}$ & $\begin{array}{c}\text { End- } \\
\text { konzentration }\end{array}$ \\
\hline$-1584 G>C$ & $5^{\prime}-(\mathrm{A}){ }_{9} \mathrm{CCTGGACAACTTGGAAGAACC}-3^{\prime}$ & 40 & $2 \mu \mathrm{M}$ \\
\hline $100 \mathrm{C}>\mathrm{T}$ & $5^{\prime}-(\mathrm{A})_{31} \mathrm{CAACGCTGGGCTGCACGCTAC-3'}$ & 52 & $3 \mu \mathrm{M}$ \\
\hline $4180 \mathrm{G}>\mathrm{C}$ & $5^{\prime}-(\mathrm{A}){ }_{37}$ CAAAGCTCATAGGGGGATGGG-3' & 58 & $3,5 \mu \mathrm{M}$ \\
\hline $31 \mathrm{G}>\mathrm{A}$ & $5^{\prime}-(\mathrm{A})_{43} \mathrm{CCAGGAGCAGGAAGATGGCCACTATCA-3'}$ & 70 & $2,5 \mu \mathrm{M}$ \\
\hline
\end{tabular}

\subsubsection{Bestimmung der CYP2C9- und CYP2C19-Allele}

Für die Genotypisierung der Genvarianten CYP2C9*2 und *3 sowie der Varianten CYP2C19*2 und *17 wurde das Taqman-Verfahren verwendet, benannt nach der Taq-DNAPolymerase, die neben der Polymerase-Funktion auch eine 5 ` $^{`}$ Exonukleaseaktivität besitzt (siehe unten).

In unserer Studie wurden für alle oben genannten Genvarianten Reaktionsgemische, die in Tab. 29 dargestellt sind, aus jeweils $1 \mu 1$ der extrahierten DNA (Konzentration 10 ng DNA/ $\mu 1$ Lösung), aus TaqMan ® Universal PCR Mastermix (Applied Biosystems, Carlsbad, USA), aus TaqMan® Sonden- und Primer Mix für die untersuchten SNPs, sowie aus bidestilliertem Wasser hergestellt. Der TaqMan ${ }^{\circledR}$ Universal PCR Mastermix enthielt neben AmpliTaq ${ }^{\circledR G o l d-D N A-P o l y m e r a s e ~ d N T P s, ~ M a g n e s i u m c h l o r i d ~ u n d ~ P u f f e r . ~}$

Die allel-spezifischen fluoreszenzmarkierten TaqMan®-Sonden (einzelsträngige Oligonukleotide) besitzen am 5 `Ende einen Reporter (Fluoreszenzmarker) und am 3 `-Ende einen Quencher (Fluoreszenzlöscher). Je nachdem welche Genvariante untersucht wird heißen die Reporter VIC oder FAM (6-Carboxyfluorescein). Diese fluoreszenzmarkierten Sonden lagern sich in der Annealing-Phase der PCR an den ihnen komplementären DNAStrang an. Nur wenn Reporter und Quencher räumlich nah beieinander sind, wird das Fluoreszenz-Signal des Reporters durch den Quencher aufgenommen und damit neutralisiert. Nachdem auch die Primer sich an den DNA-Strang angelagert haben, beginnt die Amplifikation durch die Taq-DNA-Polymerase, die - wie bereits oben beschrieben zusätzlich eine 5`3`-Exonukleaseaktivität besitzt und die an die DNA angelagerten fluoreszenzmarkierten Sonden abspaltet. Dadurch kommt es zu einer räumlichen Distanz zwischen Reporter und Quencher, sodass das Fluoreszenz-Signal freigesetzt wird. Die Zunahme der Fluoreszenz-Signale der freigesetzten Marker (Reporter) verhält sich direkt proportional zur Anzahl PCR-amplifizierter DNA. 
Material und Methoden

Im letzten Schritt wurden die PCR-Produkte samt der freigesetzten fluoreszenzmarkierten Reporter (VIC, FAM) im 7900HT Sequence Detection System (Applied Biosystems, Carlsbad, USA) analysiert. Dabei wurde die Fluoreszenz der freigesetzten Marker durch Laserlicht aus einem Argon-Laser angeregt. Mit Hilfe der unterschiedlichen Emissionswellenlängen der fluoreszenzmarkierten Reporter (VIC, FAM) konnte man auf das Vorkommen der jeweiligen Genvarianten schließen.

Tab. 29 PCR- und Zyklerprogramm für CYP2C9*2, *3 und CYP2C19*2, *17

\begin{tabular}{|c|c|c|c|}
\hline Genvarianten & CYP2C9 $* 2, * 3$ & CYP2C19*2 & CYP2C19*17 \\
\hline Substanzen & & Volumen $(\mu \mathrm{l})$ & \\
\hline 2fach TaqMan Master Mix & 2,5 & 2,5 & 2,5 \\
\hline 20fach Sonden- und Primer-Ansatz & 0,25 & 0,25 & $0,125^{\mathrm{a}}$ \\
\hline Bidestilliertes Wasser & 1,25 & 1,25 & 1,375 \\
\hline Verdünnte DNA (10 ng/ $\mu 1)$ & 1 & 1 & 1 \\
\hline Endvolumen $(\mu \mathrm{l})$ & 4 & 4 & 4 \\
\hline \multirow{8}{*}{$\begin{array}{l}\text { TaqMan®-SNP-Genotypisierungs- } \\
\text { Assays }{ }^{\text {b }}\end{array}$} & \#C__25625805_10 (*2) & \#C___1329163_10 & \#C__469857_10 \\
\hline & \#C___27104892_10 (*3) & & \\
\hline & \multicolumn{3}{|c|}{ Zyklerprogramm } \\
\hline & Zeit (min) & Temperatur $\left({ }^{\circ} \mathrm{C}\right)$ & Zyklen \\
\hline & 2 & 50 & \\
\hline & 2 & 95 & \\
\hline & 0,5 & 92 & $50 x$ \\
\hline & 1,3 & 60 & \\
\hline
\end{tabular}

${ }^{\mathrm{a}}$ Hier wurde ein 40fach Sonden- und Primer-Ansatz benützt. Reaktionen fanden im vollautomatischen Thermocycler (Eppendorf Mastercycler®, Eppendorf, Hamburg, Deutschland) statt. b Die Sequenzen der Primer und Sonden wurden dabei vom Hersteller nicht angegeben.

\subsection{Konzentrationsbestimmung}

Die Konzentrationen von Carvedilol und seiner Metaboliten wurden in der Abteilung Klinische Pharmakologie der Universitätsmedizin Göttingen bestimmt. Die Konzentrationsbestimmung in den Plasma- und Urinproben erfolgte mittels HPLC (high performance liquid chromatography) mit Fluoreszenz- und UV-Detektion, wobei diese Methode auf der 1989 von Eisenberg beschriebenen Methode basiert. Im Folgenden wird lediglich auf die Konzentrationsbestimmung der Plasmaproben eingegangen. 
Material und Methoden

\subsubsection{Analyten und Stammlösungen}

Zunächst wurden Stammlösungen mit definierten Konzentrationen von Carvedilol (R, SEnantiomere) (Roche (Mannheim, Deutschland)), Desmethylcarvedilol und 4'-und 5'-OHCarvedilol (Firma Synfine (Richmond Hill, Kanada)) durch Lösung und Verdünnung in Methanol hergestellt. Die Stammlösungen wurden zur Herstellung der Eichproben und der Qualitätskontrollen verwendet. Weitere Proben wurden zur Ermittlung der Bestimmungsgrenze der Analysenmethode hergestellt. Als Bestimmungsgrenze wird die kleinste messbare Konzentration eines Analyten, die noch mit einer definierten Richtigkeit und Präzision bestimmt werden kann, bezeichnet.

\subsubsection{Probenvorbereitung}

Bevor jedoch Carvedilol und seine Metaboliten in der HPLC analysiert werden konnten, mussten diese zunächst aus den Proben durch die im Folgenden beschriebene Flüssig-FlüssigExtraktion mittels Diethylether extrahiert werden.

Dazu wurden $1 \mathrm{ml}$ Plasma und $25 \mu \mathrm{l}$ der internen Standard-Arbeitslösung (N, N-bisCarvedilol in Methanol (Konzentration $=1 \mu \mathrm{g} / \mathrm{ml}$ ) gelöst) vermischt. Anschließend wurden 6 ml Diethylether hinzugefügt. Nach 5-minütiger Zentrifugation bei 4000 Umdrehungen/min sowie nach Separierung der organischen Phase wurde diese anschließend bei $40^{\circ} \mathrm{C}$ unter Stickstoffstrom entfernt. In einem nächsten Schritt wurde der Rückstand in $250 \mu \mathrm{l}$ der mobilen Phase aus Acetonitril/Wasser/Triethylamin (1 Molar, pH 2,5) (80/17/3, v/v/v) wieder aufgelöst. Nachdem $10 \mu \mathrm{l}$ Triethylamin hinzugefügt wurde, wurden die Proben zunächst in zwei $125 \mu \mathrm{l}$ Aliquots geteilt. Mit Hilfe des internen Standards konnten mögliche Verluste während der Extraktion und der HPLC korrigiert werden.

Damit Carvedilol und seine Metaboliten mittels Fluoreszenzdetektion nachgewiesen werden konnten, erfolgte die Derivatisierung im Falle von Carvedilol und Desmethylcarvedilol mit 10 $\mu l$ Glucopyranosyl-isothiocyanat (GITC von Sigma-Aldrich, München, Deutschland) sowie bei 4- und 5-OH-Carvedilol mit $10 \mu \mathrm{l}$ Methylbenzylisocyanat (MBI, Sigma-Aldrich, München, Deutschland). Durch Zugabe von $10 \mu 1$ 5\%iger Phosphorsäure wurde nach 30 min die oben genannte Derivatisierungsreaktion gestoppt. Schließlich wurden $50 \mu \mathrm{l}$ des Überstandes nach 5-minütiger Zentrifugation bei 14000 Umdrehungen/min in Injektionsbehälter gefüllt und der HPLC-Apparatur zugeführt. 
Material und Methoden

\subsubsection{HPLC-Trennung und Detektion}

HPLC ist eine spezielle Form der Chromatografie zur Trennung eines Stoffgemisches. Dabei wird die zu untersuchende Substanz mit einem Laufmittel (mobile Phase) durch eine Trennsäule, die die stationäre Phase enthält, gepumpt. Am Ende der Trennsäule kommen die Substanzen zu unterschiedlichen Zeiten (Retentionszeiten) an und können dann mit Hilfe eines Detektors (z. B. Fluoreszenzdetektor oder UV-Detektion) chromatographisch als Peaks dargestellt und analysiert werden. Die Retentionszeiten sind unter anderem abhängig von den Wechselwirkungen der Substanzen mit der stationären Phase.

Die Trennung der GITC-Derivate fand in der HPLC-Apparatur mit Hilfe der UV-Detektion bei $285 \mathrm{~nm}$ (LiChrospher 100 RP18e Säule $(125 \times 4 \mathrm{~mm}$, Partikelgröße von 5 $\mu \mathrm{m}$, der Firma Merck, Darmstadt, Deutschland)) statt. Das HPLC-System war mit einer passenden Vorsäule ausgerüstet. Als mobile Phase wurden eine Lösung aus 25 mmol/l Ammoniumacetat (pH 5,0) und Methanol (38/62, v/v) eingesetzt. Die Durchflussrate betrug 1,0 ml/min und die Laufzeit 45 min pro Chromatogramm.

Die MBI-Derivate durchliefen eine Gradiententrennung, wobei die Zusammensetzung der mobilen Phase (von 55\% auf 80\% Methanol in 60 min) verändert wurde. Auch hier betrug die Durchflussrate 1,0 ml/min. Die Anregungswellenlänge des Fluoreszenzdetektors war $285 \mathrm{~nm}$, wobei die Emissionswellenlänge bei $360 \mathrm{~nm}$ lag.

Für die GITC-Derivate wurden folgende Retentionszeiten ermittelt: $8,7 \mathrm{~min}$ für $\mathrm{S}$ Desmethylcarvedilol, 10,8 min für R-Desmethylcarvedilol, 14,7 min für S-Carvedilol und 18 min für R-Carvedilol.

Die MBI-Derivate wiesen folgende Retentionszeiten auf: S-4`-OH-Carvedilol 34,2 min, R-4`OH-Carvedilol 35,8 min, S-5 `-OH-Carvedilol 41,0 min und R-5 `-OH-Carvedilol 43,4 min.

Die Berechnung der unbekannten Konzentrationen in den untersuchten Proben erfolgte mit Hilfe von Eichkurven. Dazu wurden die Peakflächenquotienten Analyt/Interner Standard als Funktion der Konzentrationen von Eichproben einer linearen Regressionsanalyse unterzogen. Aus den normierten Messwerten der zu bestimmenden Proben lassen sich nun mit den erhaltenen Regressionsparametern die unbekannten Konzentrationen berechnen. Die Bestimmungsgrenze, die mit diesen Methoden erreicht wurde, lag in unserer Studie bei 2 $\mathrm{ng} / \mathrm{ml}$ mit einem Variationskoeffizienten (Mittelwert/Standardabweichung $\cdot 100$ ) von $15 \%$. In jeder Analysenserie waren 2 Qualitätskontrollen enthalten, gemessen bei 5 und $25 \mathrm{ng} / \mathrm{ml}$ für 
Material und Methoden

R, S-Carvedilol (Racemat) sowie 2 und $10 \mathrm{ng} / \mathrm{ml}$ für alle hier analysierten CarvedilolMetaboliten (R, S-Desmethylcarvedilol; R, S-4`-OH- und R, S-5`-OH-Carvedilol). Der Variationskoeffizient dieser Kontrollproben war für R-Carvedilol 16\% $(n=59)$ und 10\% ( $\mathrm{n}=57)$, für S-Carvedilol 13\% (n=58) und 9\% (n=57), für R-Desmethylcarvedilol 23\% (n=58) und $11 \%(n=57)$, für S-Desmethylcarvedilol $21 \%(n=58)$ und $15 \%(n=57)$, für R-4 -OH $25 \%$ $(n=59)$ und $23 \%(n=57)$, für S-4 $-\mathrm{OH} 28 \%(n=59)$ und $23 \%(n=57)$, für R-5 $-\mathrm{OH} 28 \%$ und $25 \% \quad(n=57)$ sowie für $\mathrm{S}-5-\mathrm{OH} \quad 28 \%$ und $25 \% \quad(\mathrm{n}=57)$. Die Ergebnisse der Konzentrationsanalythik wurden umgerechnet und in nmol/L angegeben.

\subsection{Analyse der Messdaten und Statistik}

\subsubsection{Pharmakokinetische Begriffe und Parameter}

Die Vielzahl der Blutkonzentrationsmessungen wird bei der pharmakokinetischen Analyse in charakteristische Kenngrößen (Parameter) zusammengefasst. Dabei unterscheidet man die nichtparametrische Auswertung, die ohne Annahme von Kompartiment-Modellen auskommt von der parametrischen Auswertung, die eine Beschreibung der Konzentrationsverläufe im Körper mittels Kompartiment-Modellen versucht.

Wichtige Parameter der nichtparametrischen Pharmakokinetik-Auswertung sind $\mathrm{C}_{\max }, \mathrm{t}_{\max }$, AUC, MRT, orale Clearance und die terminale Halbwertzeit. Dabei ist $\mathrm{C}_{\max }$ die maximale Blutkonzentration, die gemessen wird. Hier wird die tatsächlich pro Proband gefundene maximale Konzentration wiedergegeben mit der Zeit, wann diese erreicht wurde $\left(t_{\max }\right)$. Eine Bedeutung von $\mathrm{C}_{\max }$ liegt darin, dass zu diesen Zeiten am ehesten konzentrationsabhängige Nebenwirkungen auftreten können. Die AUC (area under the curve) stellt die Fläche unter der Konzentrations-Zeit-Kurve dar. Mit Hilfe der AUC können Aussagen sowohl über das Ausmaß der Bioverfügbarkeit eines Medikamentes, als auch über das Ausmaß der Exposition des Menschen auf dieses Medikament getroffen werden. Zur Berechnung der AUC dient die so genannte Trapezregel $\left(\left(\mathrm{C}_{1}+\mathrm{C}_{2}\right) / 2 \cdot\left(\mathrm{t}_{2}-\mathrm{t}_{1}\right)\right)\left(\mathrm{C}_{1}=\right.$ Konzentration zur Zeit $\mathrm{t}_{1}, \mathrm{C}_{2}=$ Konzentration zur Zeit $t_{2}$ ) mit der die Fläche bis zur letzten Messung erfasst wird und schließlich die Restfläche vom letzten Messzeitpunkt durch Extrapolieren gegen unendlich bestimmt wird. Die AUC ist auch bei der Berechnung der totalen Clearance, die sich aus der renalen und der extrarenalen Clearance zusammensetzt, durch die Gleichung $\mathrm{Cl}_{\text {total }}=$ Dosis/AUC wichtig. Durch die Clearance werden Eliminationsvorgänge charakterisiert und quantifiziert, sie 
Material und Methoden

benennt den Teil des Blutvolumens, der pro Zeiteinheit vom Arzneistoff völlig befreit wird. Im Gegensatz zur totalen Clearance, die für intravenöse Applikationsformen gilt, wird die orale Clearance, die neben der systemischen Elimination auch präsystemische Eliminationsprozesse beachtet und ebenfalls von der unbekannten Resorptionsquote abhängt, durch die Gleichung $\mathrm{Cl}_{\text {oral }}=\mathrm{Cl} / \mathrm{F}$ berechnet. Dabei steht das $\mathrm{F}$ für die Bioverfügbarkeit eines Stoffes, der unverändert im systemischen Kreislauf zur Verfügung steht und wird mit $\mathrm{F}=\mathrm{AUC}_{\text {per os }} / \mathrm{AUC}_{\text {intravenös. }}$ berechnet. Schließlich beschreibt die Halbwertszeit $\left(\mathrm{t}_{1 / 2}\right)$ die Zeit, bei der die Konzentration eines Medikaments auf die Hälfte gesunken ist. Hierbei wird die terminale Halbwertszeit nicht durch Modellanpassung gewonnen, sondern durch lineare Regressionsanalyse der letzten 3 messbaren Konzentrationswerte. Dabei beschreibt der Abfall der Regressionsgerade die Eliminationskonstante $\left(\mathrm{k}_{\mathrm{el}}\right)$ mit der die Halbwertszeit $\left(\mathrm{t}_{1 / 2}\right)$ durch $\mathrm{t}_{1 / 2}=\ln (2) / \mathrm{k}_{\mathrm{el}}(\ln (2)=$ natürliche Logarithmus von $2=0,693)$ berechnet werden kann. Der folgende Parameter (MRT) ist bei Mehr-Kompartiment-Systemen (siehe unten) robuster als der Parameter Halbwertszeit und wurde daher hier mit in der Auswertung verwendet. Der Parameter MRT steht für mean residence time (mittlere Verweildauer) und gibt die mediane Zeit an, für die das Medikamentenmolekül im menschlichen Körper bleibt. Die Berechnung aus AUC und dem ersten Moment der AUC (der so genannten AUMC) und insbesondere die Herleitung dieser Berechnungen basieren auf molekular-statistischen Analysen, die hier im Detail nicht dargestellt werden sollen (Cheng und Jusko 1988).

Diese nichtparametrischen Verfahren haben aber ihre Grenzen in der Beschreibung von Konzentrationsverläufen, die mit mehreren Halbwertzeiten Abfallen (2- oder 3Kompartiment-Modelle) und die nichtparametrischen Verfahren haben Schwächen in der Extrapolation. Hier bieten sich pharmakokinetische Modellanalysen an. Als Grundlage der pharmakokinetischen Modellanalyse kann vom einfachen 1-Kompartiment-Modell, bei dem ein einziger Verteilungsraum angenommen wird, ausgegangen werden. Wenn ein linearer Zusammenhang zwischen einer gegebenen Dosis (D) und der gemessenen Konzentration (C) besteht, so wird von einer linearen Pharmakokinetik (Reaktion 1. Ordnung) gesprochen. Bei einer intravenösen Applikation der Dosis, kann die Konzentration zu einer bestimmten Zeit $(C(t))$ durch die e-Funktion $C(t)=(\operatorname{Dosis}(D) /$ Verteilungsvolumen $(V)) \cdot \mathrm{e}^{-\mathrm{k} \cdot \mathrm{t}}$ bestimmt werden. Als Verteilungsvolumen wird ein fiktives Volumen bezeichnet, in das eine Substanz sich verteilen müsste, um die beobachtete Konzentration im Blutplasma zu erklären. Das Verteilungsvolumen lässt sich mit der Formel V=Dosis/Konzentration berechnen, wobei bei oraler Applikation eines Medikamentes das Verteilungsvolumen in Relation zur Bioverfügbarkeit V/F gesetzt werden muss. Im Gegensatz zur intravenösen Medikation 
Material und Methoden

müssen bei oraler Medikamenteneinnahme neben den Eliminationsprozessen zusätzlich Absorptions-(Invasions-) Prozesse beachtet werden. Dieser Zusammenhang wird durch die sogenannte Bateman-Funktion $\mathrm{C}(\mathrm{t})=\mathrm{F} \cdot \mathrm{D} / \mathrm{V} \cdot\left(\mathrm{k}_{\mathrm{a}} / \mathrm{k}_{\mathrm{a}}-\mathrm{k}_{\mathrm{el}}\right) \cdot\left(\mathrm{e}^{-\mathrm{kel} \cdot \mathrm{t}^{\mathrm{t}}}-\mathrm{e}^{-\mathrm{ka} \cdot \mathrm{t}}\right)$ beschrieben, wobei $\mathrm{k}_{\mathrm{a}}$ die Absorptionskonstante, $\mathrm{k}_{\mathrm{el}}$ die Eliminationskonstante, $\mathrm{C}(\mathrm{t})$ die Konzentration zur Zeit $\mathrm{t}, \mathrm{F}$ die Bioverfügbarkeit und V das Verteilungsvolumen darstellen.

Je nach Medikament fallen die Konzentrationen nach Dosierung entweder nur mit einer Halbwertzeit (1-Kompartiment-Modell) oder mit 2 Halbwertzeiten ab. Bei Carvedilol fiel die Konzentration anfangs recht schnell (1. Halbwertszeit) und später langsamer (2. Halbwertszeit) ab. Dies entspricht am ehesten einem 2-Kompartiment-Modell, bei dem ein zentrales (V1) (Gehirn, Blut, Leber und Niere) und ein peripheres (V2) (Fett, Muskel, Haut) Kompartiment $\mathrm{zu}$ unterscheiden sind. Man kann das 2-Kompartiment-Modell in unterschiedlicher Weise mit pharmakokinetischen Parametern beschreiben, diese Analyse der Parameter wurde von Herrn Dr. Meineke aus der Abteilung Klinische Pharmakologie der Universität Göttingen mit Hilfe des Computerprogramms NONMEM (non linear mixed effects modelling) Version 5 (level 1.1 GloboMax, Hannover, MD, USA) und der Modellanalyse ADVAN 3 durchgeführt. Wir haben diese Analysen auf die beiden Enantiomere der Muttersubstanz beschränkt, wobei sich ein vom CYP2D6-Genotyp unabhängiges peripheres Verteilungsvolumen (V2), eine Geschwindigkeitskonstante für den Übertritt vom zentralen ins periphere Kompartiment $\left(\mathrm{k}_{23}\right)$ sowie eine für den umgekehrten Vorgang $\left(\mathrm{k}_{32}\right)$ ergaben. Zusätzlich wurden in unserer Studie mit Hilfe von KompartimentModellen (modellabhängig) CYP2D6-allel-spezifische Clearances separat bestimmt.

\subsubsection{Analyse der Messdaten}

Für die Flächen unter den Konzentrations-Zeit-Kurven der beiden Carvedilol-Enantiomere wurden die AUCs (Einheit nmol · h/L) nach unendlich extrapoliert angegeben, da nur mit diesen AUCs bestimmte Berechnungen wie die der Clearance definiert sind (Gibaldi und Perrier 1982). Hingegen erschienen für die Metaboliten die nur bis zum letzten Messwert berechneten AUCs zuverlässiger, da wegen der niedrigeren Konzentrationen die Werte oft unter der Nachweisgrenze lagen, so dass zuverlässige Extrapolationen bis unendlich nicht möglich waren. Zur Analyse der Ergebnisse der Plasmakonzentrationen wurde die Computersoftware WinNonlin Version 3 verwendet. Die orale Clearance (Einheit L/h) wurde, wie oben beschrieben, berechnet, jedoch konnte die Clearance der Metaboliten nicht berechnet werden, da die Menge des Carvedilol, welche zum Metaboliten verstoffwechselt 
Material und Methoden

wurde, unbekannt war und deshalb keine Angabe zur Quantität des Metaboliten gemacht werden konnte. Weiter wurden die allel-spezifischen Clearances für die CYP2D6-Allele *1, $* 2$, *9, *10, *17 und *41 unter Verwendung der Software NONMEM in einem 2Kompartiment-Modell berechnet. Die Clearances der Allele *3, *4, *5 und *6 wurden mit 0 gleichgesetzt. Aus diesen Berechnungen konnte dann die Clearance als Summe aus einer CYP2D6 unabhängigen $\left(\mathrm{Cl}_{\mathrm{o}}\right)$ und der beiden allel-spezifischen Clearance angegeben werden $\left(\mathrm{Cl}=\mathrm{Cl}_{\mathrm{o}}+\mathrm{Cl}_{\text {Allel } 1}+\mathrm{Cl}_{\text {Allel 2 }}\right)$. Die $\mathrm{C}_{\max }(\mathrm{nmol} / \mathrm{L})$, MRT (h), das Verteilungsvolumen V/F (L) und die terminale Halbwertszeit (h) wurden wie oben beschrieben bestimmt.

\subsection{Analyse der Ergometriedaten}

Dieser Kapitel befasst sich mit der Analyse der in dieser Studie gewonnenen Ergometriedaten. Auf den Ablauf der Ergometrie wurde schon in den Kapiteln 2.1.4, sowie 2.1.7 eingegangen. In der vorliegenden Studie wurden pro Proband 10 Ergometrien durchgeführt, bei jeder Ergometrie wurden 10 - 40 Herzfrequenz- und 5 - 15 Blutdruckmessungen vorgenommen und aufgezeichnet. Um die daraus resultierende große Datenmenge auf aussagekräftige Kenngrößen reduzieren zu können, wurde, basierend auf einer Arbeit von Riley et al. (2000), von Dr. I. Meineke eine Modellanalyse entwickelt. Im Folgenden werden die Überlegungen dieser Modellanalyse geschildert.

Die Gleichung HF(Last) = HF0 + HFM - Last beschreibt die Herzfrequenz unter einer beliebigen Belastung (HF(last)) als Summe der Ruheherzfrequenz (HF0) und dem Produkt aus der belastungsabhängigen Herzfrequenzzunahme (HFM in 1/min/Watt) und der Last.

Um die Adaptation der Herzfrequenz bei Belastungsveränderungen, sowohl bei Zu- oder Abnahme der Last, beschreiben zu können, wurde eine sogenannte Adaptationskonstante (KE) eingeführt, die es ermöglichte mit $\mathrm{d}(\mathrm{HF}) / \mathrm{dt}=\mathrm{KE} \cdot(\mathrm{HF}(\mathrm{Last})-\mathrm{HF})$ die zeitliche Herzfrequenzänderung bei Belastungsänderungen $\mathrm{zu}$ beschreiben. Hierbei war HF die Herzfrequenz zu einer bestimmten Zeit (t). Mit diesem Modell konnten die Ergometriedaten mit Hilfe der Parameter HF0 (Ruheherzfrequenz), HFM (belastungsabhängige HF-Zunahme) und KE (Adaptationskonstante) so gut dargestellt werden, dass die gemessenen Daten sehr gut mit den vorhergesagten korrespondierten und sich für jeden Probanden eine ErgometrieLast berechnen ließ, unter der er ohne Carvedilol eine Herzfrequenz von 140/min 
Material und Methoden

(HF(Last 140$))$ hatte. Um diese $\mathrm{HF}\left(\right.$ Last $\left._{140}\right)$ berechnen zu können, musste die individuelle Last $\left(\right.$ ILast $\left._{140}\right)$, die ohne Carvedilol zu dieser HF(Last $\left.{ }_{140}\right)$ führte, durch Extrapolieren mit ILast ${ }_{140}=$ (140 - HF0)/HFM bestimmt werden. Dann wurde ILast140 unter Verwendung der Gleichung $\mathrm{HF}\left(\operatorname{Last}_{140}\right)=\mathrm{HF} 0+\mathrm{HFM} \cdot$ ILast $_{140}$ zur Berechnung der Herzfrequenz bei ILast $_{140}$ unter Carvedilol eingesetzt.

Weiterhin soll die Gleichung $H F 0=H F B A \cdot\left(1-\frac{E_{\max } \cdot C}{E C_{50}+C}\right)$ die pharmakokinetischpharmakodynamische Beziehung zwischen der R- und S-Carvedilol-Blutkonzentration und der Ruheherzfrequenz (HF0) beschreiben. Hierbei entspricht HFBA der Ruheherzfrequenz unter Baselinebedingungen, also ohne Medikation, $\mathrm{E}_{\max }$ stellt den maximalen Effekt von Rund S-Carvedilol dar und $\mathrm{EC}_{50}$ beschreibt die Carvedilolkonzentration, bei der der halb maximale Effekt erreicht wird (Michaelis-Menten-Beziehung). Schließlich wurde die Gleichung $H F=H F 0+H F M 140 \cdot\left(1-\frac{E_{\max 2} \cdot C}{E C_{50}+C}\right)$ benützt, um z.B. die Herzfrequenz bei 140 Watt angeben zu können, wobei HFM140 die Herzfrequenzzunahme bei Zunahme der Belastung von 0 auf 140 Watt darstellt und $\mathrm{E}_{\max 2}$ den maximalen Carvedilol-Effekt darstellt.

\subsection{Statistische Analysen}

Zur Ermittlung signifikanter Unterschiede hinsichtlich pharmakokinetischer und pharmakodynamischer Eigenschaften in Bezug auf die einzelnen Genotypen diente der parameterfreie statistische Trendtest nach Jonckheere-Terpstra. Statistische Berechnungen und Grafiken wurden mittels SPSS, Version 17 (SPSS Inc., Chicago, Il, USA) und S-Plus 6.2 (Insightful Corp, Seattle, USA) durchgeführt. So wurden sowohl die nichtparametrischen statistischen Kenngrößen Minimum, Maximum, 1. Quartil (25. Perzentil), 2. Quartil (Median, 50. Perzentil), 3. Quartil (75. Perzentil) und Interquartilenbereich als auch die parametrischen statistischen Kenngrößen Mittelwert, Standardabweichung (SD, standard deviation), Standardfehler (SE, standard error), sowie 95\%-Konfidenzintervall berechnet.

Die oben erwähnten nichtparametrischen statistischen Kenngrößen Median, 1. und 3. Quartil sowie der Interquartilenbereich wurden zusätzlich mit Hilfe des SPSS-Programmes (Version 17) in sogenannten Boxplots graphisch zusammengefasst. Ein Boxplot besteht aus einem Rechteck (Box) und zwei Linien, die dieses Rechteck verlängern (Whiskers). Die Box wird durch das untere und obere Quartil begrenzt, wobei die Länge dem Interquartilbereich 
Material und Methoden

entspricht. Der Median wird als durchgehender Strich in der Box dargestellt. Mit Schwarz ausgefüllte Kreise in den Boxplots stellen milde und Sterne extreme Ausreißer dar. 
Ergebnisse

\section{Ergebnisse}

\subsection{Untersuchte Probanden}

Insgesamt haben 110 gesunde Probanden und Probandinnen an der Carvedilol-Studie teilgenommen. Im Folgenden wird für Probandinnen aus Gründen der sprachlichen Vereinfachung die männliche Form verwendet. Die Daten von allen diesen 110 Personen konnten, wie im Folgenden dargestellt, ausgewertet werden. Wichtige demografische und medizinische Daten der Stichprobe sind in Tab. 30 zusammengefasst.

Tab. 30 Demografische und medizinische Daten der Probanden

\begin{tabular}{ll}
\hline Parameter & Zahlenwerte (Minimum - Maximum) \\
Gesamtzahl & 110 \\
davon Frauen & 36 \\
Alter (Median) & $28(20-49)$ \\
Körpergewicht $(\mathrm{kg})($ Median $)$ & $72(52-99)$ \\
Body Mass Index $\left(\mathrm{kg} / \mathrm{m}^{2}\right)($ Median$)$ & $23,2(17,4-29,8)$ \\
\hline
\end{tabular}

\subsection{Art und Häufigkeit der genetischen Polymorphismen}

Die Probanden sind aus einer großen Stichprobe so selektiert worden, dass alle interessierenden Genotypen möglichst mindestens mit einer Fallzahl von 9 vertreten waren. Dabei musste akzeptiert werden, dass auch bei einer Suche aus mehr als ca. 700 möglichen Studienteilnehmern einige seltene Genotypen nicht in dieser Häufigkeit gefunden werden konnten. Die Häufigkeiten der tatsächlich in der Studie analysierten Personen sind in den Tabellen 31 bis 33 dargestellt. 
Ergebnisse

Tab.31 CYP2D6-Häufigkeit

\begin{tabular}{|c|c|c|c|}
\hline CYP2D6-Genotyp & Phänotyp & Gendosis & Probandenanzahl \\
\hline Ultraschnell & & & 1 \\
\hline $2 \mathrm{x} * 2 / * 2$ & UM & 3 & 1 \\
\hline Schnell & & & 50 \\
\hline$* 1 / * 1$ & EM & 2 & 10 \\
\hline$* 1 / * 2$ & EM & 2 & 18 \\
\hline$* 2 / * 2$ & EM & 2 & 6 \\
\hline $2 x * 2 / * 3$ & EM & 2 & 1 \\
\hline $2 x * 2 / * 4$ & EM & 2 & 1 \\
\hline $2 \mathrm{x} * 1 / * 2 \mathrm{x} * 4$ & EM & 2 & 1 \\
\hline$* 1 / * 9$ & EM & 1,5 & 3 \\
\hline$* 1 / * 10$ & EM & 1,5 & 1 \\
\hline$* 1 / * 41$ & EM & 1,5 & 5 \\
\hline$* 2 / * 9$ & EM & 1,5 & 2 \\
\hline$* 2 / * 10$ & EM & 1,5 & 2 \\
\hline Intermediär & & & 46 \\
\hline$* 1 / * 3$ & IM & 1 & 1 \\
\hline$* 1 / * 4$ & IM & 1 & 11 \\
\hline$* 1 / * 5$ & IM & 1 & 3 \\
\hline$* 1 / * 6$ & IM & 1 & 1 \\
\hline$* 2 / * 3$ & IM & 1 & 3 \\
\hline$* 2 / * 4$ & IM & 1 & 7 \\
\hline$* 2 / * 5$ & IM & 1 & 1 \\
\hline$* 2 / * 6$ & IM & 1 & 1 \\
\hline$* 10 / * 10$ & IM & 1 & 1 \\
\hline$* 17 / * 17$ & IM & 1 & 2 \\
\hline$* 17 / * 41$ & IM & 1 & 1 \\
\hline$* 41 / * 41$ & IM & 1 & 1 \\
\hline$* 41 / * 9$ & IM & 1 & 1 \\
\hline$* 4 / * 10$ & IM & 0,5 & 2 \\
\hline$* 4 / * 9$ & IM & 0,5 & 3 \\
\hline$* 4 / * 17$ & IM & 0,5 & 1 \\
\hline$* 4 / * 41$ & IM & 0,5 & 4 \\
\hline$* 5 / * 41$ & IM & 0,5 & 2 \\
\hline Defizient & & & 13 \\
\hline$* 3 / * 4$ & $\mathrm{PM}$ & 0 & 3 \\
\hline$* 4 / * 4$ & PM & 0 & 7 \\
\hline$* 4 / * 5$ & PM & 0 & 2 \\
\hline$* 4 / * 6$ & PM & 0 & 1 \\
\hline
\end{tabular}

Die Gendosis wurde als Rangzahl in der Reihenfolge steigender Zahlen mit steigender Aktivität angegeben, wie sie aus vielen anderen Medikamenten gut etabliert ist. 
Ergebnisse

Tab. 32 CYP2C9-Häufigkeit

\begin{tabular}{llll}
\hline CYP2C9-Genotyp & Phänotyp & Gendosis & Probandenanzahl \\
$* 1 / * 1$ & EM & 6 & 77 \\
$* 1 / * 2$ & IM & 5 & 16 \\
$* 1 / * 3$ & IM & 4 & 12 \\
$* 2 / * 2$ & PM & 3 & 3 \\
$* 2 / * 3$ & PM & 2 & 2 \\
\hline
\end{tabular}

Die Gendosis wurde als Rangzahl in der Reihenfolge steigender Zahlen mit steigender Aktivität angegeben, wie sie aus vielen anderen Medikamenten gut etabliert ist.

Tab. 33 CYP2C19-Häufigkeit

\begin{tabular}{llll}
\hline CYP2C19 & Phänotyp & Gendosis & Probandenzahl \\
$* 17 / * 17$ & UM & 6 & 8 \\
$* 1 / * 17$ & EM & 5 & 23 \\
$* 1 / * 1$ & EM & 4 & 40 \\
$* 2 / * 17$ & IM & 3 & 10 \\
$* 1 / * 2$ & IM & 2 & 21 \\
$* 2 / * 2$ & PM & 1 & 8 \\
\hline
\end{tabular}

Die Gendosis wurde als Rangzahl in der Reihenfolge steigender Zahlen mit steigender Aktivität angegeben, wie sie aus vielen anderen Medikamenten gut etabliert ist.

\subsection{Darstellung der pharmakokinetischen Ergebnisse}

In der folgenden Abbildung sind die gemessenen Blutkonzentrations-Zeit-Verläufe von Rund S-Carvedilol von allen Probanden dargestellt. Es zeigt sich eine große interindividuelle Streubreite der Blutkonzentration, wobei alle Probanden die gleiche Dosis eingenommen hatten, alle gesund waren und möglichst Personen mit extremem Körpergewicht ausgeschlossen worden waren. Die nach einer Stunde bei allen Probanden gemessene mediane maximale Plasmakonzentration betrug für R-Carvedilol 99,3 (Bereich: 24,0 - 327,2) nmol/L sowie für S-Carvedilol 32,5 (Bereich: 7,9 - 109) nmol/L.

Die Daten aus den Konzentrationsverläufen wurden durch eine pharmakokinetische Analyse aufgearbeitet. Dabei wurde zunächst eine nichtparametrische pharmakokinetische Analyse durchgeführt, bei der ohne Berücksichtigung von pharmakokinetischen Modellvorstellungen die gemessenen Einzelwerte $\left(\mathrm{C}_{\max }, \mathrm{t}_{1 / 2}, \mathrm{~V} / \mathrm{F}, \mathrm{Cl} / \mathrm{F}\right.$ und $\left.\mathrm{MRT}\right)$ und die Fläche unter der Konzentrations-Zeit-Kurve (AUC) dargestellt wurden. Da die Grafiken einen biphasischen Konzentrationsabfall zeigten, indem die Konzentrationen anfangs recht schnell und später langsamer abfielen, musste das einfache 1-Kompartiment-Modell durch das offene 2Kompartiment-Modell ersetzt werden. Um Verhältnisse in einem 2-Kompartiment-Modell beschreiben zu können, wurden Modellanalysen durchgeführt. 
Ergebnisse

Abb. 3 Streuung der Konzentrations-Zeit-Verläufe der Carvedilol-Enantiomere im Blutplasma aller Probanden
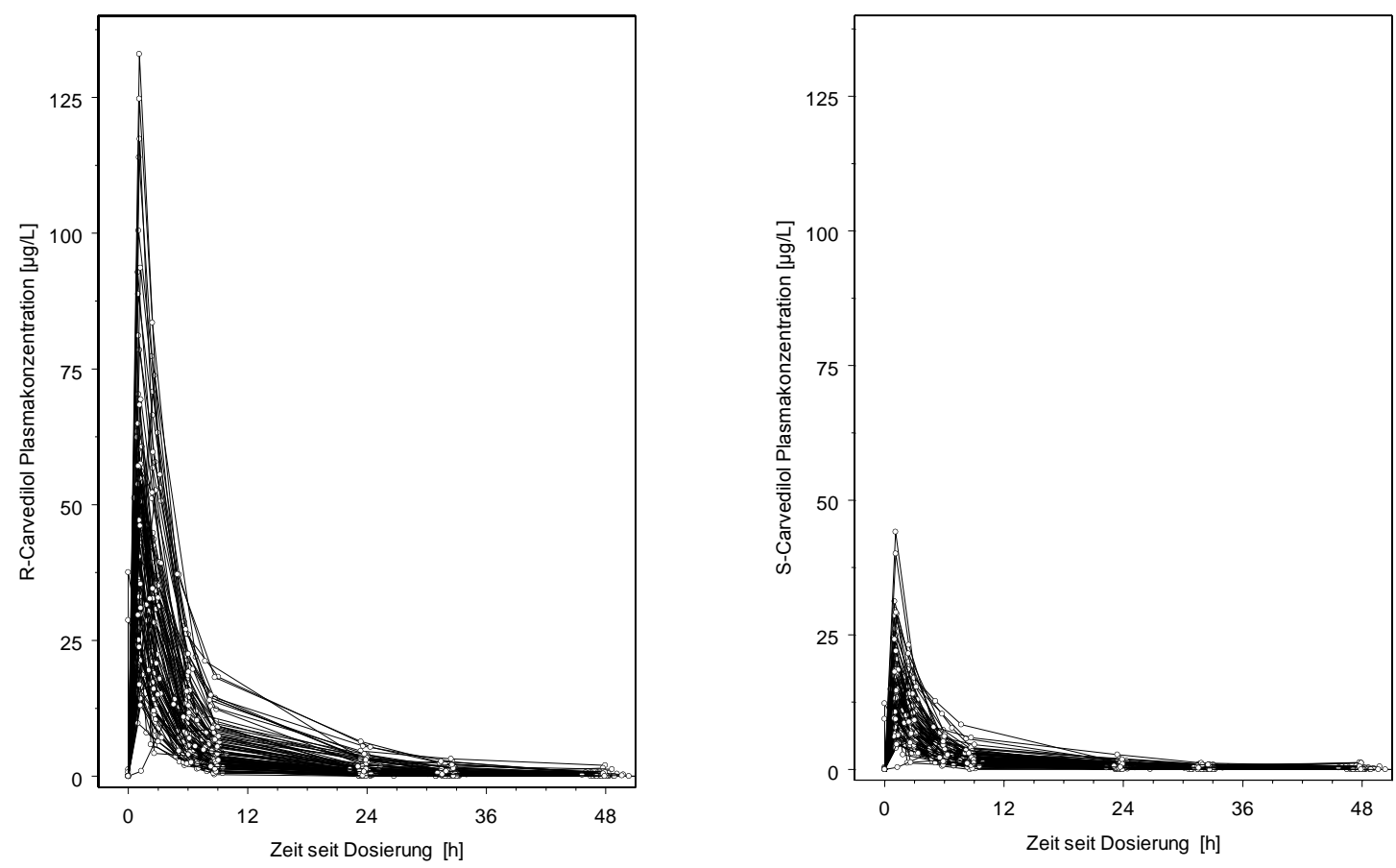

Wie man sieht, gab es eine erhebliche Streuung und die mittleren Konzentrationen von S-Carvedilol im Plasma waren nur etwa $30 \%$ so hoch wie die von R-Carvedilol.

In den folgenden Kapiteln werden zunächst die Ergebnisse der Carvedilol-Pharmakokinetik und der Pharmakokinetik seiner Metaboliten in Abhängigkeit vom CYP2D6-, CYP2C9sowie CYP2C19-Genotyp dargestellt. Danach werden die modellanalytisch gewonnenen CYP2D6-allel-spezifischen Clearances gezeigt.

\subsubsection{Pharmakokinetik von R- und S-Carvedilol in Relation zum CYP2D6- Genotyp}

Die pharmakokinetischen Kenngrößen (Parameter) $\mathrm{C}_{\max }, \mathrm{t}_{1 / 2}, \mathrm{~V} / \mathrm{F}, \mathrm{AUC}_{0-\infty}, \mathrm{Cl} / \mathrm{F}$ und MRT sind in der folgenden Tabelle jeweils mit den Medianen und den entsprechenden Interquartilbereichen in Abhängigkeit der verschiedenen CYP2D6-Genotypen dargestellt. 
Ergebnisse

Tab. 34 Pharmakokinetische Parameter für die beiden Carvedilol-Enantiomere in Relation zum CYP2D6Genotyp

\begin{tabular}{|c|c|c|c|c|c|c|}
\hline & \multicolumn{5}{|c|}{ Anzahl aktiver CYP2D6-Gene* } & \multirow[t]{2}{*}{$\mathrm{P} * *$} \\
\hline & 0 & 0.5 & 1 & 1.5 & $\geq 2$ & \\
\hline \multirow{2}{*}{$\begin{array}{l}\text { Probanden- } \\
\text { Anzahl } \\
\text { Parameter } \\
\text { Substanz }\end{array}$} & 13 & 12 & 34 & 13 & 38 & \\
\hline & \multicolumn{5}{|c|}{$\begin{array}{c}\text { Median } \\
\text { Interquartilbereich }\left(Q_{1}-Q_{3}\right)\end{array}$} & \\
\hline \multicolumn{7}{|l|}{$\mathbf{C}_{\max }$} \\
\hline R-Carvedilol & $\begin{array}{c}154 \\
140-223\end{array}$ & $\begin{array}{c}89,2 \\
55,8-122\end{array}$ & $\begin{array}{c}123 \\
80,3-148\end{array}$ & $\begin{array}{c}99,2 \\
39,4-135\end{array}$ & $\begin{array}{c}72,4 \\
52,3-102\end{array}$ & $<0,001$ \\
\hline S-Carvedilol & $\begin{array}{c}43,3 \\
35,1-58,2\end{array}$ & $\begin{array}{c}24,2 \\
13,8-30,9\end{array}$ & $\begin{array}{c}36,3 \\
28,2-50,8\end{array}$ & $\begin{array}{c}36,6 \\
18,6-45,9\end{array}$ & $\begin{array}{c}27,8 \\
22,3-37,0\end{array}$ & n. s. \\
\hline \multicolumn{7}{|l|}{$\mathbf{t}_{1 / 2}$} \\
\hline R-Carvedilol & $\begin{array}{c}8,61 \\
6,05-9,01\end{array}$ & $\begin{array}{c}7,23 \\
6,67-8,30\end{array}$ & $\begin{array}{c}7,25 \\
4,91-9,35\end{array}$ & $\begin{array}{c}8,09 \\
6,61-13,9\end{array}$ & $\begin{array}{c}7,24 \\
5,31-9,71\end{array}$ & n. s. \\
\hline S-Carvedilol & $\begin{array}{c}9,62 \\
7,37-12,2\end{array}$ & $\begin{array}{c}8,92 \\
6,03-10,6\end{array}$ & $\begin{array}{c}8,53 \\
5,95-11,0\end{array}$ & $\begin{array}{c}9,64 \\
7,38-16,3\end{array}$ & $\begin{array}{c}8,92 \\
6,13-12,5\end{array}$ & n. s. \\
\hline \multicolumn{7}{|l|}{$\mathbf{V} / \mathbf{F}$} \\
\hline R-Carvedilol & $\begin{array}{c}258 \\
177-358\end{array}$ & $\begin{array}{c}546 \\
316-900\end{array}$ & $\begin{array}{c}388 \\
252-883\end{array}$ & $\begin{array}{c}871 \\
301-1567\end{array}$ & $\begin{array}{c}928 \\
616-1438\end{array}$ & $<0,001$ \\
\hline S-Carvedilol & $\begin{array}{c}1371 \\
1020-2010\end{array}$ & $\begin{array}{c}1763 \\
1356-2627\end{array}$ & $\begin{array}{c}1419 \\
1032-2633\end{array}$ & $\begin{array}{c}1603 \\
1220-4368\end{array}$ & $\begin{array}{c}2249 \\
1820-3597\end{array}$ & $<0,001$ \\
\hline \multicolumn{7}{|l|}{$\mathbf{A} \mathbf{U} \mathbf{C}_{0-\infty}$} \\
\hline R-Carvedilol & $\begin{array}{c}1376 \\
965-1575\end{array}$ & $\begin{array}{c}567 \\
393-894\end{array}$ & $\begin{array}{c}605 \\
396-813\end{array}$ & $\begin{array}{c}453 \\
307-1105\end{array}$ & $\begin{array}{c}386 \\
260-496\end{array}$ & $<0,001$ \\
\hline S-Carvedilol & $\begin{array}{c}301 \\
221-397\end{array}$ & $\begin{array}{c}164 \\
130-239\end{array}$ & $\begin{array}{c}213 \\
170-310\end{array}$ & $\begin{array}{c}265 \\
150-390\end{array}$ & $\begin{array}{c}158 \\
120-224\end{array}$ & 0,002 \\
\hline \multicolumn{7}{|l|}{$\mathbf{C l} / \mathbf{F}$} \\
\hline R-Carvedilol & $\begin{array}{c}22,3 \\
19,5-31,9\end{array}$ & $\begin{array}{c}56,2 \\
34,4-78,2\end{array}$ & $\begin{array}{c}50,8 \\
37,8-77,6\end{array}$ & $\begin{array}{c}67,8 \\
27,9-100\end{array}$ & $\begin{array}{c}79,7 \\
62,0-118\end{array}$ & $<0,001$ \\
\hline S-Carvedilol & $\begin{array}{c}102 \\
78-140\end{array}$ & $\begin{array}{c}188 \\
132-237\end{array}$ & $\begin{array}{c}147 \\
103-185\end{array}$ & $\begin{array}{c}98,0 \\
77-189\end{array}$ & $\begin{array}{c}195 \\
137-257\end{array}$ & 0,002 \\
\hline \multicolumn{7}{|l|}{ MRT } \\
\hline R-Carvedilol & $\begin{array}{c}11,6 \\
7,49-13,1\end{array}$ & $\begin{array}{c}8,49 \\
6,59-12,2\end{array}$ & $\begin{array}{c}7,89 \\
5,15-10,1\end{array}$ & $\begin{array}{c}10,83 \\
8,03-14,6\end{array}$ & $\begin{array}{c}7,84 \\
4,85-11,5\end{array}$ & n. s. \\
\hline S-Carvedilol & $\begin{array}{c}12,9 \\
8,27-14,8\end{array}$ & $\begin{array}{c}11,7 \\
9,29-12,9\end{array}$ & $\begin{array}{c}9,37 \\
7,01-12,9\end{array}$ & $\begin{array}{c}12,7 \\
10,2-18,9\end{array}$ & $\begin{array}{c}9,61 \\
6,12-14,3\end{array}$ & n. s. \\
\hline
\end{tabular}

Für alle Daten sind die Mediane und die Interquartilbereiche dargestellt. $\mathrm{C}_{\max }(\mathrm{nmol} / \mathrm{L})$, maximale Blutkonzentration; $t_{1 / 2}(h)$, Halbwertszeit; V/F (L), Verteilungsvolumen dividiert durch Bioverfügbarkeit; $\mathrm{AUC}_{0-\infty}(\mathrm{nmol} \cdot \mathrm{h} / \mathrm{L})$, Fläche unter der Konzentrations-Zeit-Kurve; $\mathrm{Cl} / \mathrm{F}(\mathrm{L} / \mathrm{h})$, Clearance dividiert durch Bioverfügbarkeit; MRT (h), mean residuel time. " Die Gendosis wurde als Rangzahl in der Reihenfolge steigender Zahlen mit steigender Aktivität angegeben, wie sie aus vielen anderen Medikamenten gut etabliert ist. In dieser Studie war lediglich ein UM, dieser wurde in die Gruppe mit 2 Aktivitätseinheiten zugeordnet. ** P, P-Wert. Der P-Wert wurde mittels des nichtparametrischen Jonckheere-Terpstra-Trend-Tests bestimmt, P-Werte > 0,05 wurden als nicht signifikant (n. s.) angegeben. 
Ergebnisse

Wie in der Tab. 34 aufgeführt, gab es bei beiden Carvedilol Enantiomeren statistisch signifikante Unterschiede zwischen den CYP2D6-Genotypen sowohl in den medianen $\mathrm{AUC}_{0} \infty^{-}$und den medianen $\mathrm{Cl} / \mathrm{F}$ - als auch in den medianen V/F-Werten. Des Weiteren konnten lediglich in den medianen $\mathrm{C}_{\max }$-Werten des R-Carvedilol signifikante Unterschiede zwischen den CYP2D6-Genotypen gesehen werden, wobei die mediane $\mathrm{C}_{\max }$ bei Trägern keines aktiven CYP2D6-Allels (PM) um das 2,1-fache größer war als bei Trägern von 2 aktiven CYP2D6Allelen ( $\mathrm{p}<0,001$, JTTT). Bei den folgenden Vergleichen, war der Unterschied quantitativ bei den R-Enantiomeren größer als bei den S-Enantiomeren, sodass der CYP2D6-abhängige Metabolismus für R-Carvedilol größer zu sein scheint. Bei PM war die mediane AUC des REnantiomer um das 3,6-fache und die mediane AUC des S-Enantiomer um das 2-fache größer als bei Trägern von 2 aktiven CYP2D6-Allelen ( $p<0,001$ im JTTT für beide Enantiomere). Die medianen Cl/F-Werte verhielten sich bei beiden Carvedilol Enantiomeren umgekehrt, bei PM waren sie für R-Carvedilol mit 3,6- ( $<<0,001$, JTTT) und für das S-Carvedilol mit 1,9fach $(\mathrm{p}=0,002$, JTTT) signifikant niedriger als bei Trägern von 2 aktiven CYP2D6-Allelen.

Abb. 4 AUC des R-Carvedilol in Relation zum CYP2D6-Genotyp

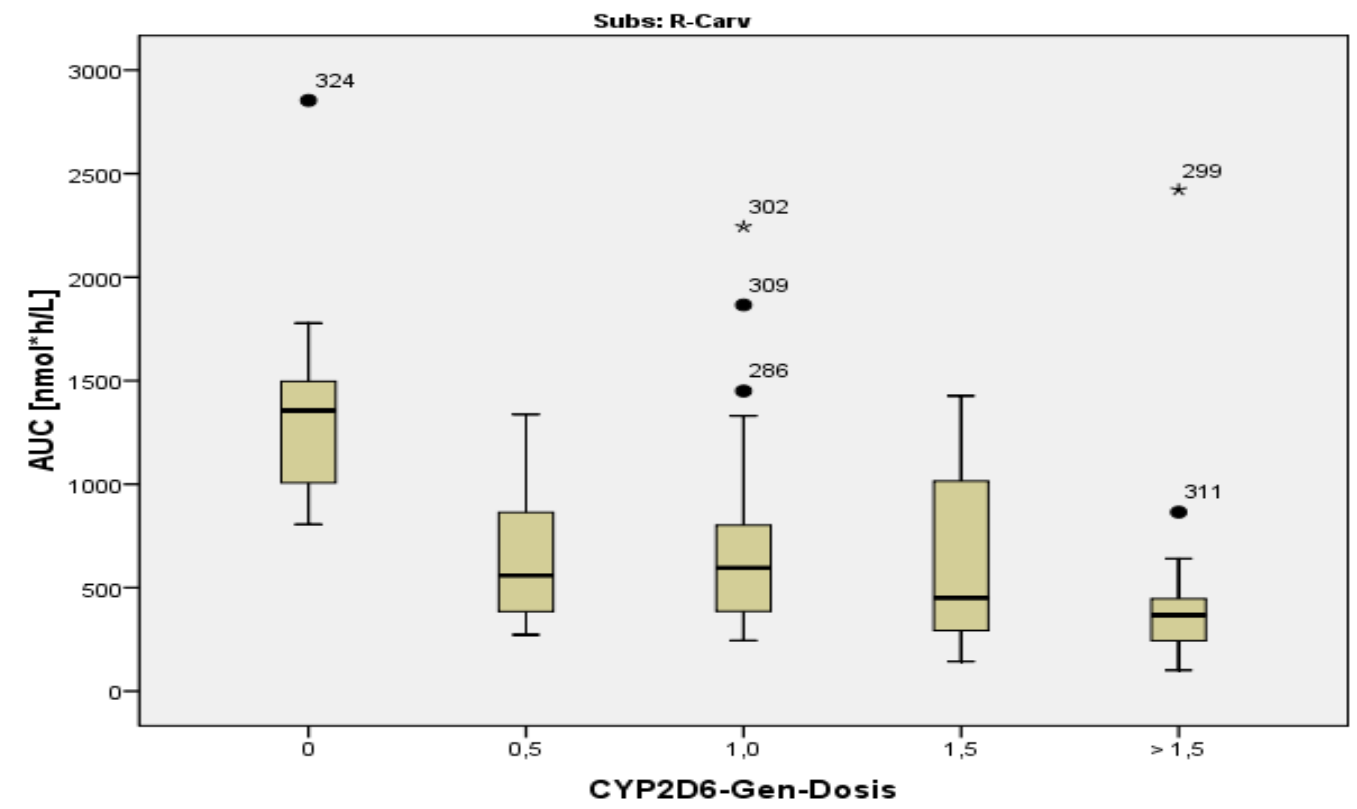

Fläche unter der Konzentrations-Zeit-Kurve (AUC in nmol · h/L) von R-Carvedilol (R-Carv) in Abhängigkeit vom CYP2D6-Genotyp. Mit steigender Genaktivität nimmt die AUC tendenziell ab. Schwarz ausgefüllte Kreise mit Nummerierung (Probandencode) stellen Ausreißer dar, wobei die Sterne extreme Ausreißer darstellen. In der > 1,5-Gruppe sind Träger von 2 aktiven CYP2D6-Allelen und der einzige UM vertreten. Subs, Substanz.

Schließlich zeigte das zur oralen Bioverfügbarkeit in Relation gesetzte Verteilungsvolumen V/F bei beiden Enantiomeren signifikante Unterschiede zwischen den Genotypen. Dabei war der mediane V/F bei PM ca. 3,6-fach (R-Carvedilol) bzw. 1,6-fach (S-Carvedilol) niedriger 
Ergebnisse

als bei EM (für beide Enantiomere $p<0,001$, JTTT). Die Unterschiede im Verteilungsvolumen in Abhängigkeit vom metabolisierenden Enzym CYP2D6 müssen als Unterschiede in der Bioverfügbarkeit interpretiert werden. Die Bioverfügbarkeit ist bei PM deutlich höher als bei EM, damit ist V/F bei PM kleiner als bei EM.

\subsubsection{Carvedilol-Metaboliten in Relation zum CYP2D6-Genotyp}

Im Folgenden werden lediglich die pharmakokinetischen Parameter $\mathrm{AUC}_{0 \text {-last }}$ und $\mathrm{C}_{\max }$ der Carvedilol-Metaboliten in Abhängigkeit zum CYP2D6-Genotyp beschrieben. Einschränkend ist dabei zu sagen, dass die Menge an Carvedilol, die zum jeweiligen Metaboliten verstoffwechselt wurde, unbekannt war. Dadurch war eine präzise Aussage zur Menge der gebildeten Metaboliten nicht möglich und es konnte somit auch die Clearance der Metaboliten nicht berechnet werden. Die Mediane und Interquartilbereiche sind für die oben genannten Parameter für die Metaboliten in der Tab. 35 dargestellt.

Wie man aus der Tab. 35 erkennt, gab es statistisch signifikante Unterschiede zwischen den CYP2D6-Genotypen sowohl in den medianen $\mathrm{C}_{\max }$ als auch in den medianen AUC bei beiden Desmethylcarvedilol Enantiomeren. Außerdem waren die medianen $\mathrm{C}_{\max }$-Werte beider 4 OH-Carvedilol Enantiomere und die medianen AUC des R-4-OH-Carvedilol signifikant unterschiedlich zwischen den CYP2D6-Genotyp-Gruppen. Quantitativ war der Unterschied bei den R-Enantiomeren deutlich größer als bei den S-Enantiomeren. Die mediane AUC von R-Desmethylcarvedilol war bei PM um das 4-fache größer als bei Trägern von 2 aktiven CYP2D6-Allelen ( $\mathrm{p}<0,001$, JTTT), entsprechend ergab sich bei S-Desmethylcarvedilol ein Unterschied um das 3-fache $\left(p=0,012\right.$, JTTT). Für die medianen $\mathrm{C}_{\max }$ beider Enantiomere galt entsprechendes, wobei die Unterschiede zwischen PM und Trägern von 2 aktiven Allelen beim R-Enantiomer ca. 2,3- (p<0,001, JTTT) und beim S-Enantiomer ca. 1,6-fach ( $\mathrm{p}=0,005$, JTTT) größer waren. Im Gegensatz zum AUC-Verlauf des S-4`-OH- war der des R-4`-OHMetaboliten in Relation zum CYP2D6-Genotypen signifikant unterschiedlich und verhielt sich umgekehrt zu dem AUC-Verlauf des Carvedilol und Desmethylcarvedilol beider Enantiomere. Bei Trägern von 2 aktiven CYP2D6-Allelen war die AUC für den R-4-OHMetaboliten 1,2-fach höher als bei PM ( $\mathrm{p}=0,009$, JTTT). 
Ergebnisse

Tab. $35 \mathrm{AUC}_{0 \text {-last }}$ aller Metaboliten und $\mathrm{C}_{\max }$ für einige Metaboliten in Relation zum CYP2D6-Genotyp

\begin{tabular}{|c|c|c|c|c|c|c|}
\hline & \multicolumn{5}{|c|}{ Anzahl aktiver CYP2D6-Gene* } & \multirow[t]{2}{*}{$\mathrm{P} * *$} \\
\hline & 0 & 0.5 & 1 & 1.5 & $\geq 2$ & \\
\hline Anzahl & 13 & 12 & 34 & 13 & 38 & \\
\hline Parameter & \multirow{2}{*}{\multicolumn{5}{|c|}{ Median }} & \\
\hline Substanz & & & & & & \\
\hline \multicolumn{7}{|l|}{$\mathbf{A} \mathbf{U} \mathbf{C}_{0 \text {-last }}(\mathrm{nmol} \cdot \mathrm{h} / \mathrm{L})$} \\
\hline R-Desmethylcarvedilol & $\begin{array}{c}91,3 \\
66,3-148\end{array}$ & $\begin{array}{c}41,1 \\
20,9-50,6\end{array}$ & $\begin{array}{c}42,4 \\
32,4-73,8\end{array}$ & $\begin{array}{c}45,8 \\
32,9-69,2\end{array}$ & $\begin{array}{c}22,6 \\
12,8-50,6\end{array}$ & $<0,001$ \\
\hline S-Desmethylcarvedilol & $\begin{array}{c}44,2 \\
14,3-86,5\end{array}$ & $\begin{array}{c}16,9 \\
11,3-41,7\end{array}$ & $\begin{array}{c}41,4 \\
22,9-88,0\end{array}$ & $\begin{array}{c}22,8 \\
10,8-34,4\end{array}$ & $\begin{array}{c}14,6 \\
9,45-37,4\end{array}$ & 0,012 \\
\hline R-4'-OH-Carvedilol & $\begin{array}{c}16,7 \\
14,2-19,7\end{array}$ & $\begin{array}{c}13,9 \\
6,9-18,6\end{array}$ & $\begin{array}{c}16,6 \\
11,5-25,5\end{array}$ & $\begin{array}{c}19,2 \\
14,5-25,6\end{array}$ & $\begin{array}{c}19,2 \\
16,1-25,3\end{array}$ & 0,009 \\
\hline S-4'-OH-Carvedilol & $\begin{array}{c}32,8 \\
27,6-37,6\end{array}$ & $\begin{array}{c}23,9 \\
11,1-35,3\end{array}$ & $\begin{array}{c}29,3 \\
21,7-49,2\end{array}$ & $\begin{array}{c}32,9 \\
26,3-53,9\end{array}$ & $\begin{array}{c}32,9 \\
22,6-43,7\end{array}$ & n. s. \\
\hline R-5'-OH-Carvedilol & $\begin{array}{c}32,7 \\
23,2-39,2\end{array}$ & $\begin{array}{c}22,6 \\
10,8-34,3\end{array}$ & $\begin{array}{c}27,5 \\
19,9-40,2\end{array}$ & $\begin{array}{c}25,0 \\
19,9-37,3\end{array}$ & $\begin{array}{c}24,2 \\
18,7-32,1\end{array}$ & n. s. \\
\hline S-5'-OH-Carvedilol & $\begin{array}{c}39,1 \\
30,6-52,5\end{array}$ & $\begin{array}{c}26,8 \\
12,5-45,5\end{array}$ & $\begin{array}{c}33,8 \\
24,9-44,2\end{array}$ & $\begin{array}{c}33,4 \\
21,9-37,3\end{array}$ & $\begin{array}{c}25,1 \\
21,4-39,4\end{array}$ & n. s. \\
\hline \multicolumn{7}{|l|}{$\mathbf{C}_{\max }(\mathrm{nmol} / \mathrm{L})$} \\
\hline R-Desmethylcarvedilol & $\begin{array}{c}17,0 \\
13,8-22,2\end{array}$ & $\begin{array}{c}11,2 \\
5,84-18,5\end{array}$ & $\begin{array}{c}11,3 \\
8,77-16,9\end{array}$ & $\begin{array}{c}10,2 \\
6,58-15,1\end{array}$ & $\begin{array}{c}7,45 \\
5,28-13,4\end{array}$ & $<0,001$ \\
\hline S-Desmethylcarvedilol & $\begin{array}{c}8,14 \\
6,14-21,9\end{array}$ & $\begin{array}{c}6,67 \\
3,15-9,64\end{array}$ & $\begin{array}{c}9,94 \\
5,92-15,8\end{array}$ & $\begin{array}{c}6,09 \\
4,07-11,1\end{array}$ & $\begin{array}{c}4,97 \\
3,22-8,35\end{array}$ & 0,005 \\
\hline R-4'-OH-Carvedilol & $\begin{array}{c}3,95 \\
3,43-5,38\end{array}$ & $\begin{array}{c}5,02 \\
2,63-6,19\end{array}$ & $\begin{array}{c}4,98 \\
3,95-7,70\end{array}$ & $\begin{array}{c}6,35 \\
5,02-9,24\end{array}$ & $\begin{array}{c}7,26 \\
5,71-9,00\end{array}$ & $<0,001$ \\
\hline S-4'-OH-Carvedilol & $\begin{array}{c}10,5 \\
5,79-13,4\end{array}$ & $\begin{array}{c}8,89 \\
4,00-11,4\end{array}$ & $\begin{array}{c}10,0 \\
7,77-16,6\end{array}$ & $\begin{array}{c}13,4 \\
9,00-19,5\end{array}$ & $\begin{array}{c}12,8 \\
9,65-19,0\end{array}$ & 0,003 \\
\hline R-5 -OH-Carvedilol & $\begin{array}{c}12,2 \\
6,0-14,8\end{array}$ & $\begin{array}{c}10,6 \\
4,9-13,5\end{array}$ & $\begin{array}{c}9,5 \\
6,5-12,4\end{array}$ & $\begin{array}{c}9,3 \\
7,3-13,2\end{array}$ & $\begin{array}{c}8,4 \\
7,2-12,3\end{array}$ & n.s \\
\hline S-5'-OH-Carvedilol & $\begin{array}{c}12,4 \\
6,7-15,6\end{array}$ & $\begin{array}{c}9,8 \\
6,6-14,3\end{array}$ & $\begin{array}{c}10,0 \\
7,7-12,9\end{array}$ & $\begin{array}{c}9,9 \\
7,5-13,6\end{array}$ & $\begin{array}{c}9,5 \\
7,7-13,4\end{array}$ & n.s. \\
\hline
\end{tabular}

Für alle Daten sind die Mediane und die Interquartilbereiche dargestellt. $\mathrm{C}_{\max }$, maximale Blutkonzentration; $\mathrm{AUC}_{\text {0-last }}$, Fläche unter der Konzentrations-Zeit-Kurve bis zum letzten Messzeitpunkt. * Die Gendosis wurde als Rangzahl in der Reihenfolge steigender Zahlen mit steigender Aktivität angegeben, wie sie aus vielen anderen Medikamenten gut etabliert ist. In dieser Studie war lediglich ein UM, dieser wurde in die Gruppe mit 2 Aktivitätseinheiten zugeordnet. ** P, P-Wert. Der P-wert wurde mittels des nichtparametrischen Jonckheere-Terpstra-Trend-Tests bestimmt, P-Werte > 0,05 wurden als nicht signifikant (n. s.) angegeben.

Die maximalen Blutkonzentrationen von 4`-OH-Carvedilol waren bei PM niedriger als bei Trägern von 2 aktiven CYP2D6-Allelen, was gut mit der Hypothese übereinstimmt, dass 4`OH-Carvedilol über CYP2D6 gebildet wird. Folglich war der Unterschied der medianen $\mathrm{C}_{\max }$ beim R-4`-OH-Metaboliten bei Trägern von 2 aktiven CYP2D6-Allelen 1,8-fach höher als bei PM ( $\mathrm{p}<0,001$, JTTT) und entsprechend beim S-4`-OH-Metaboliten bei Trägern von 2 aktiven CYP2D6-Allelen 1,2-fach höher als bei PM (p=0,003, JTTT). 
Ergebnisse
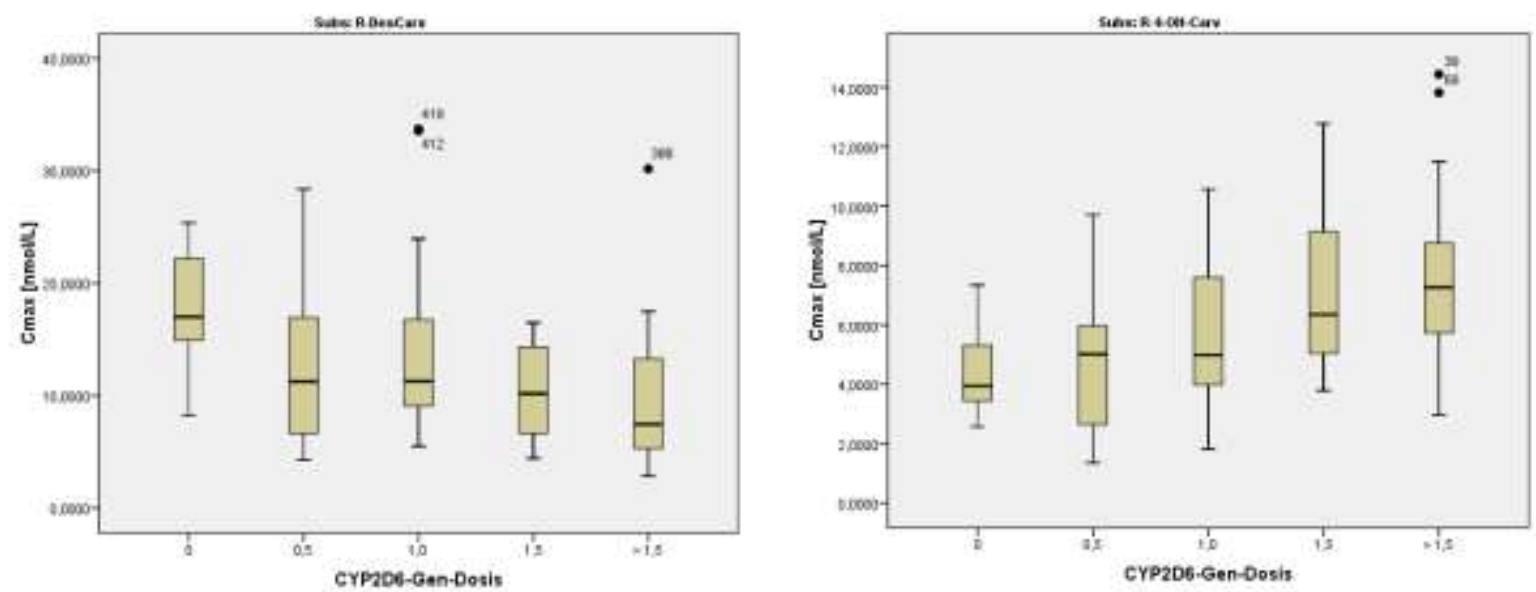

Abb. 5 Mediane $\mathrm{C}_{\max }$-Verlauf des R-Desmethylcarvedilol und des R-4`-OH-Carvedilol aller Probanden in Abhängigkeit zum CYP2D6-Genotyp. Mediane $\mathrm{C}_{\max }$ nimmt mit steigender Genaktivität bei $\mathrm{R}$ Desmethylcarvedilol (R-DesCar) tendenziell ab. Während der mediane $\mathrm{C}_{\max }$ des R-4`-OH-Carvedilol mit steigender Genaktivität zunimmt. Schwarz ausgefüllte Kreise mit Nummerierung (Probandencode) stellen Ausreißer dar. In der > 1,5-Gruppe sind Träger von 2 aktiven CYP2D6-Allelen und der einzige UM vertreten. Subs, Substanz.

\subsubsection{Carvedilol-Enantiomere und -Metaboliten in Relation zum CYP2C9- und CYP2C19-Genotyp}

In den Tab. 36 sowie 37 sind die Mediane und Interquartilbereiche der AUCs der CarvedilolEnantiomere und -Metaboliten in Relation zum CYP2C9- und- C19- Enzym angegeben.

Wie man aus der folgenden Tab. 36 erkennen kann, wurden in Relation zum CYP2C9-Genotyp weder bei den Carvedilol-Enantiomeren noch bei den Metaboliten signifikante Unterschiede der AUCs festgestellt. 
Ergebnisse

Tab. $36 \mathrm{AUC}_{0 \text {-last }}$ von R- und S-Carvedilol und der Carvedilol-Metaboliten in Relation zum CYP2C9Genotyp

\begin{tabular}{|c|c|c|c|c|c|c|}
\hline & \multicolumn{5}{|c|}{ CYP2C9-Genotyp (Gendosiszuordnung ${ }^{\#}$ ) } & \multirow[t]{2}{*}{$\mathrm{P}^{\# \#}$} \\
\hline & $* 2 / * 3(2)$ & $* 1 / * 3(3)$ & $* 2 / * 2(4)$ & $* 1 / * 2(5)$ & $* 1 / * 1(6)$ & \\
\hline Anzahl & 2 & 12 & 3 & 16 & 77 & \\
\hline Substanz & \multicolumn{5}{|c|}{$\begin{array}{l}\text { Median } \\
\text { Interquartilbereich }\left(\mathrm{Q}_{1}-\mathrm{Q}_{3}\right)(\mathrm{nmol} \cdot \mathrm{h} / \mathrm{L})\end{array}$} & \\
\hline R-Carvedilol & 310 & $\begin{array}{c}527 \\
344-668\end{array}$ & 416 & $\begin{array}{c}436 \\
353-1020\end{array}$ & $\begin{array}{c}534 \\
348-867\end{array}$ & n.s. \\
\hline S-Carvedilol & 169 & $\begin{array}{c}210 \\
168-280\end{array}$ & 215 & $\begin{array}{c}150 \\
109-315\end{array}$ & $\begin{array}{c}190 \\
140-277\end{array}$ & n.s. \\
\hline R-Desmethylcarvedilol & 20,2 & $\begin{array}{c}37,5 \\
19,9-46,6\end{array}$ & 83,6 & $\begin{array}{c}34,8 \\
18,8-85,5\end{array}$ & $\begin{array}{c}42,9 \\
27,2-77,9\end{array}$ & n.s. \\
\hline S-Desmethylcarvedilol & 38 & $\begin{array}{c}14,2 \\
11,4-40,7\end{array}$ & 64,2 & $\begin{array}{c}17,8 \\
11,1-44,5\end{array}$ & $\begin{array}{c}27,1 \\
12,6-57,7\end{array}$ & n.s. \\
\hline R-4'-OH-Carvedilol & 20,1 & $\begin{array}{c}18,5 \\
16,1-20,7\end{array}$ & 27,4 & $\begin{array}{c}16,6 \\
12,4-20,8\end{array}$ & $\begin{array}{c}16,9 \\
13,6-24,3\end{array}$ & n.s. \\
\hline S-4'-OH-Carvedilol & 29,7 & $\begin{array}{c}32,2 \\
20,6-43,9\end{array}$ & 61,3 & $\begin{array}{c}28,2 \\
22,2-35,6\end{array}$ & $\begin{array}{c}32,9 \\
23,5-44,2\end{array}$ & n.s. \\
\hline R-5'-OH-Carvedilol & 23,2 & $\begin{array}{c}25,9 \\
18,3-35,3\end{array}$ & 44,8 & $\begin{array}{c}23,4 \\
18,1-36,3\end{array}$ & $\begin{array}{c}26,6 \\
19,6-37,1\end{array}$ & n.s. \\
\hline S-5'-OH-Carvedilol & 20,4 & $\begin{array}{c}25,8 \\
22,3-40,7\end{array}$ & 48,4 & $\begin{array}{c}27,5 \\
20,6-39,2\end{array}$ & $\begin{array}{c}31,9 \\
22,4-45,2\end{array}$ & n.s. \\
\hline
\end{tabular}

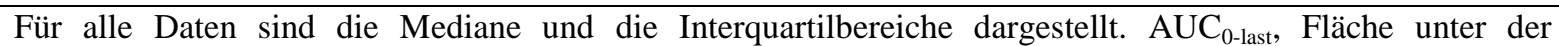
Konzentrations-Zeit-Kurve bis zum letzten Messzeitpunkt. \# Die Gendosis wurde als Rangzahl in der Reihenfolge steigender Zahlen mit steigender Aktivität angegeben, wie sie aus vielen anderen Medikamenten gut etabliert ist. ${ }^{\#}$ P, P-Wert. Der P-wert wurde mittels des nichtparametrischen Jonckheere-Terpstra-TrendTests bestimmt, P-Werte > 0,05 wurden als nicht signifikant (n. s.) angegeben.

Wie man aus der folgenden Tabelle erkennen kann, zeigten sowohl die Enantiomere als auch die demethylierten und die hydroxylierten Metaboliten des Carvedilol bei der Darstellung der medianen AUCs keine signifikanten Trends in Abhängigkeit vom CYP2C19-Genotyp. Lediglich für die medianen $\mathrm{C}_{\max }$-Werte des $\mathrm{R}-4^{-}-\mathrm{OH}-\mathrm{Carvedilol}$ konnte in Bezug auf den CYP2C19-Genotyp ein signifikanter Verlauf gesehen werden. Hierbei konnten in Richtung von niedriger $\mathrm{zu}$ steigender Gendosis folgende mediane $\mathrm{C}_{\max }$-Werte gesehen werden (in Klammern ist die Gendosis angegeben): 6,0 (1), 5,4 (2), 5,6 (3), 6,2 (4), 4,6 (5) sowie 5,1 (6) $\mathrm{nmol} / \mathrm{L}$ ( $\mathrm{p}=0.040$, JTTT). Einerseits könnte dieses Ergebnis ein Zufallsbefund sein, andererseits würde es dafür sprechen, dass das R-4`-OH-Carvedilol weiter durch CYP2C19 metabolisiert wird. Dieses Ergebnis wird jedoch nicht überbewertet. 
Ergebnisse

Tab. $37 \mathrm{AUC}_{0-\text { last }}$ von R- und S-Carvedilol und der Carvedilol-Metaboliten in Relation zum CYP2C19 Genotyp

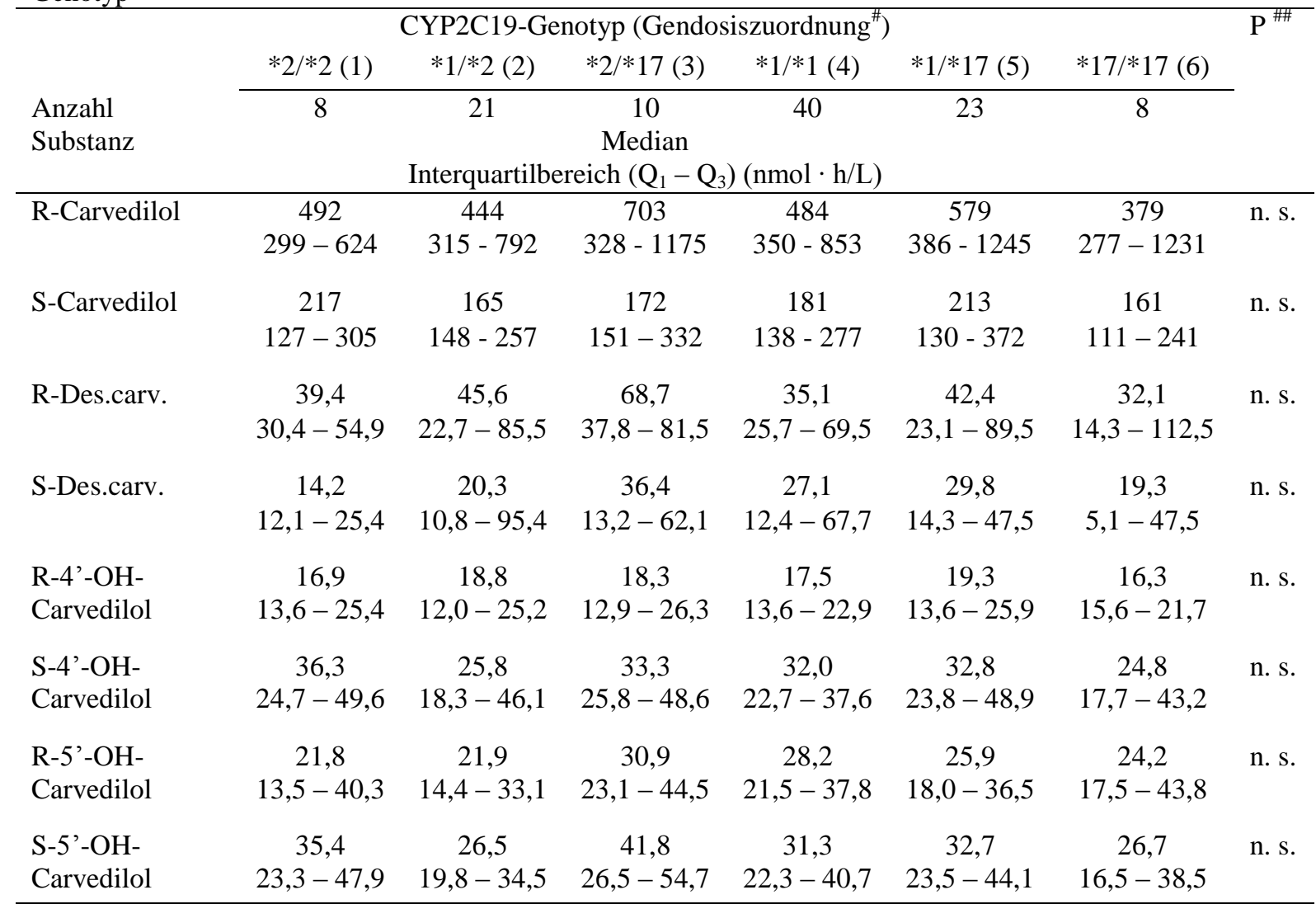

Für alle Daten sind die Mediane und die Interquartilbereiche dargestellt. $\mathrm{AUC}_{0 \text {-last }}$ Fläche unter der Konzentrations-Zeit-Kurve bis zum letzten Messzeitpunkt. R-Des.carv., R-Desmethylcarvedilol. S-Des.carv., S-Desmethylcarvedilol. \# Die Gendosis wurde als Rangzahl in der Reihenfolge steigender Zahlen mit steigender Aktivität angegeben, wie sie aus vielen anderen Medikamenten gut etabliert ist. \#\# P, P-Wert. Der P-Wert wurde mittels des nichtparametrischen Jonckheere-Terpstra-Trend-Tests bestimmt, P-Werte > 0,05 wurden als nicht signifikant (n. s.) angegeben.

\subsection{CYP2D6-Allel-spezifische Clearance}

Es war offenkundig, dass ein 1-Kompartiment-Modell zur Beschreibung der anfangs schnell und am Ende langsam abfallenden Blutkonzentrationen von Carvedilol inadäquat war. Deshalb wurde ein 2-Kompartiment-Modell gewählt (siehe Kap. 2.4.1). Einige aus dieser Modellanalyse gewonnenen Parameter sind in der Tab 38 dargestellt.

Wie zu sehen ist, erfolgte die Bestimmung für die jeweilige Clearance der individuellen Genotypen aus der Summe der CYP2D6 unabhängigen Clearance-Mittelwerte $\left(\mathrm{Cl}_{0}\right)$ für Rund S-Carvedilol mit 36.0 L/h und 129.5 L/h und der beiden CYP2D6-Allel-spezifischen mittleren Clearances. Allel-spezifische mittlere Clearances sind für beide CarvedilolEnantiomere dargestellt. Es fällt auf, dass die mittleren Allel-spezifischen Clearances der *9und *17-Variante bei R-Carvedilol sehr klein und beim S-Enantiomer annähernd Null waren. 
Ergebnisse

Bei Trägern des CYP2D6*1/*1 betrug die mittlere Clearance des R-Carvedilol 101,4 L/h und des S-Carvedilol 204,7 L/h. Beim Vergleich dieser zuletzt berechneten mittleren Clearances mit den CYP2D6 unabhängigen mittleren Clearances der entsprechenden Enantiomere kann schlussfolgernd gesagt werden, dass ca. 64\% des R-Carvedilol und lediglich ca. 37\% des SCarvedilol CYP2D6 abhängig eliminiert werden. Der Rest wird durch andere CYP2D6unabhängige Mechanismen eliminert. Darüberhinaus kann der Tabelle 38 entnommen werden, dass die berechneten CYP2D6-Allel-spezifischen Clearances des *2 kleiner sind als die des $* 1$.

Tab. 38 CYP2D6-Allel/Genotyp-spezifische Clearances

\begin{tabular}{|c|c|c|c|c|c|}
\hline \multirow[b]{2}{*}{ Parameter } & \multirow[b]{2}{*}{ Einheit } & \multicolumn{2}{|c|}{ R-Carvedilol } & \multicolumn{2}{|c|}{ S-Carvedilol } \\
\hline & & Mittelwert & SE & Mittelwert & SE \\
\hline V2 peripheries Verteilungsvolumen & $\mathrm{L}$ & 240,1 & 30,9 & 739 & 81,1 \\
\hline $\mathrm{k}_{23}$ & $\mathrm{~h}^{-1}$ & 0,075 & 0,006 & 0,117 & 0,01 \\
\hline $\mathrm{k}_{32}$ & $\mathrm{~h}^{-1}$ & 0,06 & 0,004 & 0,059 & 0,006 \\
\hline $\mathrm{Cl}_{0}$ CYP2D6 unabhängige Clearance ${ }^{\mathrm{a}}$ & $\mathrm{L} / \mathrm{h}$ & 36,0 & 3,94 & 129,5 & 16,36 \\
\hline $\mathrm{Cl}_{* l}$ Clearance des $C Y P 2 D 6 * 1$ Allels & $\mathrm{L} / \mathrm{h}$ & 32,7 & 7,18 & 37,6 & 13,4 \\
\hline $\mathrm{Cl}_{*_{2}}$ Clearance des $C Y P 2 D 6 * 2$ Allels & $\mathrm{L} / \mathrm{h}$ & 18,3 & 6,07 & 20,6 & 14,3 \\
\hline $\mathrm{Cl}_{* 9}$ Clearance des $C Y P 2 D 6 * 9$ Allels & $\mathrm{L} / \mathrm{h}$ & 16,1 & 8,13 & $0^{\mathrm{b}}$ & \\
\hline $\mathrm{Cl}_{* 10}$ Clearance des $C Y P 2 D 6 * 10$ Allels & $\mathrm{L} / \mathrm{h}$ & 14,8 & 6,69 & 0 & \\
\hline $\mathrm{Cl}_{* 17}$ Clearance des $C Y P 2 D 6 * 17$ Allels & $\mathrm{L} / \mathrm{h}$ & 1,3 & 4,65 & 0 & \\
\hline $\mathrm{Cl}_{* 41}$ Clearance des $C Y P 2 D 6 * 41$ Allels & $\mathrm{L} / \mathrm{h}$ & 8,2 & 6,78 & 0 & \\
\hline \multicolumn{6}{|l|}{ Genotyp spezifische Clearance (Beispiele) } \\
\hline$C Y P 2 D 6 * 1 / * 1$ & $\mathrm{~L} / \mathrm{h}$ & 101,4 & & 204,7 & \\
\hline$C Y P 2 D 6 * 1 / * 4$ & $\mathrm{~L} / \mathrm{h}$ & 68,7 & & 167,1 & \\
\hline$C Y P 2 D 6 * 4 / * 4$ & $\mathrm{~L} / \mathrm{h}$ & 36,0 & & 129,5 & \\
\hline
\end{tabular}

k23; Geschwindigkeit, mit der die Substanz vom zentralen in das periphere Kompartiment übertritt; k32, Geschwindigkeit, mit der die Substanz vom peripheren in das zentrale Kompartiment übertritt; SE, Standard error (Standardfehler). ${ }^{a}$ Die individuelle Clearance ergab sich aus Summe der CYP2D6 unabhängigen Clearance plus der CYP2D6-Allel-spezifischen Clearance der zwei CYP2D6-Allele. Bei einem Träger des Genotypes CYP2D6*1/*4 wurde somit die S-Carvedilol-Clearance folgendermaßen berechnet: 129,5 + 37,6 = $167,1 \mathrm{~L} / \mathrm{h} .{ }^{\mathrm{b}}$ S-Carvedilol Clearances für die CYP2D6 Allele $* 9, * 10, * 17$ und $* 41$ sind annähernd mit Null gleichzusetzen.

Weiterhin zeigt die folgende Abbildung, dass auch innerhalb eines gleichen CYP2D6 Genotyps eine große Streubreite (Variabilität) der gemessenen Clearance-Werte von R- und S-Carvedilol gesehen werden konnte. Mit Hilfe der Regressionsanalyse konnte gezeigt werden, dass nur 35,7\% der Variabilität der totalen Clearance bei R-Carvedilol und lediglich 15,3\% der Variabilität der totalen Clearance bei S-Carvedilol durch den CYP2D6-Genotyp 
Ergebnisse

erklärt werden konnten. Dieses Ergebnis lässt vermuten das noch andere CYP2D6 unabhängige metabolisierende Mechanismen auf den Carvedilol-Metabolismus Einfluss haben. Allerdings unterschieden sich die Mittelwerte vieler nach CYP2D6-Genotyp definierter Gruppen signifikant voneinander.

Abb. 6 Zusammenhang zwischen gemessener Clearance und CYP2D6-Genotyp
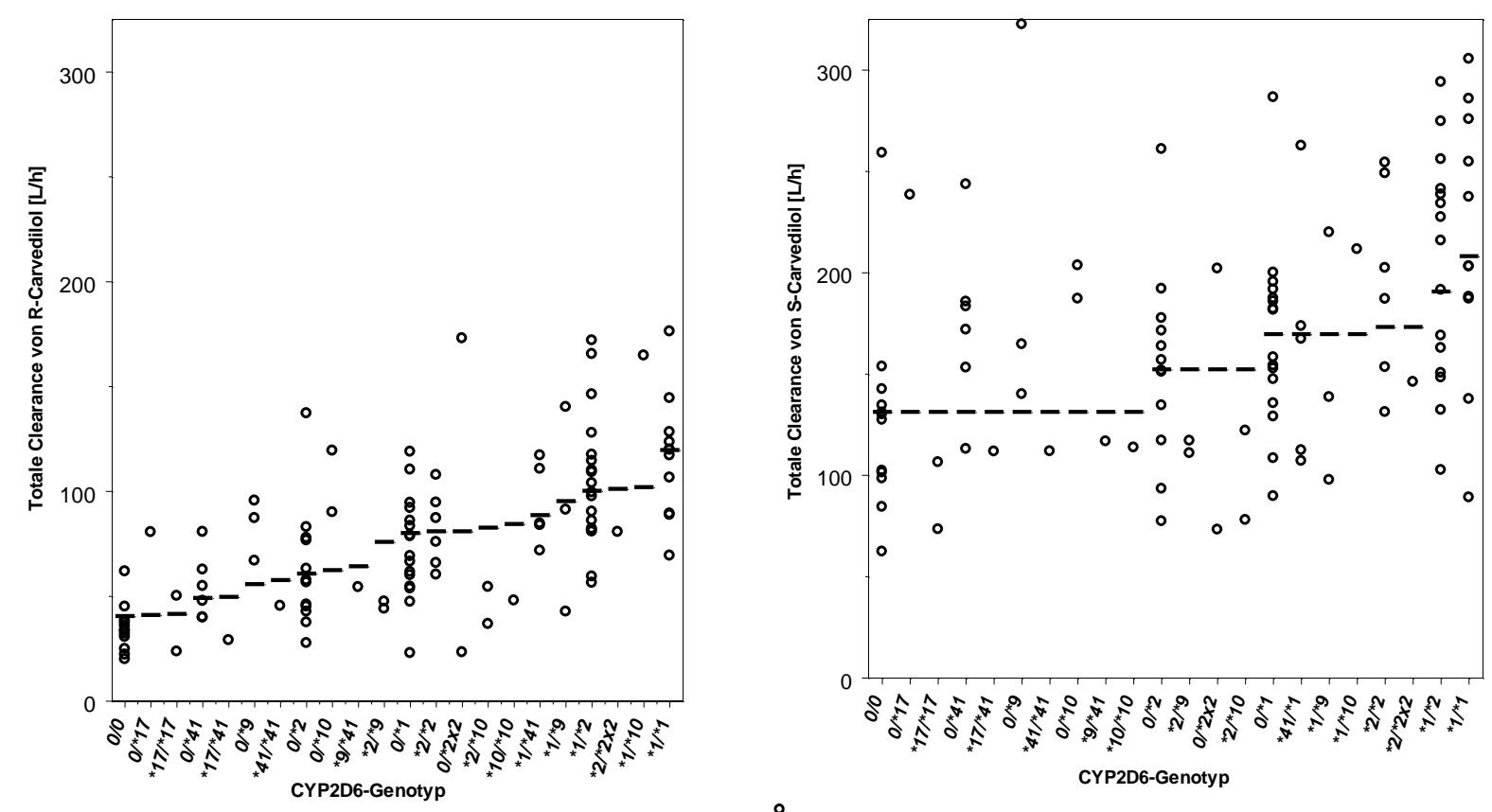

Totale Clearances für R- und S-Carvedilol, gemessene Clearance-Werte werden als offene Kreise angezeigt, des Weiteren werden Mittelwerte CYP2D6 definierter Gruppen als waagerechte Balken dargestellt. Die defizienten CYP2D6 Allele *3, *4, *5, und *6 wurden nicht weiter differenziert und nicht dargestellt.

\subsection{Wirkungen von Carvedilol auf Herzfrequenz und Blutdruck in der Ergometrie}

Auch wenn die Wirkungen von Carvedilol auf Herzfrequenz und Blutdruck seit langem bekannt sind, sollte hier noch einmal zusammenfassend illustriert werden, was in der vorliegenden Studie bei den 110 gesunden Probanden beobachtet wurde. Die Beziehung der Carvedilol-Wirkungen zu den CYP2D6-Genotypen wird in den Kapitel 3.6 sowie 3.7 dargestellt 
Ergebnisse

\subsubsection{Herzfrequenz in Ruhe}

Die mediane Ruheherzfrequenz betrug ohne Carvedilol-Medikation 81/min mit einer individuellen Schwankungsbreite zwischen 56 (Minimum) und 109 (Maximum). Es konnte keine statistisch signifikante Abhängigkeit zwischen individueller Ruheherzfrequenz vor der Carvedilol-Medikation und Geschlecht, Gewicht oder Körpergröße gefunden werden. Unterschiede zwischen den CYP2D6-Genotypen existierten ebenfalls nicht (physiologisch auch nicht zu erwarten, aber relevant, falls die Basiswerte unterschiedlich wären).

Nach Applikation von $25 \mathrm{mg}$ Carvedilol konnte eine maximale Reduktion der RuheHerzfrequenz von -11,7 (-37,4 - 0) Schläge/min (Median (Minimum - Maximum)), was einer 14\%igen Reduktion entspricht, gemessen werden. Weiter wurde die über $24 \mathrm{~h}$ integrierte Ruhe-Herzfrequenz nach Medikation um -6789 (-28458 - -14790) Schläge/24 h reduziert. Während sowohl die maximale als auch die über $24 \mathrm{~h}$ integrierte Ruhe-HerzfrequenzReduktion nach Medikation unabhängig von Geschlecht, Alter und Körpergröße war, konnte jedoch eine Abhängigkeit vom Körpergewicht gesehen werden. Mit fallendem Gewicht konnte eine Zunahme des Carvedilol-Effektes gesehen werden.

Abb. 7 Zusammenhang zwischen Körpergewicht und maximaler Reduktion der Ruhe-Herzfrequenz unter Carvedilol

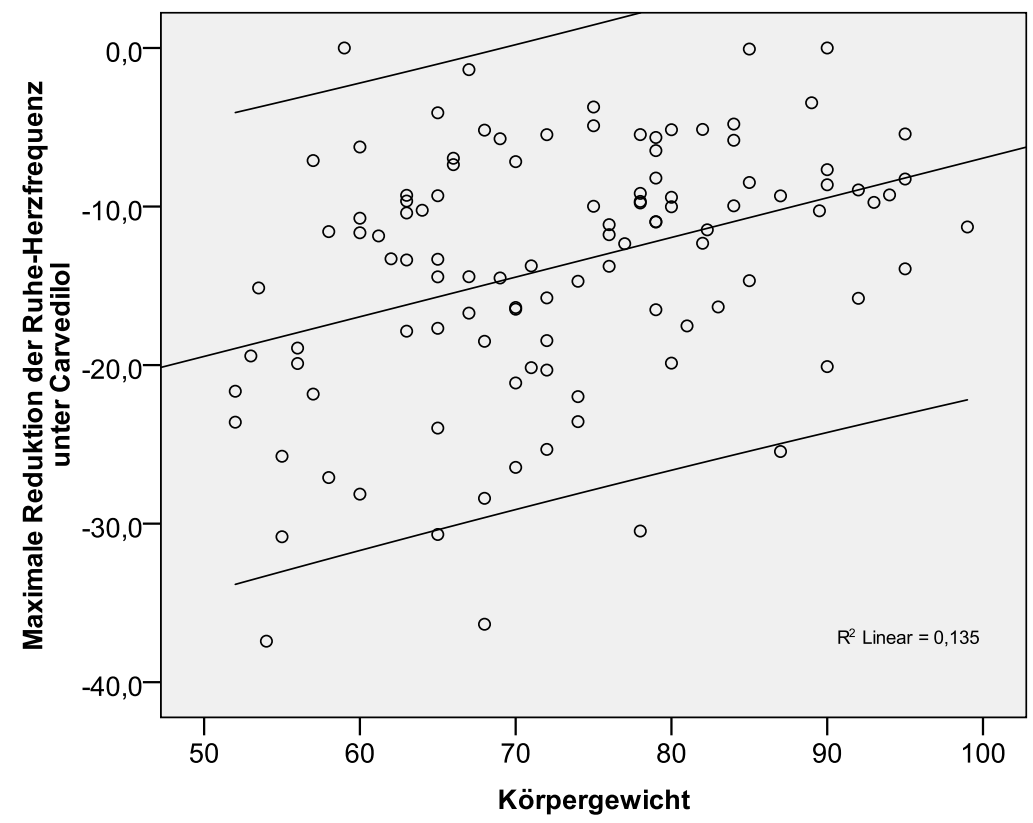

$\mathrm{R}^{2}$, Bestimmtheitsmaß (wie gut ist maximale Reduktion der Ruhe-Herzfrequenz unter Carvedilol durch Körpergewicht erklärbar). Die mittlere Gerade stellt die Regressionsgerade dar, wobei die obere und untere Gerade den 95\%-Konfidenzintervall angeben. 
Ergebnisse

Die mediane maximale Ruhe-Herzfrequenz-Reduktion nahm um 2,5 Schläge/min pro $10 \mathrm{~kg}$ Gewichtsabnahme zu ( $\mathrm{p}<$ 0,0001). Dabei zeigt das Streudiagramm, dass dennoch eine erhebliche Variabilität in der Reduktion der Ruhe-Herzfrequenz nach Berücksichtigung von Körpergewicht bleibt, die nicht erklärbar ist (Abb. 7).

Die Verfügbarkeit der Carvedilol-Blutkonzentrationsdaten erlaubt eine pharmakokinetischpharmakodynamische Analyse, in der die Konsequenzen spezifischer Blutkonzentrationen für die kardiovaskulären Parameter analysiert wurden. Die Beziehung zwischen S-CarvedilolKonzentration und Effekt konnte mit einer medianen $\mathrm{EC}_{50}$ (mediane CarvedilolKonzentration, die zum halbmaximalen Effekt führt) beschrieben werden. Diese betrug für die Ruhe-Herzfrequenz-Reduktion 7,7 (1,7 - 24,5) nmol/L und der mediane maximale Effekt $\left(E_{\max }\right)$ betrug -16,4 (-11,5 - -29,5) Schläge/min. Dabei ist dieser maximale Effekt der extrapolierte maximale Effekt, der bei sehr hohen Carvedilol-Blutkonzentrationen für die Ruhe-Herzfrequenz vorausgesagt wurde. Die Beziehung zwischen CarvedilolBlutkonzentration und Effekt, wie sie durch nichtlineare Regressionsanalyse ermittelt wurde, ist in Abb. 8 Illustriert.

Abb. 8 Zusammenhang zwischen S-Carvedilol-Konzentration und Ruhe-Herzfrequenz

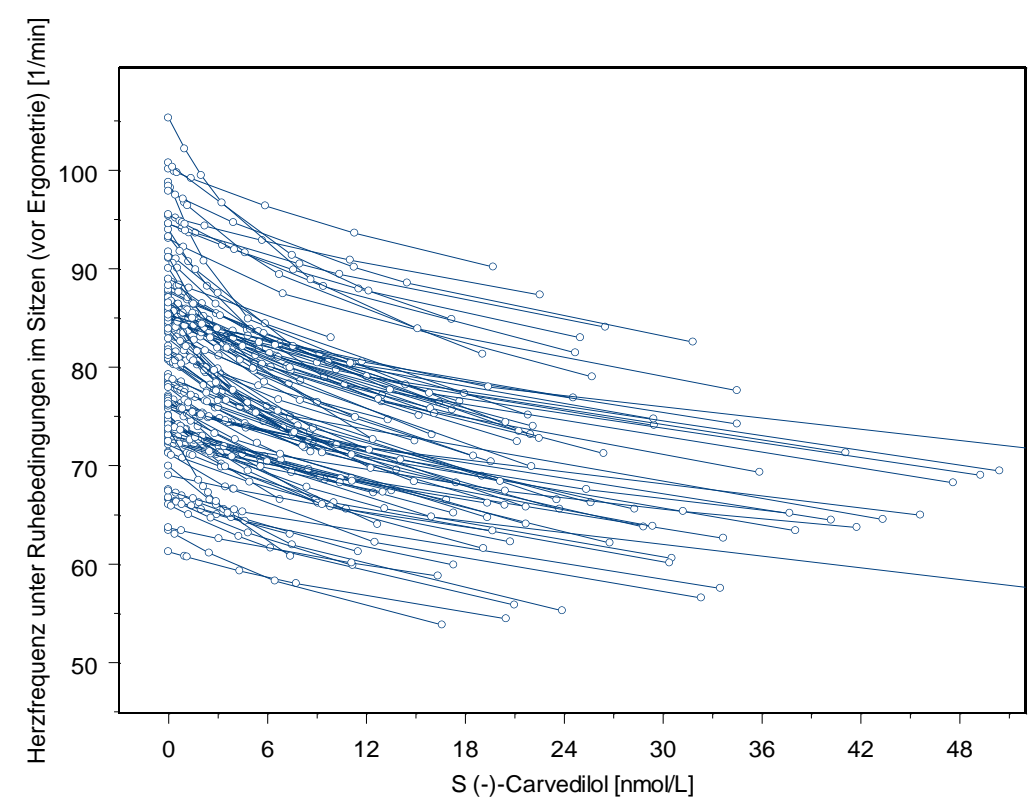

Einerseits sieht man die Herzfrequenzabnahme mit steigender S-Carvedilol-Konzentration, andererseits die starke interindividuelle Variabilität in der Herzfrequenz. 
Ergebnisse

\subsubsection{Herzfrequenz unter Belastung}

Die Herzfrequenz unter Belastung wurde ebenfalls vor und nach der Carvedilol-Applikation untersucht. Hier wurde aus der großen Zahl von Herzfrequenzdaten zu unterschiedlichen Belastungen diejenige individuelle Last ( ILast $_{140}$ ) ermittelt, unter der die Probanden vor der Carvedilol-Einnahme eine Herzfrequenz von 140/min aufwiesen. Die mediane Last ${ }_{140}$ betrug $121(39,4$ - 344) Watt.

Nach der Carvedilol-Applikation ergab sich eine mediane Belastungs-Herzfrequenzreduktion von -20 (-37,8 - -2,4) Schläge/min, entsprechend einer Reduktion von 14\%. Die über $24 \mathrm{~h}$ integrierte mediane Belastungs-Herzfrequenz-Reduktion betrug -13092 (-34581 - 11169) Schläge/24 h. Die maximale und ebenso die über $24 \mathrm{~h}$ integrierte Belastungs-HerzfrequenzReduktion zeigten keine Abhängigkeit vom Geschlecht, Alter, Körpergewicht und Körpergröße der Probanden.

Der mediane $\mathrm{EC}_{50}$-Wert betrug für die Reduktion der Belastungs-Herzfrequenz 7,7 (1,7 24,5) nmol/L und der extrapolierte, bei sehr hohen Carvedilol-Blutkonzentrationen für die Belastungs-Herzfrequenz vorausgesagte maximale Effekt $\left(\mathrm{E}_{\max }\right)-37,9(29,9$ - 46,2) Schläge/min.

Abb. 9 Zusammenhang zwischen S-Carvedilol-Konzentration und Belastungs-Herzfrequenz bei ILast ${ }_{140}$

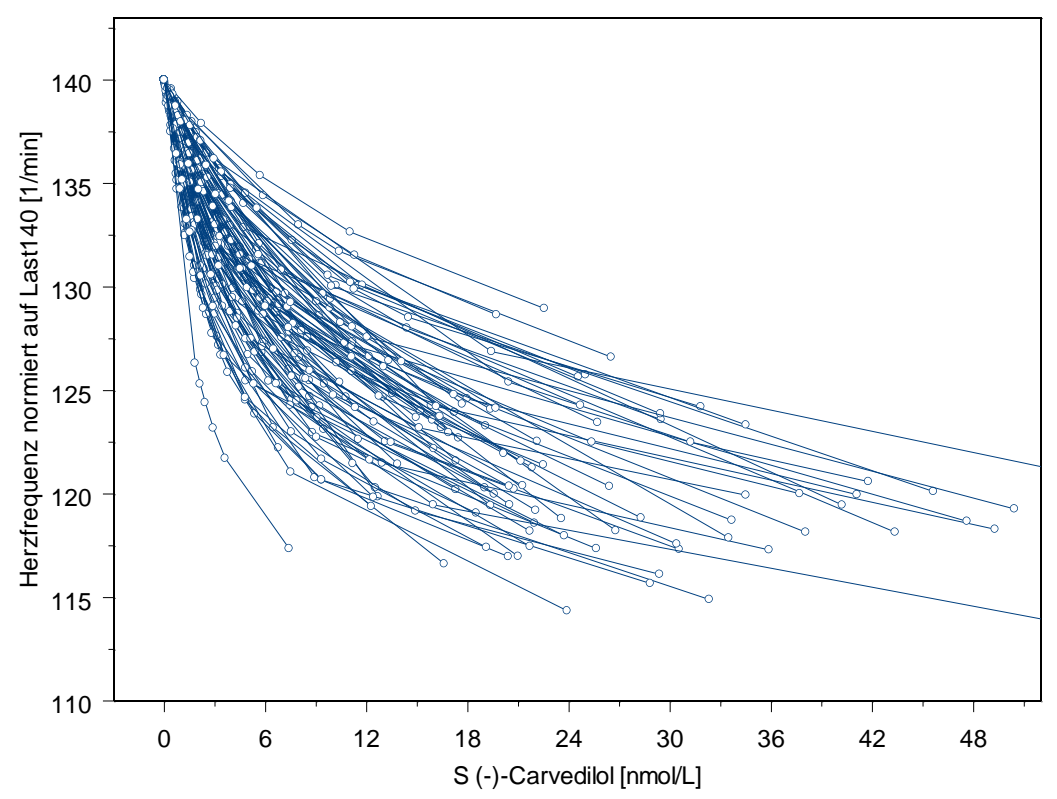

Einerseits sieht man mit steigender S-Carvedilol-Konzentration die maximale Herzfrequenzabnahme, andererseits die große Variabilität in der individuellen Belastungs-Herzfrequenz. 
Ergebnisse

\subsubsection{Blutdruck in Ruhe}

Der mediane systolische Blutdruck in Ruhe vor der Carvedilol-Medikation betrug $109(87,4$ 132) $\mathrm{mm} \mathrm{Hg}$. Es gab keine signifikante Abhängigkeit zwischen dem systolischen Ruheblutdruck vor der Medikation und Geschlecht, Körpergewicht oder Körpergröße.

Nach Einnahme von $25 \mathrm{mg}$ Carvedilol zeigte sich eine maximale Abnahme des Ruheblutdruckes um 8\%, was einer Reduktion um -9,1 (Median) (-29,6 - 0) $\mathrm{mm} \mathrm{Hg}$ entspricht. Die über $24 \mathrm{~h}$ integrierte Abnahme des systolischen Blutdruckes betrug -11,5 (Median) (-452,1 - 157,6) $\mathrm{mm} \mathrm{Hg} \cdot \mathrm{h}$. Weder die maximale Reduktion des systolischen Ruheblutdruckes noch die über $24 \mathrm{~h}$ integrierte Reduktion des systolischen Blutdruckes korrelierten mit Geschlecht, Alter, Körpergröße und Körpergewicht.

\subsubsection{Blutdruck unter Belastung}

Vor der Carvedilol- Medikation wurde eine Last bei den Probanden ermittelt, unter der der systolische Blutdruck 160 mm Hg betrug 137 (2,5 - 427) Watt. Nach Einnahme von 25 mg Carvedilol wurde die maximale Blutdruckreduktion bei dieser Last ermittelt. Diese lag bei 24,7 (Median) (-72 - 0) mm Hg. Folglich wurde der systolische Belastungsblutdruck im Vergleich zur Vormedikation um ca. 15\% reduziert. Die über $24 \mathrm{~h}$ integrierte mediane systolische Belastungs-Blutdruck-Reduktion nach Medikation betrug -375 (-1332 - 1395) $\mathrm{mm} \mathrm{Hg} \cdot \mathrm{h}$. Diese maximalen und über $24 \mathrm{~h}$ integrierten Carvedilol-Effekte auf den Belastungs-Blutdruck wiesen keine Korrelation zum Geschlecht, Alter, Körpergröße und Körpergewicht auf.

\subsection{Herzfrequenz- und Blutdruck-Wirkungen von Carvedilol in der Ergometrie in Relation zum CYP2D6-Genotyp}

In den folgenden zwei Kapiteln sollen die Ergebnisse der Herzfrequenz- und BlutdruckWirkungen von Carvedilol in der Ergometrie in Abhängigkeit vom CYP2D6-Genotyp dargestellt werden. 
Ergebnisse

\subsubsection{Herzfrequenz-Wirkungen von Carvedilol in Relation zum CYP2D6- Genotyp}

Eine Korrelation zum CYP2D6-Genotyp konnte weder bei der maximalen und bei der über 24

$\mathrm{h}$ integrierten Reduktion der Ruhe-Herzfrequenz, noch bei der maximalen und bei der über 24 $\mathrm{h}$ integrierten Reduktion der Belastungs-Herzfrequenz gesehen werden. Da es für meine Studie von zentralem Interesse ist, ob der CYP2D6-Genotyp einen Einfluss auf CarvedilolWirkungen hat, werden diese negativen Ergebnisse im Folgenden detaillierter dargestellt und erläutert.

Der Einfluss vom CYP2D6-Genotyp auf die maximale Reduktion der Ruhe- und BelastungsHerzfrequenz sowie auf die über $24 \mathrm{~h}$ integrierte Reduktion der Ruhe- und BelastungsHerzfrequenz ist in den folgenden Boxplots (Abb. 3.8) dargestellt. Es konnte zwischen dem CYP2D6-Genotyp und den oben erwähnten Parametern keine signifikanten Unterschiede im Jonckheere-Terpstra-Trend-Test gesehen werden. 
Ergebnisse
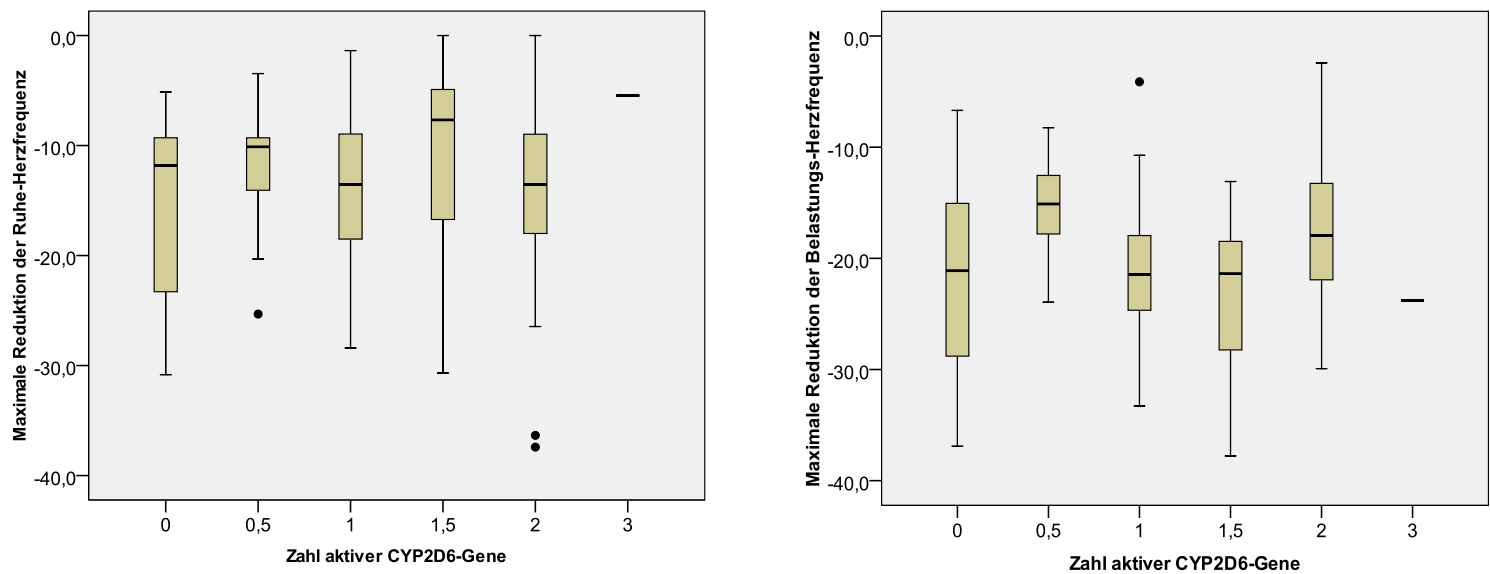

Abb. 10 a Zusammenhang zwischen maximaler Abb. 10 c Zusammenhang zwischen maximaler Reduktion der Ruhe-Herzfrequenz (in 1/min) und Reduktion der Belastungs-Herzfrequenz (in 1/min) CYP2D6-Genotyp (Schwarz ausgefüllte Kreise stellen und CYP2D6-Genotyp (Schwarz ausgefüllter Kreis Ausreißer dar). stellt Ausreißer dar).
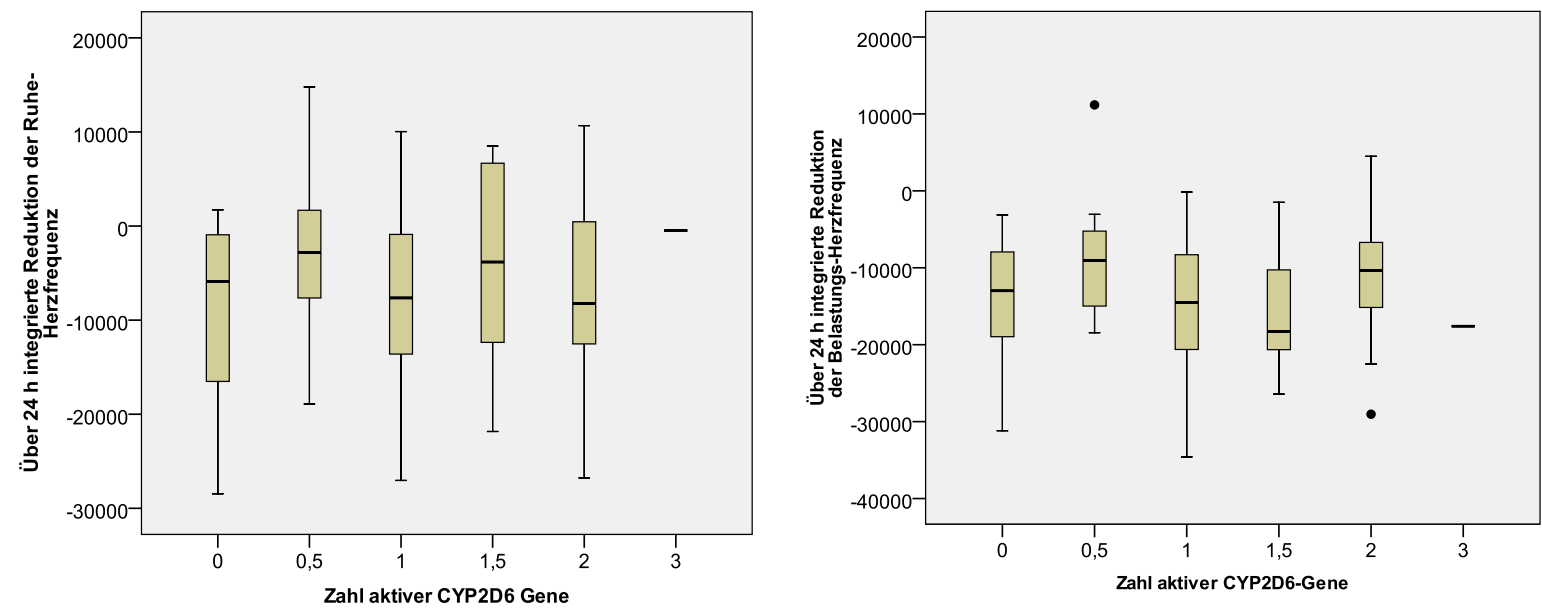

Abb. 10 b Zusammenhang zwischen CYP2D6- Abb. 10 d Zusammenhang zwischen CYP2D6Genotyp und über $24 \mathrm{~h}$ integrierten Reduktion der Genotyp und über $24 \mathrm{~h}$ integrierten Reduktion der Ruhe-Herzfrequenz (in 1/24 h).

Belastungsherzfrequenz (in $1 / 24$ h) (Schwarz ausgefüllte Kreise stellen Ausreißer dar).

Auch in den Mittelwerten der oben erwähnten Parameter konnten im Jonckheere-TerpstraTrend-Test in Relation zum CYP2D6-Genotyp keine signifikanten Unterschiede gesehen werden (Tab. 39). 
Ergebnisse

Tab. 39 Carvedilol-Wirkung auf die Herzfrequenz-Parameter in Relation zum CYP2D6-Genotyp

\begin{tabular}{|c|c|c|c|c|c|c|}
\hline \multicolumn{7}{|c|}{ Anzahl aktiver CYP2D6 Gene* } \\
\hline \multirow[b]{2}{*}{ Parameter } & 0 & 0.5 & 1 & 1.5 & 2 & 3 \\
\hline & \multicolumn{5}{|c|}{$\begin{array}{c}\text { Mittelwert } \\
\text { Minimum - Maximum }\end{array}$} & \multirow[b]{2}{*}{$-5,46$} \\
\hline $\begin{array}{l}\text { Max. Reduktion der } \\
\text { Ruhe-Herzfrequenz }\end{array}$ & $\begin{array}{c}-15,9 \\
-30,8--5,1\end{array}$ & $\begin{array}{c}-11,9 \\
-25,3--3,5\end{array}$ & $\begin{array}{c}-13,7 \\
-28,4--1,4\end{array}$ & $\begin{array}{c}-12,0 \\
-30,7-0\end{array}$ & $\begin{array}{c}-14,3 \\
-37,4-0\end{array}$ & \\
\hline $\begin{array}{l}\text { Int. Reduktion der } \\
\text { Ruhe-Herzfrequenz }\end{array}$ & $\begin{array}{c}-9618 \\
-28458-1725\end{array}$ & $\begin{array}{c}-2528 \\
-18905-14790\end{array}$ & $\begin{array}{c}-7542 \\
-27038-10041\end{array}$ & $\begin{array}{c}-4541 \\
-21836-8495\end{array}$ & $\begin{array}{c}-8045 \\
-26770-10672\end{array}$ & -483 \\
\hline $\begin{array}{l}\text { Max. Reduktion der } \\
\text { Belastungs- } \\
\text { Herzfrequenz }\end{array}$ & $\begin{array}{c}-21,6 \\
-36,9--6,7\end{array}$ & $\begin{array}{c}-15,5 \\
-23,9--8,2\end{array}$ & $\begin{array}{c}-21,1 \\
-33,3--4,1\end{array}$ & $\begin{array}{c}-22,8 \\
-37,8--13,1\end{array}$ & $\begin{array}{c}-17,4 \\
-29,9--2,4\end{array}$ & $-23,8$ \\
\hline $\begin{array}{l}\text { Int. Reduktion der } \\
\text { Belastungs- } \\
\text { Herzfrequenz }\end{array}$ & $\begin{array}{c}-14465 \\
-31185--3122\end{array}$ & $\begin{array}{c}-8685 \\
-18440-11169\end{array}$ & $\begin{array}{c}-14787 \\
-34581--159\end{array}$ & $\begin{array}{c}-16311 \\
-26425--1490\end{array}$ & $\begin{array}{c}-10502 \\
-29035-4491\end{array}$ & -17590 \\
\hline \multicolumn{7}{|c|}{$\begin{array}{l}\text { Int. (integrierte) Reduktion der Ruhe- und Belastungsherzfrequenz (angegeben in } 1 / 24 \mathrm{~h} \text { ); Max. (maximale) } \\
\text { Reduktion der Ruhe- und Belastungsherzfrequenz (angegeben in } 1 / \mathrm{min} \text { ). *Die Gendosis wurde als Rangzahl } \\
\text { in der Reihenfolge steigender Zahlen mit steigender Aktivität angegeben, wie sie aus vielen anderen } \\
\text { Medikamenten gut etabliert ist. Bei allen beobachteten Parametern konnten im Jonckeere-Terpstra-Trend-Test } \\
\text { keine Signifikanzen gesehen werden (P-Werte nicht dargestellt). }\end{array}$} \\
\hline
\end{tabular}

\subsubsection{Blutdruck-Wirkungen von Carvedilol in Relation zum CYP2D6- Genotyp}

In Relation zum CYP2D6-Genotyp konnten keine Unterschiede sowohl in der maximalen und in der über $24 \mathrm{~h}$ integrierten systolischen Ruhe-Blutdruck-Reduktion als auch in der maximalen und in der über $24 \mathrm{~h}$ integrierten systolischen Belastungs-Blutdruck-Reduktion nachgewiesen werden.

Der Einfluss von CYP2D6 auf die maximale Reduktion des systolischen Ruhe- und Belastungs-Blutdruckes, sowie auf die über $24 \mathrm{~h}$ integrierte Reduktion des systolischen Ruheund Belastungs-Blutdruckes ist in den folgenden Boxplots (Abb. 11) dargestellt. Es konnten zwischen dem CYP2D6-Genotyp und den oben erwähnten Parametern keine signifikanten Unterschiede im Jonckheere-Terpstra-Trend-Test gesehen werden. 
Ergebnisse
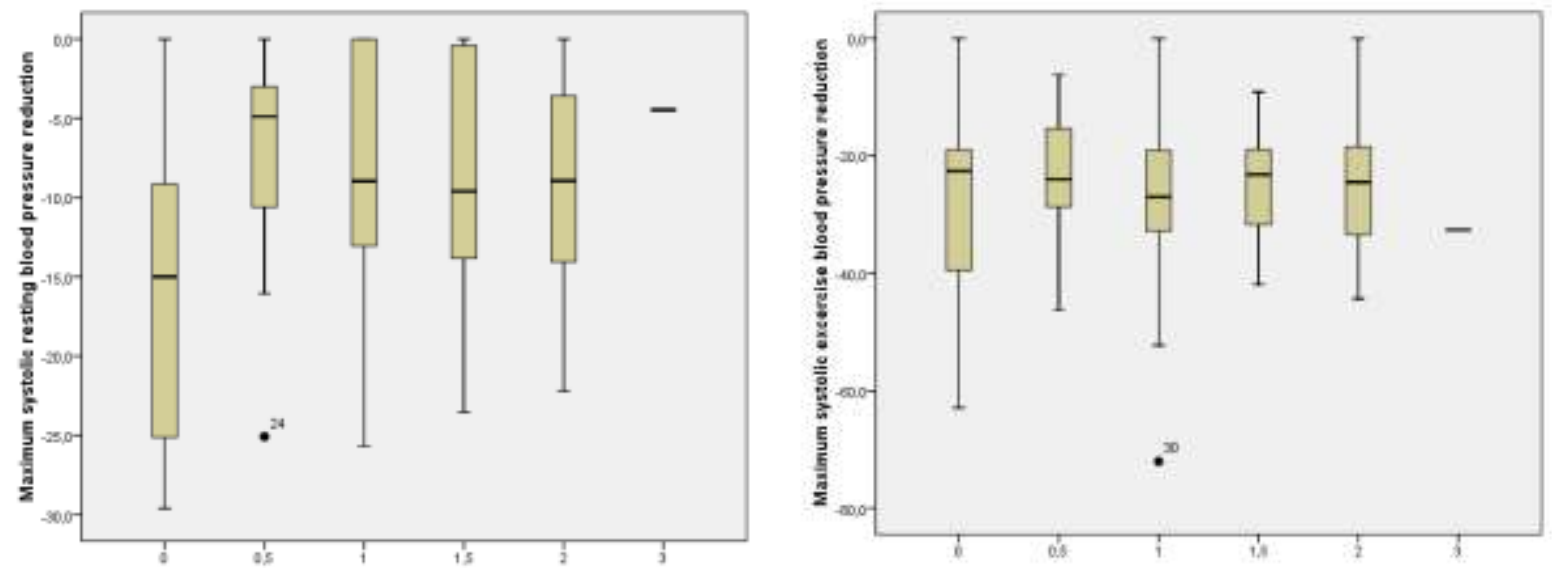

Abb. 11 a Zusammenhang zwischen maximaler Abb. 11 c Zusammenhang zwischen maximaler Reduktion des systolischen Ruhe-Blutdruckes (in mm Reduktion des systolischen Belastungs-Blutdruckes $\mathrm{Hg}$ ) und CYP2D6-Genotyp (Schwarz ausgefüllter (in $\mathrm{mm} \mathrm{Hg}$ ) und CYP2D6-Genotyp (Schwarz Kreis mit Nummerierung (Probandencode) stellt ausgefüllter Kreis mit Nummerierung Ausreißer dar).

(Probandencode) stellt Ausreißer dar).
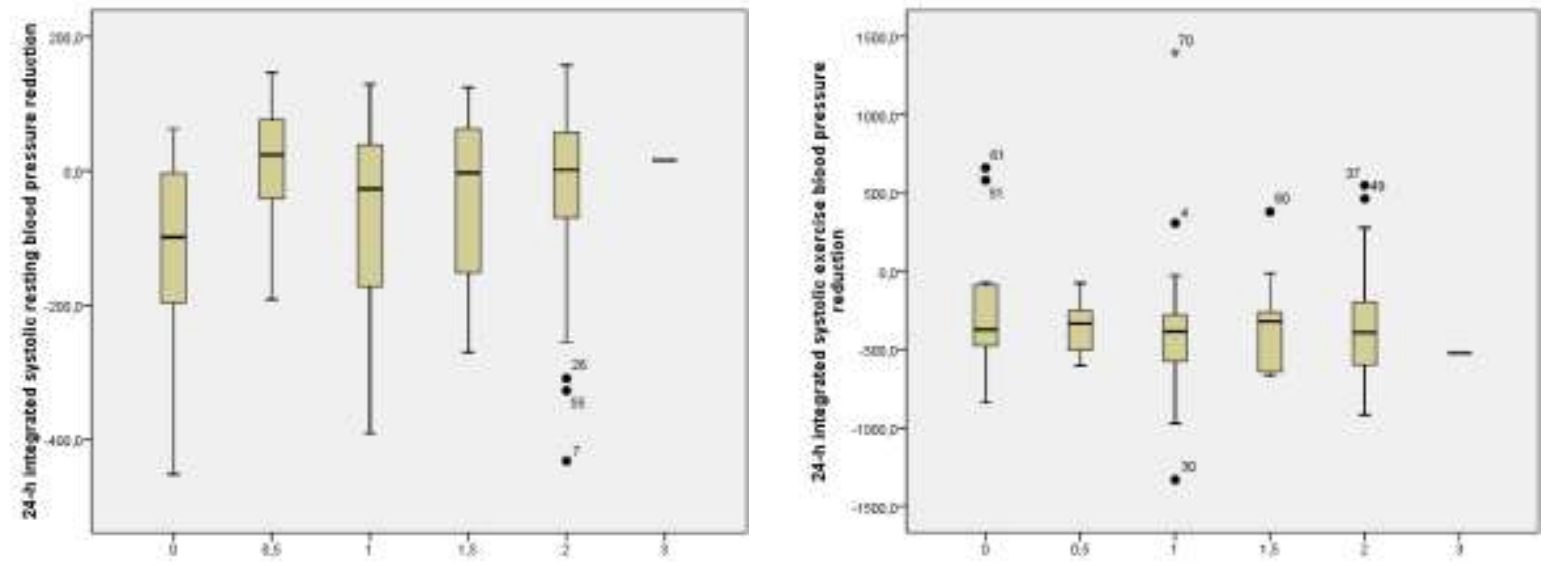

Abb. 11 b Zusammenhang zwischen CYP2D6- Abb. 11 d Zusammenhang zwischen CYP2D6Genotyp und über $24 \mathrm{~h}$ integrierten Reduktion des Genotyp und über $24 \mathrm{~h}$ integrierten Reduktion des systolischen Ruhe-Blutdruckes (in $\mathrm{mm} \mathrm{Hg} \cdot \mathrm{h}$ ) systolischen Belastungs-Blutdruckes (in $\mathrm{mm} \mathrm{Hg} \cdot \mathrm{h}$ ) (Schwarz ausgefüllte Kreise stellen mit Nummerierung (Schwarz ausgefüllten Kreise mit Nummerierung (Probandencode) Ausreißer dar).

(Probandencode) stellen Ausreißer dar).

Auch in den Mittelwerten der oben erwähnten Parameter konnten im Jonckheere-TerpstraTrend-Test in Relation zum CYP2D6-Genotyp keine signifikanten Unterschiede gesehen werden (Tab. 40). 
Ergebnisse

Tab. 40 Carvedilol-Wirkung auf die systolischen Blutdruck-Parameter in Relation zum CYP2D6-Genotyp

\begin{tabular}{|c|c|c|c|c|c|c|}
\hline \multirow[b]{3}{*}{ Parameter } & \multicolumn{5}{|c|}{ Anzahl aktiver CYP2D6-Gene* } & \multirow{3}{*}{3} \\
\hline & 0 & 0.5 & 1 & 1.5 & 2 & \\
\hline & \multicolumn{5}{|c|}{$\begin{array}{c}\text { Mittelwert } \\
\text { Minimum - Maximum }\end{array}$} & \\
\hline $\begin{array}{l}\text { Max. Reduktion des } \\
\text { sys. Ruhe- } \\
\text { Blutdruckes }\end{array}$ & $\begin{array}{c}-16,1 \\
-29,6-0\end{array}$ & $\begin{array}{c}-7,52 \\
-25,1-0\end{array}$ & $\begin{array}{c}-8,93 \\
-25,7-0\end{array}$ & $\begin{array}{c}-9,14 \\
-23,5-0\end{array}$ & $\begin{array}{c}-9,02 \\
-22,2-0\end{array}$ & $-4,46$ \\
\hline $\begin{array}{l}\text { Int. Reduktion des } \\
\text { sys. Ruhe- } \\
\text { Blutdruckes }\end{array}$ & $\begin{array}{c}-121 \\
-452-62,7\end{array}$ & $\begin{array}{c}6,37 \\
-192-146\end{array}$ & $\begin{array}{c}-69,0 \\
-391-129\end{array}$ & $\begin{array}{c}-27,2 \\
-270-124\end{array}$ & $\begin{array}{c}-32,8 \\
-432-158\end{array}$ & 15,7 \\
\hline $\begin{array}{l}\text { Max. Reduktion des } \\
\text { sys. Belastungs- } \\
\text { Blutdruckes }\end{array}$ & $\begin{array}{c}-27,1 \\
-62,9-0\end{array}$ & $\begin{array}{c}-23,9 \\
-46,3--6,2\end{array}$ & $\begin{array}{c}-27,3 \\
-72,0-0\end{array}$ & $\begin{array}{c}-24,7 \\
-41,9--9,1\end{array}$ & $\begin{array}{c}-24,8 \\
-44,3-0\end{array}$ & $-32,6$ \\
\hline $\begin{array}{l}\text { Int. Reduktion des } \\
\text { sys. Belastungs- } \\
\text { Blutdruckes }\end{array}$ & $\begin{array}{c}-242 \\
-835-661\end{array}$ & $\begin{array}{c}-360 \\
-604--75,6\end{array}$ & $\begin{array}{c}-370 \\
-1332-1395\end{array}$ & $\begin{array}{c}-353 \\
-667-381\end{array}$ & $\begin{array}{c}-341 \\
-916-549\end{array}$ & -522 \\
\hline
\end{tabular}

Int. (integrierte) Reduktion des sys. (systolischen) Ruhe- und Belastungs-Blutdruckes (angegeben in $\mathrm{mm} \mathrm{Hg} \cdot$ h); Max. (maximale) Reduktion des sys. (systolischen) Ruhe- und Belastungs-Blutdruckes (angegeben in mm $\mathrm{Hg}$ ). Die Gendosis wurde als Rangzahl in der Reihenfolge steigender Zahlen mit steigender Aktivität angegeben, wie sie aus vielen anderen Medikamenten gut etabliert ist. Bei allen beobachteten Parametern konnten im Jonckeere-Terpstra-Trend-Test keine Signifikanzen gesehen werden (P-Werte nicht dargestellt).

\subsection{Wirkungen von Carvedilol auf Herzfrequenz und Blutdruck im Schellong-Test in Relation zum CYP2D6-Genotyp}

Neben der Ergometrie wurde die Wirkung von Carvedilol mittels Schellong-Tests untersucht. Am Baseline-Tag wurden 2 Schellong-Tests durchgeführt, am 1. Studientag wurden nach 3, 6 und $9 \mathrm{~h}$ nach der Carvedilol-Applikation Schellong-Tests durchgeführt. Die nach der Carvedilol-Applikation durchgeführten Schellong-Tests wurden mit dem 1. Schellong-Test des Baseline-Tages verglichen. In den folgenden 3 Kapiteln werden die 3 Parameter (Herzfrequenz, systolischer sowie diastolischer Blutdruck) im Liegen und Stehen in Abhängigkeit vom CYP2D6-Genotyp betrachtet.

\subsubsection{Herzfrequenz im Liegen und Stehen in Relation zum CYP2D6- Genotyp}

In der Tab. 41 sind die Mediane und Interquartilbereiche der Herzfrequenzen im Liegen und Stehen aller Probanden dargestellt. Nach 3 Stunden nach der Carvedilol-Applikation lag die mediane Herzfrequenzreduktion bei -7/min im Liegen und -13/min im Stehen. 
Ergebnisse

Tab. 41 Herzfrequenz im Liegen und Stehen

\begin{tabular}{llcc}
\hline Parameter & Einheit & Median & Interquartilbereich \\
\hline Herzfrequenz im Liegen & & & $55-70$ \\
Baseline & $1 /$ min & 61 & $48-58$ \\
3 h nach Carvedilol & & 53 & $58-72$ \\
6 h nach Carvedilol & & 63 & $56-69$ \\
9 h nach Carvedilol & & 62 & $75-90$ \\
\hline Herzfrequenz im Stehen & $1 /$ min & 82 & $64-77$ \\
Baseline & & 69 & $75-89$ \\
3 h nach Carvedilol & & 83 & $73-87$ \\
6 h nach Carvedilol & & 79 & \\
9 h nach Carvedilol & & & \\
\hline
\end{tabular}

Dargestellt sind die Mediane und Interquartilbereiche der Herzfrequenzen im Liegen und Stehen. h, Stunde; min, Minute.

Die Beziehung der Parameter Herzfrequenz im Liegen und Stehen zum CYP2D6-Genotyp wird in der Tab. 42 gezeigt. Neun Stunden nach der Carvedilol-Applikation wird in der Herzfrequenz im Liegen in Relation zum CYP2D6-Genotyp eine Signifikanz gesehen ( $\mathrm{p}=$ 0,048, JTTT). Aufgrund der Tatsache, dass sich keine eindeutige Tendenz in dem Verlauf der medianen Herzfrequenzen $9 \mathrm{~h}$ nach der Carvedilol-Applikation im Liegen erkennen lässt, wird die oben geschilderte Signifikanz nicht überbewertet. 
Ergebnisse

Tab. 42 Herzfrequenz im Liegen und Stehen in Relation zum CYP2D6-Genotyp

\begin{tabular}{|c|c|c|c|c|c|c|c|}
\hline & \multicolumn{6}{|c|}{ Anzahl aktiver CYP2D6-Gene* } & \multirow[t]{2}{*}{$\mathrm{P} * *$} \\
\hline & 0 & 0,5 & 1 & 1,5 & 2 & 3 & \\
\hline Parameter & \multicolumn{6}{|c|}{$\begin{array}{l}\text { Median } \\
\text { Interquartilbereich }\left(\mathrm{Q}_{1}-\mathrm{Q}_{3}\right)\end{array}$} & \\
\hline \multicolumn{8}{|l|}{$\begin{array}{l}\text { Herzfrequenz im } \\
\text { Liegen }(1 / \mathrm{min})\end{array}$} \\
\hline \multirow[t]{2}{*}{ Baseline } & 71 & 58 & 63 & 58 & 60 & 63 & n. s. \\
\hline & $60-75$ & $47-65$ & $55-70$ & $54-67$ & $55-66$ & & \\
\hline \multirow[t]{2}{*}{$3 \mathrm{~h}$ nach Carvedilol } & 56 & 50 & 54 & 52 & 52 & 60 & n. s. \\
\hline & $51-66$ & $46-56$ & $47-59$ & $49-57$ & $46-58$ & & \\
\hline \multirow[t]{2}{*}{$6 \mathrm{~h}$ nach Carvedilol } & 70 & 61 & 64 & 61 & 62 & 72 & n. s. \\
\hline & $63-75$ & $53-73$ & $58-74$ & $57-69$ & $57-68$ & & \\
\hline \multirow[t]{2}{*}{$9 \mathrm{~h}$ nach Carvedilol } & 66 & 58 & 65 & 61 & 58 & 67 & 0,048 \\
\hline & $59-71$ & $53-69$ & $57-72$ & $57-66$ & $54-65$ & & \\
\hline \multicolumn{8}{|l|}{$\begin{array}{l}\text { Herzfrequenz im } \\
\text { Stehen }(1 / \mathrm{min})\end{array}$} \\
\hline \multirow[t]{2}{*}{ Baseline } & 85 & 81 & 83 & 84 & 81 & 75 & n. s. \\
\hline & $79-91$ & $65-85$ & $75-95$ & $73-91$ & $75-89$ & & \\
\hline \multirow[t]{2}{*}{$3 \mathrm{~h}$ nach Carvedilol } & 68 & 74 & 71 & 67 & 68 & 76 & n. s. \\
\hline & $65-80$ & $58-82$ & $65-80$ & $64-72$ & $62-72$ & & \\
\hline \multirow[t]{2}{*}{$6 \mathrm{~h}$ nach Carvedilol } & 85 & 82 & 86 & 77 & 83 & 91 & n. s. \\
\hline & $83-88$ & $71-89$ & $77-97$ & $71-82$ & $74-87$ & & \\
\hline \multirow[t]{2}{*}{9 h nach Carvedilol } & 78 & 78 & 87 & 75 & 78 & 85 & n. s. \\
\hline & $73-82$ & $72-96$ & $79-92$ & $71-80$ & $70-84$ & & \\
\hline
\end{tabular}

Für alle Parameter sind die Mediane und die Interquartilbereiche dargestellt. * Die Gendosis wurde als Rangzahl in der Reihenfolge steigender Zahlen mit steigender Aktivität angegeben, wie sie aus vielen anderen Medikamenten gut etabliert ist. ** P, P-Wert. Der P-wert wurde mittels des nichtparametrischen JonckheereTerpstra-Trend-Tests bestimmt, P-Werte > 0,05 wurden als nicht signifikant (n. s.) angegeben.

\subsubsection{Systolischer Blutdruck im Liegen und Stehen in Relation zum CYP2D6-Genotyp}

In der Tab. 43 sind die Mediane und Interquartilbereiche der systolischen Blutdrücke im Liegen und Stehen aller Probanden dargestellt. Nach 3 Stunden nach der CarvedilolApplikation lag die mediane Reduktion des systolischen Blutdruckes bei -7 mm Hg im Liegen und -13 mm Hg im Stehen. Die Beziehung der Parameter systolischer Blutdruck im Liegen und Stehen zum CYP2D6-Genotyp wird in der Tab. 44 gezeigt. Es wurden zwischen systolischem Blutdruck im Liegen und Stehen in Relation zum CYP2D6-Genotyp keine signifikanten Unterschiede gesehen. 
Ergebnisse

Tab. 43 Systolischer Blutdruck im Liegen und Stehen

\begin{tabular}{cccc}
\hline Parameter & Einheit & Median & Interquartilbereich \\
\hline Systolischer Blutdruck im Liegen & & & $107-119$ \\
Baseline & $\mathrm{mm} \mathrm{Hg}$ & 112 & $99-110$ \\
3 h nach Carvedilol & & 105 & $102-114$ \\
6 h nach Carvedilol & & 108 & $104-115$ \\
9 h nach Carvedilol & & 109 & $106-119$ \\
\hline Systolischer Blutdruck im Stehen & $\mathrm{mm} \mathrm{Hg}$ & 112 & $93-108$ \\
Baseline & & 99 & $95-112$ \\
3 h nach Carvedilol & & 102 & $100-113$ \\
6 h nach Carvedilol & & 105 & \\
9 h nach Carvedilol & & & \\
\hline
\end{tabular}

Dargestellt sind die Mediane und Interquartilbereiche der systolischen Blutdrücke im Liegen und Stehen. h, Stunde; min, Minute.

Tab. 44 Systolischer Blutdruck im Liegen und Stehen in Relation zum CYP2D6-Genotyp

\begin{tabular}{|c|c|c|c|c|c|c|c|}
\hline & \multicolumn{6}{|c|}{ Anzahl aktiver CYP2D6-Gene* } & \multirow[t]{2}{*}{$\mathrm{P}^{* *}$} \\
\hline & 0 & 0,5 & 1 & 1,5 & 2 & 3 & \\
\hline Parameter & & Interquartil & $\begin{array}{l}\text { Median } \\
\text { reich }\left(\mathrm{Q}_{1}-\right.\end{array}$ & $(\mathrm{mm} \mathrm{Hg})$ & & & \\
\hline $\begin{array}{l}\text { Systolischer } \\
\text { Blutdruck im Liegen }\end{array}$ & & & & & & & \\
\hline Baseline & $\begin{array}{c}116 \\
111-124\end{array}$ & $\begin{array}{c}115 \\
109-121\end{array}$ & $\begin{array}{c}111 \\
105-118\end{array}$ & $\begin{array}{c}110 \\
104-119\end{array}$ & $\begin{array}{c}114 \\
109-120\end{array}$ & 112 & n. s. \\
\hline $3 \mathrm{~h}$ nach Carvedilol & $\begin{array}{c}107 \\
100-119\end{array}$ & $\begin{array}{c}109 \\
102-110\end{array}$ & $\begin{array}{c}104 \\
100-115\end{array}$ & $\begin{array}{c}103 \\
98-108\end{array}$ & $\begin{array}{c}105 \\
98-110\end{array}$ & 113 & n. s. \\
\hline $6 \mathrm{~h}$ nach Carvedilol & $\begin{array}{c}113 \\
100-118\end{array}$ & $\begin{array}{c}112 \\
109-120\end{array}$ & $\begin{array}{c}107 \\
101-115\end{array}$ & $\begin{array}{c}106 \\
101-108\end{array}$ & $\begin{array}{c}109 \\
100-114\end{array}$ & 110 & n. s. \\
\hline $9 \mathrm{~h}$ nach Carvedilol & $\begin{array}{c}112 \\
104-124 \\
\end{array}$ & $\begin{array}{c}114 \\
109-119\end{array}$ & $\begin{array}{c}106 \\
102-113 \\
\end{array}$ & $\begin{array}{c}107 \\
102-113\end{array}$ & $\begin{array}{c}110 \\
104-117 \\
\end{array}$ & 114 & n. s. \\
\hline $\begin{array}{l}\text { Systolischer } \\
\text { Blutdruck im Stehen }\end{array}$ & & & & & & & \\
\hline Baseline & $\begin{array}{c}114 \\
109-119\end{array}$ & $\begin{array}{c}111 \\
108-120\end{array}$ & $\begin{array}{c}112 \\
103-117\end{array}$ & $\begin{array}{c}108 \\
104-112\end{array}$ & $\begin{array}{c}114 \\
107-121\end{array}$ & 120 & n. s. \\
\hline $3 \mathrm{~h}$ nach Carvedilol & $\begin{array}{c}103 \\
99-111\end{array}$ & $\begin{array}{c}104 \\
93-109\end{array}$ & $\begin{array}{c}99 \\
93-106\end{array}$ & $\begin{array}{c}95 \\
92-99\end{array}$ & $\begin{array}{c}99 \\
92-108\end{array}$ & 111 & n. s. \\
\hline $6 \mathrm{~h}$ nach Carvedilol & $\begin{array}{c}112 \\
98-123\end{array}$ & $\begin{array}{c}106 \\
98-115\end{array}$ & $\begin{array}{c}100 \\
93-107\end{array}$ & $\begin{array}{c}100 \\
94-107\end{array}$ & $\begin{array}{c}105 \\
96-112\end{array}$ & 109 & n. s. \\
\hline $9 \mathrm{~h}$ nach Carvedilol & $\begin{array}{c}114 \\
99-122\end{array}$ & $\begin{array}{c}110 \\
106-116\end{array}$ & $\begin{array}{c}104 \\
96-110\end{array}$ & $\begin{array}{c}105 \\
97-109\end{array}$ & $\begin{array}{c}104 \\
100-114\end{array}$ & 113 & n. s. \\
\hline
\end{tabular}

Für alle Parameter sind die Mediane und die Interquartilbereiche dargestellt. h, Stunde. * Die Gendosis wurde als Rangzahl in der Reihenfolge steigender Zahlen mit steigender Aktivität angegeben, wie sie aus vielen anderen Medikamenten gut etabliert ist. ** $\mathrm{P}, \mathrm{P}-\mathrm{Wert}$. Der P-wert wurde mittels des nichtparametrischen Jonckheere-Terpstra-Trend-Tests bestimmt, P-Werte > 0,05 wurden als nicht signifikant (n. s.) angegeben. 
Ergebnisse

\subsubsection{Diastolischer Blutdruck im Liegen und Stehen in Relation zum CYP2D6-Genotyp}

In der Tab. 45 sind die Mediane und Interquartilbereiche der diastolischen Blutdrücke im Liegen und Stehen aller Probanden dargestellt. Nach 6 Stunden nach der CarvedilolApplikation lag die mediane Reduktion des diastolischen Blutdruckes bei $-8 \mathrm{~mm} \mathrm{Hg}$ im Liegen und $-9 \mathrm{~mm} \mathrm{Hg}$ im Stehen.

Tab. 45 Diastolischer Blutdruck im Liegen und Stehen

\begin{tabular}{|c|c|c|c|}
\hline Parameter & Einheit & Median & Interquartilbereich \\
\hline \multicolumn{4}{|c|}{ Diastolischer Blutdruck im Liegen } \\
\hline Baseline & $\mathrm{mm} \mathrm{Hg}$ & 60 & $55-64$ \\
\hline $3 \mathrm{~h}$ nach Carvedilol & & 55 & $51-61$ \\
\hline $6 \mathrm{~h}$ nach Carvedilol & & 52 & $47-58$ \\
\hline 9 h nach Carvedilol & & 54 & $50-59$ \\
\hline \multicolumn{4}{|c|}{ Diastolischer Blutdruck im Stehen } \\
\hline Baseline & $\mathrm{mm} \mathrm{Hg}$ & 62 & $58-69$ \\
\hline 3 h nach Carvedilol & & 56 & $50-61$ \\
\hline $6 \mathrm{~h}$ nach Carvedilol & & 53 & $48-59$ \\
\hline $9 \mathrm{~h}$ nach Carvedilol & & 56 & $51-60$ \\
\hline
\end{tabular}

Dargestellt sind die Mediane und Interquartilbereiche der diastolischen Blutdrücke im Liegen und Stehen. h, Stunde; min, Minute.

Die Beziehung der Parameter diastolischer Blutdruck im Liegen und Stehen zum CYP2D6Genotyp wird in der Tab. 46 gezeigt. Im Verlauf der medianen diastolischen Blutdruckwerte im Stehen ist nach 6 Stunden nach der Carvedilol-Applikation in Abhängigkeit vom CYP2D6-Genotyp eine Signifikanz zu sehen $(\mathrm{p}=0,038$, im JTTT). Diese Signifikanz wird jedoch nicht überbewertet, denn mit steigender Genaktivität ist paradoxerweise tendenziell eher ein Abfall in den medianen diastolischen Blutdruckwerten (abgesehen von der Genaktivitäts-Gruppe 3 mit lediglich $\mathrm{n}=1$ ) zu erkennen, eine Zunahme der Blutdruckwerte mit steigender Genaktivität würde eher passen (siehe Diskussion). 
Ergebnisse

Tab. 46 Diastolischer Blutdruck im Liegen und Stehen in Relation zum CYP2D6-Genotyp

\begin{tabular}{|c|c|c|c|c|c|c|c|}
\hline & \multicolumn{6}{|c|}{ Anzahl aktiver CYP2D6-Gene* } & \multirow[t]{2}{*}{$\mathrm{P}^{* *}$} \\
\hline & 0 & 0,5 & 1 & 1,5 & 2 & 3 & \\
\hline Parameter & & Interquart & $\begin{array}{l}\text { Median } \\
\text { eich }\left(Q_{1}-\right.\end{array}$ & $(\mathrm{mm} \mathrm{Hg})$ & & & \\
\hline $\begin{array}{l}\text { Diastolischer } \\
\text { Blutdruck im Liegen }\end{array}$ & & & & & & & \\
\hline Baseline & $\begin{array}{c}63 \\
58-77\end{array}$ & $\begin{array}{c}58 \\
54-62\end{array}$ & $\begin{array}{c}60 \\
55-64\end{array}$ & $\begin{array}{c}59 \\
55-66\end{array}$ & $\begin{array}{c}59 \\
53-63\end{array}$ & 54 & n. s. \\
\hline $3 \mathrm{~h}$ nach Carvedilol & $\begin{array}{c}60 \\
57-67\end{array}$ & $\begin{array}{c}53 \\
50-61\end{array}$ & $\begin{array}{c}55 \\
52-62\end{array}$ & $\begin{array}{c}56 \\
50-61\end{array}$ & $\begin{array}{c}55 \\
50-61\end{array}$ & 54 & n. s. \\
\hline $6 \mathrm{~h}$ nach Carvedilol & $\begin{array}{c}57 \\
49-63\end{array}$ & $\begin{array}{c}53 \\
48-58\end{array}$ & $\begin{array}{c}52 \\
48-60\end{array}$ & $\begin{array}{c}53 \\
52-60\end{array}$ & $\begin{array}{c}49 \\
46-56\end{array}$ & 52 & n. s. \\
\hline 9 h nach Carvedilol & $\begin{array}{c}60 \\
54-74\end{array}$ & $\begin{array}{c}53 \\
50-63\end{array}$ & $\begin{array}{c}53 \\
50-58\end{array}$ & $\begin{array}{c}56 \\
50-59\end{array}$ & $\begin{array}{c}54 \\
49-60\end{array}$ & 46 & n. s. \\
\hline $\begin{array}{l}\text { Diastolischer } \\
\text { Blutdruck im Stehen }\end{array}$ & & & & & & & \\
\hline Baseline & $\begin{array}{c}69 \\
58-81\end{array}$ & $\begin{array}{c}61 \\
56-67\end{array}$ & $\begin{array}{c}62 \\
57-71\end{array}$ & $\begin{array}{c}62 \\
58-68\end{array}$ & $\begin{array}{c}62 \\
59-69\end{array}$ & 69 & n. s. \\
\hline $3 \mathrm{~h}$ nach Carvedilol & $\begin{array}{c}59 \\
57-66\end{array}$ & $\begin{array}{c}56 \\
44-60\end{array}$ & $\begin{array}{c}54 \\
48-62\end{array}$ & $\begin{array}{c}53 \\
50-59\end{array}$ & $\begin{array}{c}54 \\
50-60\end{array}$ & 56 & n. s. \\
\hline $6 \mathrm{~h}$ nach Carvedilol & $\begin{array}{c}57 \\
52-71\end{array}$ & $\begin{array}{c}53 \\
45-66\end{array}$ & $\begin{array}{c}52 \\
48-58\end{array}$ & $\begin{array}{c}54 \\
46-58\end{array}$ & $\begin{array}{c}53 \\
48-59\end{array}$ & 55 & 0,038 \\
\hline $9 \mathrm{~h}$ nach Carvedilol & $\begin{array}{c}61 \\
56-74\end{array}$ & $\begin{array}{c}55 \\
52-64\end{array}$ & $\begin{array}{c}54 \\
49-60\end{array}$ & $\begin{array}{c}53 \\
49-59\end{array}$ & $\begin{array}{c}57 \\
52-61\end{array}$ & 56 & n. s. \\
\hline
\end{tabular}

Für alle Parameter sind die Mediane und die Interquartilbereiche dargestellt. h, Stunde. * Die Gendosis wurde als Rangzahl in der Reihenfolge steigender Zahlen mit steigender Aktivität angegeben, wie sie aus vielen anderen Medikamenten gut etabliert ist. ** $\mathrm{P}, \mathrm{P}-\mathrm{Wert}$. Der P-wert wurde mittels des nichtparametrischen Jonckheere-Terpstra-Trend-Tests bestimmt, P-Werte > 0,05 wurden als nicht signifikant (n. s.) angegeben.

\subsection{Carvedilol-Wirkungen in Relation zum CYP2C9- und CYP2C19- Genotyp}

Die pharmakokinetischen Untersuchungen von Carvedilol in Relation zum CYP2C9- und CYP2C19-Genotyp zeigten keine wesentlichen relevanten Unterschiede. Entsprechend wurden keine signifikanten Unterschiede der Carvedilol-Wirkung in Ergometrie und Schellong-Tests in Abhängigkeit vom CYP2C9- sowie vom CYP2C19-Genotyp gesehen (Daten nicht dargestellt). 
Ergebnisse

\subsection{Nebenwirkungen in Relation zum CYP2D6-Genotyp}

Wie in Kap. 2.1.4 beschrieben, wurde der Fragebogen 1 mit den häufigsten Nebenwirkungen am Morgen, Mittag und Nachmittag des Baseline-Tags und am Morgen des 1. Studientages vor der Carvedilol-Applikation sowie 3, 6, 9, 24, 33 und 48 h nach der Carvedilol-Einnahme abgefragt. Zusätzlich mussten die Probanden am Baseline-Tag sowie an den 3 Studientagen den Fragebogen 2 (siehe Kap. 2.1.4) ausfüllen. Nach der Carvedilol-Applikation wurden bei den 110 Probanden keine ernsten Nebenwirkungen beobachtet. Nur Schwindel, Müdigkeit und Konzentrationsprobleme wurden im Vergleich zum Baseline-Tag unter Carvedilol häufiger beobachtet. Eine statistisch signifikante Abhängigkeit dieser letztgenannten Nebenwirkungen vom CYP2D6-Genotyp konnte aber nicht gesehen werden (Daten nicht dargestellt). 
Diskussion

\section{Diskussion}

In dieser klinischen Studie sollte geklärt werden, ob und inwiefern die genetische Variabilität in den Cytochrom-P450-Enzymen CYP2D6, CYP2C9 und CYP2C19 für die Pharmakokinetik und entsprechend für die Wirkung von Carvedilol relevant ist. Sowohl für R- als auch für S-Carvedilol konnten signifikante Unterschiede der Pharmakokinetik in Relation zum CYP2D6-Genotyp festgestellt werden. Hinsichtlich der Carvedilol-Metaboliten konnten lediglich bei beiden demethylierten Metaboliten und in geringem Umfang bei beiden 4-OH-Carvedilol-Metaboliten signifikante Unterschiede zwischen den CYP2D6-Genotypen gesehen werden. Im Gegensatz zum CYP2D6-Genotyp, konnten in der CarvedilolPharmakokinetik in Abhängigkeit vom CYP2C9-Genotyp keine signifikanten Unterschiede gesehen werden. Dagegen wies der Verlauf der medianen maximalen Plasmakonzentrationen des R-4`-OH-Metaboliten in Abhängigkeit vom CYP2C19-Genotyp gewisse signifikante Differenzen auf.

Zur Erfassung der Carvedilol-Wirkungen wurden die Herzfrequenz sowie der Blutdruck in Ruhe und unter Belastung sowohl in Ergometrien als auch in Schellong-Tests gemessen. Obwohl die Carvedilol-Pharmakokinetik bei den CYP2D6-Genotypen sehr unterschiedlich war, konnten wir keine wesentlich signifikanten Unterschiede in den Wirkungen zwischen den CYP2D6-Genotypen sehen. Ebenso gab es gewisse Unterschiede in der Pharmakokinetik zwischen den CYP2C19-Genotypen, aber wiederum keine Unterschiede in den Wirkungen zwischen den CYP2C19-Genotypen. 
Diskussion

\subsection{Carvedilol-Pharmakokinetik}

In den folgenden Kapiteln wird zunächst die Pharmakokinetik des Carvedilol und seiner Metaboliten in Relation zum CYP2D6-, CYP2C9- und CYP2C19-Genotyp diskutiert. Ab Kapitel 4.2 werden dann die pharmakokinetischen Ergebnisse zusammen mit den pharmakodynamischen Ergebnissen betrachtet und diskutiert.

\subsubsection{Pharmakokinetik der Carvedilol-Enantiomere in Relation zum CYP2D6-Genotyp}

Bereits in vorausgegangenen in-vitro- und in-vivo-Studien konnte die Beteiligung des CYP2D6-Enzyms am Carvedilol-Metabolismus gezeigt werden (Zhou und Wood 1995, Oldham und Clarke 1997, Giessmann et al. 2004, Honda et al. 2006; Takekuma et al. 2006). Da unser Probandenkollektiv bezüglich des CYP2D6-Genotyps 35 unterschiedliche Genotypen aufwies und diese Vielzahl der unterschiedlichen Genotypen statistisch nicht gut $\mathrm{zu}$ analysieren ist, erfolgte die bereits in Kapitel 3.2 genannte Zuordnung der Genvarianten zu den Gendosen. Einige für meine Diskussion relevante Studien sind in Tab. 47 zusammengestellt.

Tab. 47 Zusammenfassung der zitierten Studien zur Carvedilol-Pharmakokinetik bei Gesunden in Relation zum CYP2D6-Genotyp

\begin{tabular}{llllllll}
\hline $\mathbf{n}$ & Parameter & Dosis & $\begin{array}{l}\text { Einzel/ } \\
\text { Mehrfach }\end{array}$ & PM & IM & EM & Zitat \\
16 & $\mathrm{AUC}_{0-\infty}, \mathrm{Cl}, \mathrm{t}_{1 / 2}$ & $25 \mathrm{mg}$ & Einzel & 7 & & 9 & Zhou und Wood. 1995 \\
12 & $\mathrm{AUC}_{0-24}, \mathrm{Cl}$ & $12,5-25 \mathrm{mg}$ & Mehrfach & 6 & & 6 & Giessmann et al. 2004 \\
54 & $(\mathrm{Cl} / \mathrm{F}) / \mathrm{WT},(\mathrm{V} / \mathrm{F}) / \mathrm{WT}$ & $5-10 \mathrm{mg}$ & Einzel & & 12 & 42 & Honda et al. 2006 \\
110 & $\mathrm{AUC}_{0-\infty}, \mathrm{Cl} / \mathrm{F}, \mathrm{V} / \mathrm{F}$ & $25 \mathrm{mg}$ & Einzel & 13 & 46 & $51^{\mathrm{b}}$ & Vorliegende Studie \\
\hline
\end{tabular}

n, Probandenanzahl; $\mathrm{AUC}_{0-\infty}$, area under the curve vom Zeitpunkt 0 bis unendlich; $\mathrm{AUC}_{0-24}$, area under the curve vom Zeitpunkt 0 bis 24 Stunden; Cl/F, Clearance dividiert durch Bioverfügbarkeit; WT, Körpergewicht; V/F, Verteilungsvolumen dividiert durch Bioverfügbarkeit; $t_{1 / 2}$, Halbwertszeit; a Für 2 Tage 12,5 mg Carvedilol oral, dann weiter mit $25 \mathrm{mg}$ oral für 5 Tage; ${ }^{\mathrm{b}}$ Ein UM wurde in die EM-Gruppe eingeordnet.

Im Folgenden soll zunächst auf die beiden Enantiomere des Carvedilol eingegangen werden. In unserer Studie war die mediane $\mathrm{AUC}_{0-\infty}$ der Träger keines aktiven CYP2D6-Allels (PM) im Vergleich zu Trägern von 2 aktiven Allelen bei R-Carvedilol um das 3,6-fache und entsprechend bei S-Carvedilol um das 2-fache signifikant größer. Bei beiden Enantiomeren nahmen die AUCs mit steigender Anzahl aktiver CYP2D6-Gene ab. Zu ähnlichen 


\section{Diskussion}

Ergebnissen kamen auch Zhou und Wood (1995), die nach Applikation von 25 mg Carvedilol hinsichtlich des R-Carvedilol bei PM 2,6-fach größere AUCs als bei EM gemessen hatten. Bei S-Carvedilol waren die AUCs bei PM 1,4-fach größer als bei EMs (siehe Tab. 4.2). Im Gegensatz zu unserer Studie wurden die Probanden bei Zhou und Wood durch Debrisoquin phänotypisiert und nicht molekulargenetisch genotypisiert. Schlussfolgernd zeigen die AUCErgebnisse sowohl aus der Studie von Zhou und Wood (1995) als auch aus unserer Studie, dass das R-Carvedilol durch den CYP2D6-Polymorpismus stärker beeinflusst wird als das SCarvedilol. Auch Giessmann et al. (2004) konnten die stärkere Beeinflussung des RCarvedilol durch den CYP2D6-Polymorphismus im Vergleich zum S-Carvedilol demonstrieren. Da Giessmann et al. (2004) im Gegensatz zu Zhou und Wood (1995) sowie zu unserer Studie die $\mathrm{AUC}_{0-24}$ verwendet haben, sind die Werte nicht in der folgenden Tabelle dargestellt.

Tab. 48 Vergleich der AUCs aus der Studie von Zhou und Wood (1995) mit unserer Studie

\begin{tabular}{|c|c|c|c|c|c|c|}
\hline \multirow[b]{2}{*}{ Genaktivität } & \multirow[t]{2}{*}{$\mathbf{n}$} & \multirow{2}{*}{$\begin{array}{c}\text { AUC PM } \\
0 \\
\end{array}$} & \multicolumn{2}{|c|}{ AUC IM } & \multicolumn{2}{|c|}{ AUC EM } \\
\hline & & & 0,5 & 1 & 1,5 & $\geq 2$ \\
\hline \multicolumn{7}{|l|}{ R-Carvedilol } \\
\hline Zhou und Wood 1995 & 16 & 1006 & & & \multicolumn{2}{|c|}{392} \\
\hline Unsere Studie & 110 & 1376 & 567 & 605 & 453 & 386 \\
\hline \multicolumn{7}{|l|}{ S-Carvedilol } \\
\hline Zhou und Wood 1995 & 16 & 256 & & & \multicolumn{2}{|c|}{179} \\
\hline Unsere Studie & 110 & 301 & 164 & 213 & 265 & 158 \\
\hline
\end{tabular}

AUC (Einheit nmol $\cdot \mathrm{h} / \mathrm{L})$, area under the curve. n, Probandenanzahl.

Diese stärkere Beeinflussung des R-Carvedilol durch den CYP2D6-Polymorphismsus zeigen auch die folgenden Clearance-Ergebnisse. Wie auf Grund des rechnerischen Zusammenhangs $($ Clearance $=$ Dosis/AUC $)$ nicht anders zu erwarten, konnte in unserer Studie ein signifikanter Unterschied der oralen Clearances in Relation zum CYP2D6-Genotyp gesehen werden, wobei die oralen Clearances beider Enantiomere im Gegensatz zur medianen AUC mit steigender Anzahl aktiver CYP2D6-Allele zunahmen. Es konnte bereits durch Zhou und Wood (1995) gezeigt werden, dass die mittlere orale Clearance $(\mathrm{Cl} / \mathrm{F})$ des $\mathrm{R}$-Carvedilol bei PM mit $67 \%$ signifikant niedriger war als die bei EM und dass die mittlere orale Clearance des SCarvedilol bei PM zwar nicht signifikant, aber dennoch mit 27\% niedriger war als bei EMs. In unserer Studie konnten bei beiden Enantiomeren signifikante Unterschiede beim Vergleich der medianen oralen Clearances zwischen PM und Trägern von 2 aktiven CYP2D6-Allelen beobachtet werden. Wir konnten beim Vergleich der medianen oralen PM-Clearances mit den 


\section{Diskussion}

medianen oralen Clearances bei Trägern von zwei aktiven Genen zeigen, dass etwa $72 \%$ des R-Carvedilol und 48\% des S-Carvedilol von CYP2D6 metabolisiert wurde. Weiterhin konnte modellabhängig aus dem Vergleich zwischen Personen mit kompletter CYP2D6-Defizienz und Personen mit hoher CYP2D6-Aktivität (CYP2D6*1/*1, EM) berechnet werden, dass bei Trägern zweier aktiver CYP2D6-Allelen ca. 64\% des R-Carvedilol und lediglich 37\% des SCarvedilol über CYP2D6 eliminiert wurde. Die oben genannten Ergebnisse hinsichtlich der Clearance bestätigen die obige Annahme, dass das CYP2D6-Enzym den R-CarvedilolMetabolismus stärker beeinflusst als den von S-Carvedilol. Zweitens zeigen diese Ergebnisse, dass der Rest des R- und S-Carvedilol durch unbekannte Mechanismen CYP2D6-unabhängig eliminiert wird. Die Bedeutung der oben dargestellten Ergebnisse für die CYP2D6-abhängige Carvedilol-Pharmakodynamik wird im Kapitel 4.2.2 diskutiert.

Weiterhin wurde auch innerhalb eines gleichen CYP2D6-Genotyps eine große Streubreite der gemessenen Clearance-Werte beider Enantiomere gesehen (siehe Kap. 3.4 Abb. 6). Nur $35,7 \%$ der Variabilität der totalen Clearance bei R-Carvedilol sowie lediglich $15,3 \%$ der Variabilität der totalen Clearance bei S-Carvedilol konnte durch den CYP2D6-Genotyp erklärt werden. Zusätzlich konnte ein weiterer Teil der Streubreite in der Clearance durch die Abhängigkeit der Clearance und des Verteilungsvolumens vom Körpergewicht erklärt werden. Denn die Carvedilol-Dosis von $25 \mathrm{mg}$ wurde in unserer Studie allen Probanden gewichtsunabhängig verabreicht, somit bekamen alle Probanden die gleiche Dosis, wobei das mediane Körpergewicht der Probanden bei $72 \mathrm{~kg}$ mit einer Streuung von 52 bis $99 \mathrm{~kg}$ lag.

Bei den meisten Studien zu Carvedilol wurde Carvedilol oral verabreicht. Daher kann in diesen Studien nicht zwischen systemischer Clearance und Bioverfügbarkeit differenziert werden. Ein Teil der recht hohen Clearance ist nichts anderes als der First-pass-Effekt bzw. die fehlende Bioverfügbarkeit (Clearance nach oraler Gabe $=\mathrm{Cl} / \mathrm{F}$ ). Indirekt konnten wir durch Betrachten des Quotienten Verteilungsvolumen (V)/Bioverfügbarkeit (F) eine Aussage zur Bioverfügbarkeit machen. Sowohl in unserer als auch in der Studie von Honda et al. (2006) konnte beobachtet werden, dass mit steigender CYP2D6-Genaktivität der Quotient V/F zunahm. Da es unwarscheinlich ist, dass das Verteilungsvolumen sich genotyp-abhängig ändert, kann folglich gesagt werden, dass die Bioverfügbarkeit mit steigender Genaktivität, wohl bedingt durch gesteigerten First-pass-Metabolismus, abnimmt. Im Folgenden werden mögliche CYP2D6-unabhängige Mechanismen hinsichtlich des Carvedilol-Metabolismus diskutiert. 
Diskussion

CYP2D6-unabhängige Komponenten in der Carvedilol-Pharmakokinetik sollen EffluxProteine darstellen. Giessmann et al. (2004) konnten bereits zeigen, dass ein Teil des Carvedilol über Efflux-Transportproteine (P-Glykoprotein, MRP2 (multidrug resistanceassociated protein)) im Darm an der Resorption gehindert wird. Allerdings sollen auch weitere metabolisierende CYP-Enzyme (CYP1A2, CYP2E1, CYP3A4, CYP2C9, CYP2C19) (Oldham und Clarke 1995, Fachinformation Querto ${ }^{\circledR}$ 2009) und am Metabolismus beteiligte Glucuronosyltransferasen (Ohno et al. 2004; Takekuma et al. 2006) Einfluss auf den Carvedilol-Metabolismus haben. Weiterhin soll R-Carvedilol laut Arzneimittelfachinformation Querto ${ }^{\circledR}$ (2009) neben CYP2D6 überwiegend durch CYP1A2 metabolisiert werden, allerdings ist unklar, woher diese Information stammt. Zukünftige Studien sind daher nötig, um weitere Carvedilol metabolisierende Enzyme $\mathrm{zu}$ erforschen und den Zusammenhang zwischen den in unserer Studie wenig untersuchten Genvarianten wie z. B. CYP2D6-ultrarapid metabolizer und Carvedilol-Metabolismus zu klären.

\subsubsection{CYP2D6-Allel-spezifische Clearance}

Mit Hilfe von Modellanalysen konnten wir CYP2D6-Allel-spezifische Clearances bestimmen und mit diesen Aussagen zu bestimmten Genaktivitäten machen (siehe Kap. 3.4). Es ist bekannt, dass die CYP2D6*2-Variante sich zwar von der *1-Variante (Wildtyp) durch 2 Aminosäure-Substitutionen (Arginin296Cystein und Serin486Threonin) und weitere SNPs in der 5-Region unterscheidet, sie soll dennoch eine normale Aktivität aufweisen (www.cypalleles.ki.se/cyp2d6.htm). In unserer Studie war interessanterweise die Allelspezifische CYP2D6-Clearance der *2-Variante für beide Enantiomere signifikant kleiner als die der *1-Variante, obwohl beiden Genvarianten ähnliche Genaktivitäten zugeordnet worden waren (Steimer et al 2004; www.cypalleles.ki.se/cyp2d6.htm).

Eine zweite interessante Beobachtung aus unserer Studie betrifft die Genvarianten *17 und *41, die normalerweise der Gruppe der intermediate metabolizer zugerechnet werden. Die analysierten Clearances der *17- und *41-Genträger waren in unserer Studie bezüglich des RCarvedilol sehr klein und bezüglich des S-Carvedilol annähernd null. Somit entsprachen die Aktivitäten der $* 17$ - und $* 41$-Varianten in unserer Studie eher denen von poor metabolizern. Die oben erläuterten Ergebnisse für die Varianten *2, *17 sowie *41 sind zwar pharmakokinetisch interessant in unserer Studie aber nicht klinisch relevant, da in Relation zum CYP2D6-Genotyp in den Carvedilol-Wirkungen keine wesentlichen Unterschiede gesehen werden konnten. In weiteren Studien könnte geklärt werden, inweiweit diese 
Diskussion

geschilderten Ergebnisse Substrat-abhängig nur für Carvedilol gelten oder aber auch andere Medikamente betreffen.

\subsubsection{Pharmakokinetik der Carvedilol-Metaboliten in Relation zum CYP2D6-Genotyp}

Sowohl das R- als auch das S-Enantiomer sollen im Körper einerseits durch CYP-Enzyme in der Phase-I-Reaktion oxidiert (Oldham und Clarke 1997) und andererseits direkt ohne eine vorherige Phase-I-Reaktion durch UDP-Glucuronosyltransferasen in der Phase-II-Reaktion glucuronidiert und eliminiert werden (Ohno et al. 2004; Takekuma et al. 2006) (siehe auch hierzu Kap. 1.3.1.5). Weiter kann das Produkt eines CYP-Enzyms theoretisch als Substrat eines weiteren CYP-Enzyms fungieren und z. B 4`-OH-Desmethylcarvedilol entstehen. Einige der CYP-abhängigen Metabolisierungswege sind in der folgenden Abbildung dargestellt.

Abb. 12 Metabolisierungswege des Carvedilol

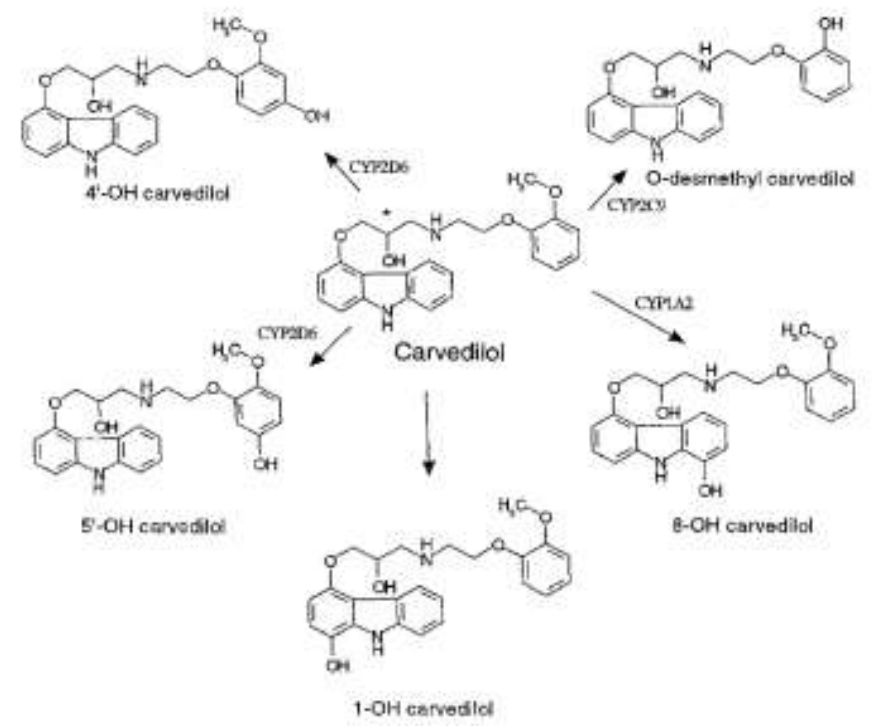

Entnommen aus Oldham und Clarke (1997), S. 971.

Unsere Studie zeigt, dass der CYP2D6-Polymorphismus die Blutkonzentrationen der beiden demethylierten und der 4`hydroxylierten Metaboliten signifikant beeinflusst. Träger inaktiver CYP2D6-Allele wiesen im Vergleich zu Trägern von 2 aktiven Allelen bei RDesmethylcarvedilol eine 4-fach erhöhte und beim S-Enantiomer eine 3-fach erhöhte mediane AUC auf, was jeweils als signifikant zu werten ist. Mit steigender Genaktivität des metabolisierenden CYP2D6-Enzyms nimmt folglich die mediane AUC der beiden demethylierten Metaboliten ab. Des Weiteren nimmt ebenfalls mit steigender Genaktivität die mediane maximale Plasmakonzentration beider demethylierten Metaboliten ab. Die oben genannten Ergebnisse deuten darauf hin, dass der R-Desmethylcarvedilol-Metabolismus 
Diskussion

stärker durch CYP2D6-Polymorphismen beeinflusst wird als der S-DesmethylcarvedilolMetabolismus. Zusätzlich kann man das Ergebnis auch so deuten, dass die R- und Sdemethylierten Metaboliten durch das CYP2D6 weiter metabolisiert werden, da mit steigender Genaktivität die AUC und $\mathrm{C}_{\max }$ der demethylierten Metaboliten abnimmt. Dagegen postulierten Oldham und Clarke (1997), dass das CYP2D6-Enzym neben der Bildung der hydroxylierten Metaboliten die Bildung der R- und S-demetylierten Metaboliten katalysiert.

Im Vergleich zur Muttersubstanz Carvedilol soll der 4`-OH-Metabolit eine 13-fach stärkere $\beta$ Rezeptor blockierende Aktivität besitzen (Tenero et al. 2000). In unserer Studie verhielt sich der Verlauf der medianen $\mathrm{C}_{\max }$ der 4`-OH-Metaboliten folgendermaßen: mit steigender CYP2D6-Genaktivität stieg die mediane maximale Blutkonzentration beider 4-OHMetaboliten an. Weiterhin war bei dem R-4`-OH-Metaboliten bei Trägern von 2 aktiven CYP2D6-Alellen die AUC 1,2-fach signifikant höher als bei PM. Wie schon durch Oldham und Clarke (1997) postuliert, stärken unsere Ergebnisse bezüglich des $4 `$ `OH-Metaboliten die Hypothese, dass 4`-OH-Carvedilol durch CYP2D6 gebildet wird.

\subsubsection{Pharmakokinetik von Carvedilol und seiner Metaboliten in Relation zum CYP2C9- und C19-Genotyp}

In der Publikation von Oldham und Clarke (1997), in der Carvedilol in vitro mit Lebermikrosomen inkubiert wurde, konnte eine Beteiligung des CYP2C9-Enzyms bei der Bildung der Desmethylderivate gesehen werden. In der vorliegenden Studie konnte kein signifikanter Unterschied der Carvedilol-Pharmakokinetik in Relation zum CYP2C9-Genotyp nachgewiesen werden. Dieses Ergebnis ist auch kongruent mit Giessmann et al. (2004), die ebenfalls keine signifikanten Veränderungen der pharmakokinetischen Parameter des Carvedilol zum CYP2C9-Genotyp darstellen konnten. Allerdings konnte mit einer Fallzahl von n=12 bei Giessmann et al. (2004) keinerlei endgültige Feststellung getroffen werden, während bei unserer Analyse an 110 Personen zu Pharmakokinetik und Wirkungen doch endgültiger eine Bedeutung von CYP2C9 für Carvedilol ausgeschlossen werden kann. Auch die Studie von Honda et al. (2006), mit Probanden mit den Genotypen CYP2C9*1/*1 und *1/*3, die keinerlei signifikanten Unterschied auf die Carvedilol-Pharmakokinetik zeigten, bestätigt unser Ergebnis.

Laut Arzneimittelfachinformation des Handelspräparates Querto® (2009) soll das CYP2C19Enzym ebenfalls den Carvedilol-Metabolismus beeinflussen. Es bleibt unklar, aus welcher Quelle diese Information einer Beteiligung von CYP2C19 an der Biotransformation von Carvedilol kommt. Unsere Ergebnisse zeigen keinen signifikanten Unterschied der 
Diskussion

Carvedilol-Pharmakokinetik in Abhängigkeit zum CYP2C19-Genotyp. Auch Honda et al. (2006) untersuchten die Carvedilol-Pharmakokinetik in Relation zum CYP2C19-Enzym und beobachteten keine signifikanten Abweichungen, wobei dort im Gegensatz zur vorliegenden Studie nicht das hochaktive *17-Allel sondern das in der Asiatischen Bevölkerung häufige *3-Allel untersucht wurde. Wir haben lediglich beim 4-OH-Metaboliten beobachtet, dass der $\mathrm{C}_{\max }$-Wert von R-4-OH mit steigender CYP2C19-Genaktivität abfiel. Dies mag ein Zufallsbefund sein, es ist aber auch denkbar, dass weitere sekundäre Metabolisierungsschritte von CYP2C19 abhängen.

\subsection{Pharmakodynamik}

Carvedilol gehört zu den $\beta$-Blockern der 3. Generation und ist ein nicht-selektiver $\beta$-Blocker, der sowohl $\beta_{1}$ - und $\beta_{2}$ - als auch $\alpha_{1}$-Rezeptoren blockiert (Tenero et al. 2000). Während die $\alpha_{1^{-}}$ Rezeptoren von beiden Carvedilol-Enantiomeren blockiert werden, ist für die $\beta$-Blockade lediglich das S-Enantiomer verantwortlich (Bartsch et al. 1990). Die Vasodilatation als Hauptwirkung der $\alpha_{1}$-Blockade führt zum Blutdruckabfall, die Hauptwirkung der $\beta_{1}$-Blockade ist die Herzfrequenssenkung (siehe Kap. 1.3.1.1). Das Verhältnis von $\alpha_{1}$ - zu $\beta$-RezeptorBlockade soll für Carvedilol 1:10 sein (Frishman 1998). Die aus der $\alpha_{1}$-Blockade resultierende Blutdrucksenkung soll im Gegensatz $\mathrm{zu}$ reinen $\alpha$-Blockern wegen der gleichzeitigen Blockade der $\beta_{1}$-Rezeptoren, die in den Pathomechanismus der Reflextachykardie involviert sind, weniger von einer Reflextachykardie begleitet sein (Estler 2000). In vielen klinischen Studien wie z. B in der COPERNICUS-, der COMET- und der CAPRICORNStudie wurde der Benefit des Carvedilol bei Patienten mit Herzerkrankungen gezeigt (Packer et al. 2001; Dargie 2001; Poole-Wilson et al. 2003). Im Folgenden sollen zunächst die Ergebnisse unserer Studie hinsichtlich der Carvedilol-Wirkung auf Herzfrequenz sowie systolischen Ruhe- und Belastungs-Blutdruck aus der Ergometrie und diastolischen Blutdruck aus den Schellong-Tests im Vergleich zur Literatur diskutiert werden. Danach soll die Carvedilol-Wirkung in Abhängigkeit von CYP2D6-, CYP2C9- und CYP2C19Polymorphismen dargestellt und diskutiert werden. 


\section{Diskussion}

\subsubsection{Pharmakodynamische Daten von Carvedilol im Vergleich zur Literatur}

Wie in 13 dargestellt, wies in unserer Studie die Ruhe-Herzfrequenz der gesunden Probanden schon vor der Carvedilol-Medikation (bei einer Carvedilol-Konzentration $=0$ ) eine hohe interindividuelle Variabilität auf (63 - 108/min). Diese Variabilität der Ruhe-Herzfrequenz kann durch Beeinflussung des vegetativen Nervensystems - dem Sympathikus und dem Vagus - erklärt werden. Einflussfaktoren auf das vegetative Nervensystem können einerseits äußere Faktoren wie Reize, Temperatur, Luftfeuchtigkeit und andererseits innere Faktoren wie psychische Verfassung und individuelle Leistungsfähigkeit sein. Während äußere Faktoren weitestgehend in unserer Studie vermieden werden sollten, konnten die inneren Faktoren weniger beeinflusst werden.

Abb. 13 Zusammenhang zwischen S-Carvedilol-Konzentration und Ruhe-Herzfrequenz

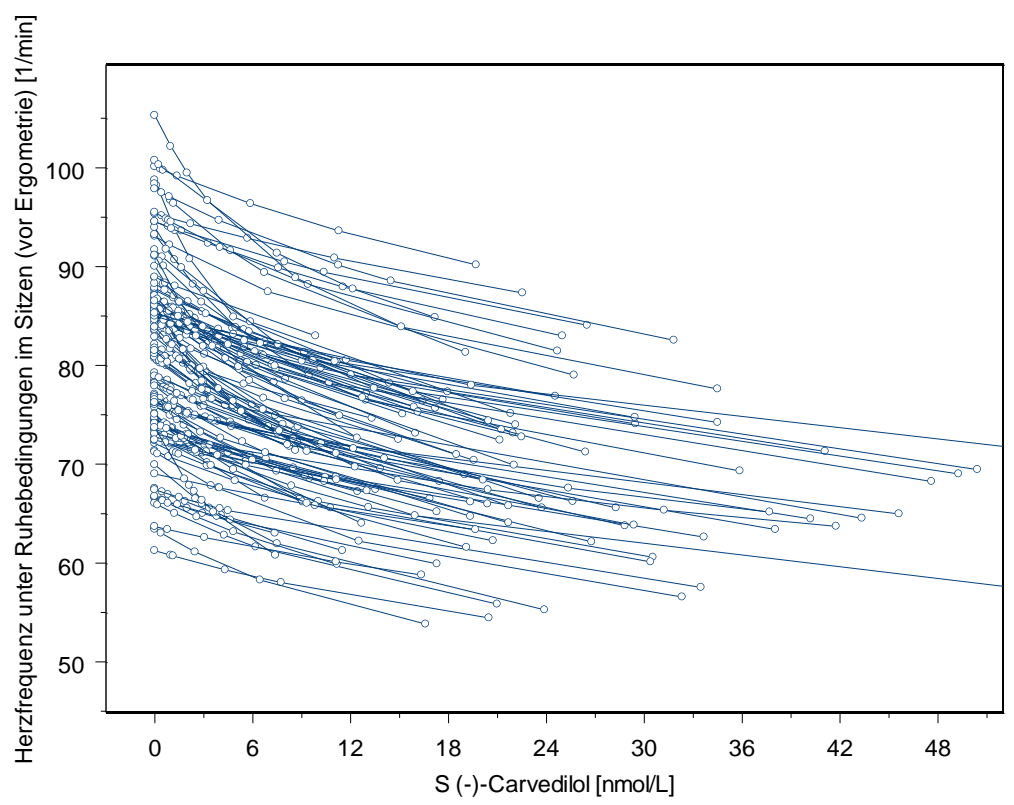

Einerseits sieht man die Herzfrequenzabnahme mit steigender S-Carvedilol-Konzentration, andererseits die interindividuelle Variabilität in der Herzfrequenz.

Die Differenz der medianen Ruhe-Herzfrequenz vor und nach der Carvedilol-Medikation betrug in unserer Studie -11,7/min, was einer Reduktion von ca. 14\% entspricht. Stoschitzky et al. (2001) kamen zu einem ähnlichen Ergebnis, die Differenz der Ruhe-Herzfrequenz mit und ohne Carvedilol betrug in ihrer Studie 13\%. Mit fallendem Körpergewicht konnte in unserer Studie eine Zunahme des Carvedilol-Effektes gesehen werden. Hierbei wurde pro 10 kg Gewichtsabnahme eine Zunahme der medianen Reduktion der Ruhe-Herzfrequenz um 2,5 Schläge/min gesehen (siehe Kap. 3.5.1). Da für die Wirkung eines Arzneistoffes seine 


\section{Diskussion}

Konzentration am Wirkort (Rezeptor) entscheidend ist und mit abnehmendem Körpergewicht die Konzentration am Wirkort steigt, könnte dies eine Erklärung für die Zunahme des Carvedilol-Effektes bei fallendem Gewicht sein.

In der Studie von Stoschitzky et al. (2001) wurden die Wirkungen klinisch empfohlener Dosen von Carvedilol (25, 50 und $100 \mathrm{mg}$ ) gegen Placebo in einer randomisierten, überkreuzten, placebokontrollierten Doppel-blind-Studie an 12 gesunden Männern verglichen. In deren Studie wurden Herzfrequenz und Blutdruck in Ruhe, in der letzten Minute der 10-minütigen Ergometrie und 15 min nach der Belastung gemessen (Stoschitzky et al. 2001). Es ist bekannt, dass die $\beta$-Blocker-Wirkung umso größer ist, je höher der Sympathikotonus ist (Estler 2000). Das heißt, die maximale Reduktion der BelastungsHerzfrequenz sollte größer sein als die maximale Reduktion der Ruhe-Herzfrequenz. In der klinischen Studie von Stoschitzky et al. (2001) wurde die Belastungs-Herzfrequenz unter 25 mg Carvedilol um ca. 16\% gesenkt. Im Vergleich dazu lag die maximale Reduktion der Belastungs-Herzfrequenz unter $25 \mathrm{mg}$ Carvedilol in unserer Studie bei ca. 14\%. Auch die Reduktion der maximalen Ruhe-Herzfrequenz unter Carvedilol lag in unserer Studie bei ca. 14\%. In absoluten Zahlen kam es in dieser vorliegenden Studie bei der maximalen Belastungs-Herzfrequenz unter Carvedilol zu einer Abnahme von -20/min und bei der maximalen Ruhe-Herzfrequenz unter Medikation zu einer Abnahme von -11,7/min.

Bei den Ergometrien wurden die systolischen Blutdruckwerte in Ruhe und unter Belastung normiert auf die Last $160 \mathrm{~mm} \mathrm{Hg}$-dargestellt und detaillierter untersucht. Der Ruhe-Blutdruck wurde nach der Carvedilol-Medikation in unserer Studie um 8\% gesenkt, im Vergleich dazu wurde dieser bei Stoschitzky et al. (2001) um 5\% gesenkt. Der systolische Blutdruck unter Belastung wurde nach der Carvedilol-Medikation in unserer Studie maximal um ca. 15\% gesenkt, während er bei Stoschitzky et al. (2001) nur um 7\% gesenkt wurde. In der folgenden Tabelle sind die oben dargestellten Ergebnisse zusammengestellt.

Tab. 49 Unterschiede in der Carvedilol-Pharmakodynamik

\begin{tabular}{lcc}
\hline & Stoschitzky et al. 2001 & Daten der vorliegenden Studie \\
\hline Herzfrequenz & Relative Reduktion in Prozent & Relative Reduktion in Prozent \\
Ruhe & 13 & 14 \\
Belastung & 16 & 14 \\
systolischer Blutdruck & Relative Reduktion in Prozent & Relative Reduktion in Prozent \\
Ruhe & 5 & 8 \\
Belastung & 7 & 15 \\
\hline
\end{tabular}




\section{Diskussion}

Die im Liegen gemessenen diastolischen Blutdruckwerte der Schellong-Tests unserer Studie wurden mit den diastolischen Ruhe-Blutdruckwerten der Studie von Baek et al. (2008) und Stoschitzky et al. (2001) verglichen. Bei Baek et al. (2008) wurde 32 gesunden männlichen Probanden einmalig $25 \mathrm{mg}$ Carvedilol verabreicht und neben pharmakokinetischen Messungen der Ruhe-Blutdruck gemessen. Der diastolische Ruhe-Blutdruck unter Carvedilol fiel im Vergleich zu den Blutdruckwerten ohne Carvedilol um 25,5\% (Baek et al. 2008). Bei Stoschitzky et al. (2001) (Studiendesign oben beschrieben) wurde der diastolische Blutdruck unter Carvedilol im Vergleich zu Placebo um ca. 2\% gesenkt. In unserer Studie wurde der mediane diastolische Ruhe-Blutdruck unter Carvedilol um ca. 13\% gesenkt.

Es ist unschwer zu erkennen, dass die Ergebnisse bezüglich der Senkung des diastolischen Ruhe-Blutdruckes unter Carvedilol zwischen Stoschitzky et al. (2001), Baek et al. (2008) und unserer Studie stark schwanken. Eine Erklärung für diese starke Schwankung könnten beispielsweise Unterschiede in der Messtechnik, im Instrumentarium sowie im Messzeitpunkt nach der Carvedilol-Applikation sein.

\subsubsection{Pharmakodynamische Daten in Relation zum CYP2D6-Genotyp}

Im Folgenden soll der Zusammenhang zwischen Carvedilol-Pharmakodynamik und CYP2D6Genotyp diskutiert werden. Am Ende dieses Kapitels wird kurz auf die Carvedilol-Wirkungen in Relation zu den 2 polymorphen Enzymen CYP2C9 und CYP2C19 eingegangen.

In vielen Studien, so auch bei uns, konnte gezeigt werden, dass die CarvedilolPharmakokinetik signifikant vom CYP2D6-Genotyp abhängig ist (Zhou und Wood 1995; Giessmann et al. 2004; Honda et al. 2006). Wir konnten jedoch keine signifikanten Unterschiede in Abhängigkeit vom CYP2D6-Genotyp in der Carvedilol-Pharmakodynamik sehen. Unser Ergebnis bezüglich der Carvedilol-Pharmakodynamik in Relation zum CYP2D6-Genotyp steht dem Studien-Ergebnis von Giessmann et al. (2004) entgegen. In der Studie von Giessmann et al. (2004) wurden bezüglich des CYP2D6-Enzyms jeweils 6 PM und 6 EM rekrutiert. Bei Giessmann et al. (2004) nahmen die Probanden für 2 Tage 12,5 mg Carvedilol und danach für weitere 5 Tage $25 \mathrm{mg}$ Carvedilol ein. Am Baseline-Tag war bei den 12 Probanden per Ergometrie die individuelle Last ermittelt worden, die zu einer Herzfrequenz von 150/min führte. Mit dieser ermittelten Last wurden dann am letzten Tag der Carvedilol-Einnahme die Probanden bei Giessman et al. (2004) 4 min lang belastet. Der 


\section{Diskussion}

systolische Blutdruck der PM war während der Carvedilol-Behandlung signifikant niedriger als der der EM (Giessmann et al. 2004).

Weiterhin stellten Zhou und Wood (1995) die Hypothese auf, dass der Blutdruck nach Carvedilol-Einnahme bei PM im Vergleich zu EM stärker sinken müsste. Diese Hypothese begründeten Zhou und Wood (1995) folgendermaßen: Sie beobachteten, dass die PM signifikant höhere Carvedilol-Plasmakonzentrationen aufwiesen als die EM (siehe Tab. 48). Dieser Unterschied in den Plasmakonzentrationen zwischen PM und EM war, wie in unserer Studie, für das R-Enantiomer größer als für das S-Enantiomer (siehe Kap. 4.1.1). Da das REnantiomer lediglich $\alpha_{1}$-Rezeptoren blockiert und somit über eine Vasodilatation zum Blutdruckabfall führt, wurde die oben genannte Hypothese aufgestellt, dass der Blutdruck bei PM im Vergleich zu EM stärker sinken müsste (Zhou und Wood 1995). Im Gegensatz zu dem Postulat von Zhou und Wood (1995) und zu den Studienergebnissen von Giessmann et al. (2004) stehen unsere Ergebnisse. Die Ergometrie-Auswertungen zeigen keine signifikante Abhängigkeit des systolischen Ruhe- und Belastungs-Blutdrucks vom CYP2D6-Genotyp. Darüber hinaus konnten wir auch keine signifikanten Unterschiede der Herzfrequenzen unter Ergometrie in Relation zum CYP2D6-Genotyp sehen. Nur in den Schellong-Test Auswertungen waren die Unterschiede der Parameter Herzfrequenz im Liegen $(9 \mathrm{~h}$ nach Carvedilol-Einnahme) und diastolischer Blutdruck im Stehen (6 h nach Carvedilol-Einnahme) in Relation zum CYP2D6-Genotyp signifikant. Allerdings sollten diese Ergebnisse nicht überbewertet werden, da beim Herzfrequenzverlauf keine eindeutige Tendenz zu erkennen ist und beim diastolischen Blutdruck entgegen der Ergebnisse vorangehender Studien der diastolische Blutdruck (6 h nach Carvedilol-Einnahme) tendenziell mit steigender Genaktivität abnimmt. Unsere Ergebnisse bezüglich der Carvedilol-Wirkung konnten wir folgendermaßen erklären:

Das Verhältnis der $\alpha_{1}$-Rezeptorblockade (bedingt durch das R- und S-Enantiomer) zur $\beta$ Rezeptorblockade (lediglich durch das S-Enantiomer bedingt) soll für Carvedilol 1:10 sein (Frishman 1998). Dieses könnte eine Erklärung dafür sein, dass zwar die R-Carvedilol Konzentration bei PM höher ist als bei EM (siehe Kap. 4.1.1), aber die Auswirkung auf den Blutdruck in Relation zum CYP2D6-Genotyp aufgrund des oben genannten Verhältnisses in unserer Studie nicht signifikant ist.

1. Wie schon erwähnt, soll laut vorangehender Studien das S-Carvedilol den Hauptanteil an der Carvedilol-Wirkung ausmachen. Der CYP2D6-Effekt auf die S-CarvedilolPharmakokinetik und folglich damit auch auf die Carvedilol-Wirkung schien in 
Diskussion

unserer Studie klein zu sein. Denn nur 15,3\% der Variabilität in der totalen Clearance und lediglich $37 \%$ der berechneten S-Carvedilol Clearance konnte durch das CYP2D6-Enzym erklärt werden.

2. Einige der Carvedilol-Metaboliten sollen im Vergleich zur Muttersubstanz Carvedilol $\beta$-Rezeptor blockierende Aktivitäten aufweisen. Dabei sollen der Desmethyl-Metabolit eine 2,5-fache und der 4-OH-Metabolit eine bis zu 13-fache $\beta$-Rezeptor blockierende Aktivität im Vergleich zu Carvedilol haben (Tenero et al. 2000). Mit steigender Genaktivität nehmen in unserer Studie einerseits die Carvedilol- und die Desmethylcarvedilol-Konzentrationen ab, andererseits nimmt gleichzeitig die Konzentration des 4-OH-Metaboliten mit steigender Genaktivität zu. Das bedeutet, dass ein Schnell-Metabolisierer (UM) zwar geringere Carvedilol-Konzentrationen aufweist und somit der $\beta$-blockierende Effekt abnehmen müsste, gleichzeitig aber die Konzentration des $4 ` \mathrm{OH}-$ Metaboliten, der 13-fach höhere $\beta$-blockierende Aktivität als Carvedilol hat, ansteigt. Dies könnte eine Erklärung dafür sein, dass man in Relation zum CYP2D6-Genotyp keine signifikanten Unterschiede in der Carvedilol-Wirkung sieht.

Schließlich sei noch zu erwähnen, dass in unserer Studie in der Carvedilol-Pharmakokinetik in Relation zum CYP2C9- und CYP2C19-Genotyp keine wesentlichen Unterschiede gesehen wurden, erwartungsgemäß wurden ebenfalls keine Unterschiede in der Wirkung in Relation zum CYP2C9- und CYP2C19-Genotyp beobachtet. 


\section{$5 \quad$ Zusammenfassung}

Die Substanz Carvedilol wird bei vielen kardiologischen Erkrankungen als Racemat aus 50\% R- und 50\% S-Carvedilol angewendet. Der Hauptanteil der Wirkung wird durch das SEnantiomer durch Blockade der $\alpha_{1^{-}}$und $\beta$-Rezeptoren erzielt, während das R-Enantiomer lediglich $\alpha_{1}$-Rezeptoren blockiert.

Die genetisch sehr variablen Cytochrom-P450-Enzyme 2D6, 2C9 sowie 2C19 sind am Stoffwechsel von mehr als $40 \%$ aller Medikamente beteiligt und weisen die Funktion beeinflussende Genvarianten auf: CYP2D6 mit *2 (normale Aktivität, EM); *3 bis *6 (keine Aktivität, PM); *9, *10,*17, *41 (verminderte Aktivität, IM) sowie Genduplikationen mit $2 \mathrm{x} * 1$ und $2 \mathrm{x} * 2$ (erhöhte Aktivität, UM), CYP2C9 mit *2 und *3 (verminderte Aktivität) sowie CYP2C19 mit *2, *3 (keine Aktivität) sowie *17 (erhöhte Aktivität).

Ziel dieser Arbeit war es, die Auswirkungen der oben genannten Genvarianten auf die Pharmakokinetik und Pharmakodynamik von Carvedilol und seiner Metaboliten zu untersuchen. Hierzu wurde unter Berücksichtigung der Ein- und Ausschlusskriterien 74 gesunden männlichen und 36 gesunden weiblichen Probanden 25 mg Carvedilol appliziert

In der Pharmakokinetik des Carvedilol und seiner Metaboliten wurden signifikante Unterschiede in Relation zum CYP2D6-Genotyp gesehen. Die AUC beider Enantiomere als Maß für die Exposition des Körpers gegenüber Carvedilol nahm in unserer Studie mit steigender CYP2D6-Genaktiviät signifikant ab. Hierbei war die AUC von R-Carvedilol bei PM um das 3,6-fache höher als bei Trägern von 2 aktiven CYP2D6-Allelen und entsprechend von S-Carvedilol bei PM um das 2-fache höher als bei Trägern von 2 aktiven CYP2D6Allelen. Ebenfalls konnten wir bei beiden Desmethylcarvedilol-Metaboliten einen signifikanten Abfall der AUCs bei steigender CYP2D6-Genaktivität verzeichnen. Während die AUC von R-Desmethylcarvedilol bei PM 4-fach höher war als bei Trägern von 2 aktiven CYP2D6-Allelen, war entsprechend die AUC von S-Desmethylcarvedilol bei PM 3-fach höher als bei Trägern von 2 aktiven CYP2D6-Allelen. Der AUC-Verlauf des R-4-OHMetaboliten verhielt sich gegenläufig zum AUC-Verlauf von Carvedilol und Desmethylcarvedilol. Bei Trägern von 2 aktiven CYP2D6-Allelen war für den R-4-OHMetaboliten die AUC 1,2-fach signifikant höher als bei PM. Weiter nahm mit steigender CYP2D6-Genaktivität die maximale Plasmakonzentration beider 4-OH-Metaboliten signifikant zu. Aus dem Vergleich zwischen Personen mit kompletter CYP2D6-Defizienz und Personen mit hoher CYP2D6-Aktivität (CYP2D6*1/*1) konnte berechnet werden, dass bei 
Zusammenfassung

den CYP2D6*1/*1-Trägern ungefähr $64 \%$ des R-Carvedilol und lediglich $37 \%$ des SCarvedilol über CYP2D6 und der Rest durch CYP2D6-unabhängige metabolisierende Enzyme eliminiert wurde. Hervorzuheben ist unsere Beobachtung bezüglich der CYP2D6Allel-spezifischen Clearance: Die in vorangegangenen Studien als normal aktiv eingestufte CYP2D6*2-Variante wies in unserer Studie bezüglich der Carvedilol-Pharmakokinetik eine verminderte und die bisher als vermindert aktiv eingestuften Varianten $* 17$ und $* 41$ wiesen annähernd keine Aktivität auf. Schließlich konnten weder in Relation zum CYP2C9- noch in Relation zum CYP2C19-Genotyp wesentliche signifikante Unterschiede in der Pharmakokinetik von Carvedilol und seiner Metaboliten gesehen werden.

Mit Hilfe von Ergometrien und Schellong-Tests wurden die Carvedilol-Wirkungen auf die Parameter Herzfrequenz und Blutdruck in Ruhe und unter Belastung erfasst. Es fanden sich genotyp-unabhängig pharmakodynamische Effekte des Carvedilol auf Herzfrequenz und Blutdruck. Jedoch konnten trotz signifikanter pharmakokinetischer Unterschiede keine wesentlich signifikanten Unterschiede in den Wirkungen und Nebenwirkungen von Carvedilol zwischen den untersuchten CYP2D6-Genotypen gesehen werden.

In Zukunft sind weitere Studien wünschenswert, die neben den in unserer Studie untersuchten polymorphen Enzymvarianten weitere Varianten wie z.B. die Gruppe der CYP2D6 ultrarapid metabolizer und andere Carvedilol metabolisierende Enzyme untersuchen. 
Literaturverzeichnis

\section{Literaturverzeichnis}

Aklillu E, Persson I, Bertilsson L, Johansson I, Rodrigues F, Ingelman-Sundberg M (1996): Frequent distribution of ultrarapid metabolizers of debrisoquine in an ethiopian population carrying duplicated and multiduplicated functional CYP2D6 alleles. J Pharmacol Exp Ther $\underline{278(1)}, 441-6$

Arzneimittelfachinformation Querto ${ }^{\circledR}$ 6,25/12,5/25 mg; NYCOMED; Deutschland 2009

Baek IH, Yun MH, Yun HY, Kwon KI (2008): Pharmacokinetic/pharmacodynamic modeling of the cardiovascular effects of beta blockers in humans. Arch Pharm Res $\underline{31(6)}, 814-21$

Bartsch W, Sponer G, Strein K, Müller- Beckmann B, Kling L, Bohm E, Martin U, Borbe HO (1990): Pharmacological characteristics of the stereoisomers of carvedilol. Eur J Clin Pharmacol $\underline{38}, 104-107$

Boelsterli UA: Mechanistic toxicology the molecular basis of how chemicals disrupt biological targets, illustrated edition; Taylor und Francis Ltd, London 2002

Böhm M, Borst UE, Schmieder RE, Wehling M, John S: Therapiehandbuch Carvedilol; Thieme-Verlag, Stuttgart 2001

Brockmöller J, Kirchheiner J, Meisel C, Roots I. (2000): Pharmacogenetic diagnostics of cytochrome P450 polymorphisms in clinical drug development and in drug treatment. Pharmacogenomics $\underline{1(2)}, 125-151$

Brodde OE, Bruck H, Leineweber K (2006): Cardiac adrenoceptors: physiological and pathophysiological relevance. J Pharmacol Sci 100(5), 323-37

Broly F, Meyer UA (1993): Debrisoquine oxidation polymorphism: phenotypic consequences of a 3-base-pair deletion in exon 5 of the CYP2D6 gene. Pharmacogenetics $\underline{3(3)}$, 123-30

Cheng HY, Jusko WJ (1988): Mean residence time concepts for pharmacokinetic systems with nonlinear drug elimination described by the Michaelis-Menten equation. Pharm Res $\underline{5(3)}, 156-64$

Dargie HJ (2001): Effect of carvedilol on outcome after myocardial infarction in patients with left-ventricular dysfunction: the CAPRICORN randomised trial. Lancet 357(9266), 1385-90 
Literaturverzeichnis

De Morais SM, Wilkinson GR, Blaisdell J, Nakamura K, Meyer UA, Goldstein JA (1994 a): The major genetic defect responsible for the polymorphism of S-mephenytoin metabolism in humans. J Biol Chem 269(22), 15419-22

De Morais SM, Wilkinson GR, Blaisdell J, Mever UA, Nakamura K, Goldstein JA (1994 b): Identification of a new genetic defect responsible for the polymorphism of (S)-mephenytoin metabolism in Japanese. Mol Pharmacol 46, 594-598

Dupont AG (1990): Effects of carvedilol on renal function. Eur J Clin Pharmacol 38 Suppl 2, 96-100

Eichelbaum M: Ein neuentdeckter Defekt im Arzneimittel-Stoffwechsel des Menschen: Die fehlende N-Oxidation des Spartein. Medizinische Habilitationsschrift Bonn 1975

Eisenberg EJ, Patterson WR, Kahn GC (1989): High-performance liquid chromatographic method for the simultaneous determination of the enantiomers of carvedilol and its $\mathrm{O}$ desmethyl metabolite in human plasma after chiral derivatization. J Chromatogr 493(1), 10515

Estler CJ: Pharmakologie und Toxikologie: Lehrbuch für Studierende der Medizin, Pharmazie und Naturwissenschaften, 5. Auflage; Schattauer-Verlag; Stuttgart 2000

Frishman WH (1998): Carvedilol. N Engl J Med 339, 1759-65

Fuselli S, Dupanloup I, Frigato E, Cruciani F, Scozzari R, Moral P, Sistonen J, Sajantila A, Barbujani G (2004): Molecular diversity at the CYP2D6 locus in the Mediterranean region. Eur J Hum Genet 12(11), 916-24

Gaedigk A, Blum M, Gaedigk R, Eichelbaum M, Meyer UA (1991): Deletion of the entire cytochrome P450 CYP2D6 gene as a cause of impaired drug metabolism in poor metabolizers of the debrisoquine/sparteine polymorphism. Am J Hum Genet 48(5), 943-50

Gaedigk A, Gotschall RR, Forbes NS, Simon SD, Kearns GL, Leeder JS (1999): Optimization of cytochrome P4502D6 (CYP2D6) phenotype assignment using a genotyping algorithm based on allele frequency data. Pharmacogenetics $\underline{9(6)}, 669-82$ 
Literaturverzeichnis

Gaedigk A, Ndjountché L, Divakaran K, Dianne Bradford L, Zineh I, Oberlander TF, Brousseau DC, McCarver DG, Johnson JA, Alander SW, Wayne Riggs K, Steven Leeder J (2007): Cytochrome P4502D6 (CYP2D6) gene locus heterogeneity: characterization of gene duplication events. Clin Pharmacol Ther $\underline{81(2)}$, 242-51

Gibaldi M, Perrier D: Pharmacokinetics, 2. Auflage; Informa Healthcare-Verlag; New York 1982

Giessmann T, Modess C, Hecker U, Zschiesche M, Dazert P, Kunert-Keil C, Warzok R, Engel G, Weitschies W, Cascorbi I, Kroemer HK, Siegmund W (2004): CYP2D6 genotype and induction of intestinal drug transporters by rifampin predict presystemic clearance of carvedilol in healthy subjects. Clin Pharmacol Ther 75(3), 213-22

Giugliano D, Acampora R, Marfella R, De Rosa N, Ziccardi P, Ragone R, De Angelis L, D'Onofrio F (1997): Metabolic and cardiovascular effects of carvedilol and atenolol in noninsulin-dependent diabetes mellitus and hypertension. A randomized, controlled trial. Ann Intern Med 126(12), 955-9

Goldstein JA, de Morais SM (1994): Biochemistry and molecular biology of the human CYP2C subfamily. Pharmacogenetics $\underline{4}$, 285-299

Gonzalez FJ, Skoda RC, Kimura S, Umeno M, Zanger UM, Nebert DW, Gelboin HV, Hardwick JP and Meyer UA (1988): Characterization of the common genetic defect in humans deficient in debrisoquine metabolism. Nature $\underline{331(6155)}$, 442-6

Gough AC, Miles JS, Spurr NK, Moss JE, Gaedigk A, Eichelbaum M, Wolf CR (1990): Identification of the primary gene defect at the cytochrome $\mathrm{P}(450)$ CYP2D locus. Nature $\underline{347}$, 773-776

Gough AC, Smith CA, Howell SM, Wolf CR, Bryant SP, Spurr NK (1993): Localization of the CYP2D gene locus to human chromosome 22q13.1 by polymerase chain reaction, in situ hybridization, and linkage analysis. Genomics $\underline{15(2)}$, 430-2

Gray IC, Nobile C, Muresu R, Ford S, Spurr NK (1995): A 2.4-megabase physical map spanning the CYP2C gene cluster on chromosome 10q24. Genomics $\underline{28(2)}$, 328-32 
Literaturverzeichnis

Hanioka N, Kimura S, Meyer UA, Gonzalez FJ (1990): The human CYP2D locus associated with a common genetic defect in drug oxidation: a G1934----A base change in intron 3 of a mutant CYP2D6 allele results in an aberrant 3' splice recognition site. Am J Hum Genet $\underline{47(6)}, 994-1001$

Hardman JG, Limbird LE, Gilman AG: Goodman and Gilman`s the pharmacological basis of therapeutics, 10. Auflage; McGraw-Hill-Verlag, New York 2001

Honda M, Ogura Y, Toyoda W, Taguchi M, Nozawa T, Inoue H, Hashimoto Y (2006): Multiple regression analysis of pharmacogenetic variability of carvedilol disposition in 54 healthy Japanese volunteers. Biol Pharm Bull 29(4), 772-8

Ingelman-Sundberg M. (2005): Genetic polymorphisms of cytochrome P450 2D6 (CYP2D6): clinical consequences, evolutionary aspects and functional diversity. Pharmacogenomics J $\underline{5(1)}, 6-13$

Jacob S, Rett K, Wicklmayr M, Agrawal B, Augustin HJ, Dietze GJ (1996): Differential effect of chronic treatment with two beta-blocking agents on insulin sensitivity: the carvedilol-metoprolol study. J Hypertens 14(4), 489-94

Johansson I, Oscarson M, Yue QY, Bertilsson L, Sjöqvist F, Ingelman-Sundberg M (1994): Genetic analysis of the Chinese cytochrome P4502D locus: characterization of variant CYP2D6 genes present in subjects with diminished capacity for debrisoquine hydroxylation. Mol Pharmacol 46(3), 452-9

Johansson I, Lundqvist E, Dahl ML, Ingelman-Sundberg M (1996): PCR-based genotyping for duplicated and deleted CYP2D6 genes. Pharmacogenetics $\underline{6(4)}, 351-5$

Kagimoto M, Heim M, Kagimoto K, Zeugin T, Meyer UA (1990): Multiple mutations of the human cytochrome P450IID6 gene (CYP2D6) in poor metabolizers of debrisoquine. Study of the functional significance of individual mutations by expression of chimeric genes. J Biol Chem 265(28), 17209-14

Kimura S., Umeno M., Skoda RC., Meyer UA., Gonzalez FJ. (1989): The human debrisoquine 4-hydroxylase (CYP2D) locus: sequence and identification of the polymorphic CYP2D6 gene, a related gene, and a pseudogene. Am J Hum Genet 45, 889-904 
Literaturverzeichnis

Kirchheiner J, Brockmöller J (2005): Clinical consequences of cytochrome P450 2C9 polymorphisms. Clin Pharmacol Ther $\underline{77(1)}$, 1-16

Kirchheiner J, Tsahuridu M, Jabrane W, Roots I, Brockmöller J (2004): The CYP2C9 polymorphism: from enzyme kinetics to clinical dose recommendations. Personalized Med $\underline{1}$, $1-22$

Kupfer A, Preisig R (1984): Pharmacogenetics of mephenytoin: a new drug hydroxylation polymorphism in man. Eur J Clin Pharmacol 26(6), 753-9

Kutt H, Wolk M, MC Dowell F (1964): Insufficient parahydroxylation as a cause of diphenylhydantoin toxicity. Neurology $\underline{14,542-548}$

Leonetti G, Sampieri L, Cuspidi C, Boselli L, Terzoli L, Rupoli L, Zanchetti A (1987): Resting and postexercise hemodynamic effects of carvedilol, a beta-adrenergic blocker and precapillary vasodilator in hypertensive patients. J Cardiovasc Pharmacol 10 Suppl 11, 94-6

Mahgoub A, Idle JR, Dring LG, Lancaster R and Smith RL (1977): Polymorphic hydroxylation of Debrisoquine in man. Lancet 1977, 2, 584-6

Masimirembwa C, Persson I, Bertilsson L, Hasler J, Ingelman-Sundberg M (1996): A novel mutant variant of the CYP2D6 gene (CYP2D6*17) common in a black African population: association with diminished debrisoquine hydroxylase activity. $\mathrm{Br} \mathrm{J}$ Clin Pharmacol 42(6), 713-9

McPhillips JJ, Schwemer GT, Scott DI, Zinny M, Patterson D (1988): Effects of carvedilol on blood pressure in patients with mild to moderate hypertension. A dose response study. Drugs 36 Suppl 6, 82-91

Miners JO, Birkett DJ (1998): Cytochrome P450C9: an enzyme of major importance in human drug metabolism. Br J Clin Pharmacol 45, 525-538

Morgan T (1994): Clinical pharmacokinetics and pharmacodynamics of carvedilol. Clin Pharmacokinet 26(5), 335-46

Moser M, Frishman W (1998): Results of therapy with carvedilol, a beta-blocker vasodilator with antioxidant properties, in hypertensive patients. Am J Hypertens $\underline{11(1 \mathrm{Pt} 2)}, 15-22$ 
Literaturverzeichnis

Molenaar P, Christ T, Ravens U, Kaumann A (2006): Carvedilol blocks beta2- more than beta1-adrenoceptors in human heart. Cardiovasc Res $\underline{69(1)}, 128-39$

Mutschler E, Geisslinger G, Kroemer HK, Schäfer-Korting M: Mutschler Arzneimittelwirkungen, Lehrbuch der Pharmakologie und Toxikologie, 8. Auflage; Wissenschaftliche Verlagsgesellschaft mbH, Stuttgart 2001

Neugebauer G, Akpan W, von Möllendorff E, Neubert P, Reiff K (1987): Pharmacokinetics and disposition of carvedilol in humans. J Cardiovasc Pharmacol 10 Suppl 11, 85-8

Neugebauer G, Akpan W, Kaufmann B, Reiff K (1990): Stereoselective disposition of carvedilol in man after intravenous and oral administration of the racemic compound. Eur $\mathbf{J}$ Clin Pharmacol 38 Suppl 2, 108-11

Ohno A, Saito Y, Hanioka N, Jinno H, Saeki M, Ando M, Ozawa S, Sawada J (2004): Involvement of human hepatic UGT1A1, UGT2B4, and UGT2B7 in the glucuronidation of carvedilol. Drug Metab Dispos 32(2), 235-9

Oldham HG, Clarke SE (1997): In vitro identification of the human cytochrome P450 enzymes involved in the metabolism of $\mathrm{R}(+)$ - and S(-)-carvedilol. Drug Metab Dispos $\underline{25}$, $970-7$

Omvik P, Lund-Johansen P (1991): Acute haemodynamic effects of carvedilol in essential hypertension at rest and during exercise. Eur Heart J 12(6), 736-40

Oscarson M, Hidestrand M, Johansson I, Ingelman-Sundberg M (1997): A combination of mutations in the CYP2D6*17 (CYP2D6Z) allele causes alterations in enzyme function. Mol Pharmacol 52(6), 1034-40

Packer M, Coats AJ, Fowler MB, Katus HA, Krum H, Mohacsi P, Rouleau JL, Tendera M, Castaigne A, Roecker EB, Schultz MK, DeMets DL (2001): Effect of carvedilol on survival in severe chronic heart failure. N Engl J Med $\underline{344(22)}, 1651-8$

Poole-Wilson PA, Swedberg K, Cleland JG, Di Lenarda A, Hanrath P, Komajda M, Lubsen J, Lutiger B, Metra M, Remme WJ, Torp-Pedersen C, Scherhag A, Skene A (2003). Comparison of carvedilol and metoprolol on clinical outcomes in patients with chronic heart failure in the Carvedilol Or Metoprolol European Trial (COMET): randomised controlled

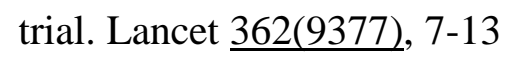


Literaturverzeichnis

Raimundo S, Fischer J, Eichelbaum M, Griese EU, Schwab M, Zanger UM (2000): Elucidation of the genetic basis of the common 'intermediate metabolizer' phenotype for drug oxidation by CYP2D6. Pharmacogenetics 10(7), 577-81

Raimundo S, Toscano C, Klein K, Fischer J, Griese EU, Eichelbaum M, Schwab M, Zanger UM (2004): A novel intronic mutation, 2988G $>$ A, with high predictivity for impaired function of cytochrome P450 2D6 in white subjects. Clin Pharmacol Ther $\underline{76}, 128-38$

Riley MS, Pórszász J, Engelen MP, Shapiro SM, Brundage BH, Wasserman K (2000): Responses to constant work rate bicycle ergometry exercise in primary pulmonary hypertension: the effect of inhaled nitric oxide. J Am Coll Cardiol 36(2), 547-56

Sachse C, Brockmöller J, Bauer S, Roots I (1997): Cytochrome P450 2D6 variants in a Caucasian population: allele frequencies and phenotypic consequences. Am J Hum Genet $\underline{60(2)}, 284-95$

Sakuyama K, Sasaki T, Ujiie S, Obata K, Mizugaki M, Ishikawa M, Hiratsuka M (2008): Functional characterization of 17 CYP2D6 allelic variants (CYP2D6.2, 10, 14A-B, 18, 27, 36, 39, 47-51, 53-55, and 57). Drug Metab Dispos 36(12), 2460-7

Saxena R, Shaw GL, Relling MV, Frame JN, Moir DT, Evans WE, Caporaso N, Weiffenbach B (1994): Identification of a new variant CYP2D6 allele with a single base deletion in exon 3 and its association with the poor metabolizer phenotype. Hum Mol Genet $\underline{3(6)}$, 923-6

Schwab M, Marx C, Zanger UM, Eichelbaum M (2002): Pharmakogenetik der Zytochrom-P450-Enzyme. Bedeutung für Wirkungen und Nebenwirkungen von Medikamenten. Dtsch Ärztebl 99(8), A $497-504$

Scott J, Poffenbarger PL (1979): Pharmacogenetics of tolbutamide metabolism in humans. Diabetes $\underline{28(1)}, 41-51$

Shimada T, Yamazaki H, Mimura M, Inui Y, Guengerich FP (1994): Interindividual Variations in Human Liver Cytochrome P-450 Enzymes Involved in the Oxidation of Drugs, Carcinogens and Toxic Chemicals: Studies with Liver Microsomes of 30 Japanese and 30 Caucasians. J Pharmacol Exp Ther 270(1), 414-423 
Literaturverzeichnis

Sim SC, Risinger C, Dahl ML, Aklillu E, Christensen M, Bertilsson L, Ingelman-Sundberg M (2006): A common novel CYP2C19 gene variant causes ultrarapid drug metabolism relevant for the drug response to proton pump inhibitors and antidepressants. Clin Pharmacol Ther $\underline{79(1)}, 103-13$

Stafylas PC, Sarafidis PA (2008): Carvedilol in hypertension treatment. Vasc Health Risk Manag 4(1), 23-30

Steen VM, Molven A, Aarskog NK, Gulbrandsen AK (1995): Homologous unequal crossover involving a $2.8 \mathrm{~kb}$ direct repeat as a mechanism for the generation of allelic variants of human cytochrome P450 CYP2D6 gene. Hum Mol Genet 4(12), 2251-7

Steimer W, Zopf K, von Amelunxen S, Pfeiffer H, Bachofer J, Popp J, Messner B, Kissling W and Leucht S (2004): Allele-specific change of concentration and functional gene dose for the prediction of steady-state serum concentrations of amitriptyline and nortriptyline in CYP2C19 and CYP2D6 extensive and intermediate metabolizers. Clin Chem 50(9), 1623-33

Stoschitzky K, Koshucharova G, Zweiker R, Maier R, Watzinger N, Fruhwald FM, Klein W (2001): Differing beta-blocking effects of carvedilol and metoprolol. Eur J Heart Fail 3(3), 343-9

Takekuma Y, Takenaka T, Kiyokawa M, Yamazaki K, Okamoto H, Kitabatake A, Tsutsui H, Sugawara M (2006): Contribution of polymorphisms in UDP-glucuronosyltransferase and CYP2D6 to the individual variation in disposition of carvedilol. J Pharm Pharm Sci 9(1), 10112

Tenero D, Boike S, Boyle D, Ilson B, Fesniak HF, Brozena S, Jorkasky D (2000): Steadystate pharmacokinetics of carvedilol and its enantiomers in patients with congestive heart failure. J Clin Pharmacol 40(8), 844-53

Van der Weide J und Hinrichs JW (2006): The Influence of Cytochrome P450 Pharmacogenetics on Disposition of Common Antidepressant and Antipsychotic Medications. Clin Biochem Rev 27(1), 17-25 www.cypalleles.ki.se/cyp2c9.htm www.cypalleles.ki.se/cyp2d6.htm 
Literaturverzeichnis

www.medicine.iupui.edu/clinpharm/ddis/table.asp

Wang G, Lei HP, Li Z, Tan ZR, Guo D, Fan L, Chen Y, Hu DL, Wang D, Zhou HH (2009):

The CYP2C19 ultra-rapid metabolizer genotype influences the pharmacokinetics of voriconazole in healthy male volunteers. Eur J Clin Pharmacol 65(3), 281-5

Weber K, Bohmeke T, van der Does R, Taylor SH (1998): Hemodynamic differences between metoprolol and carvedilol in hypertensive patients. Am J Hypertens 11(5), 614-7

Wrigthon SA, Stevens JC (1992). The human hepatic cytochromes P450 involved in drug metabolism. Crit Rev Toxicol 22, 1-21

Why HJ, Richardson PJ (1992): Effect of carvedilol on left ventricular function and mass in hypertension. J Cardiovasc Pharmacol 19 Suppl 1, 50-54

Yasar Ü, Eliasson E, Dahl ML, Johansson I, Ingelman-Sundberg M and Sjöqvist F (1999):

Validation of methods for CYP2C9 genotyping: frequencies of mutant alleles in a Swedish Population. Biochem Biophys Res Commun 254, 628-631

Yokota H, Tamura S, Furuya H, Kimura S, Watanabe M, Kanazawa I, Kondo I, Gonzalez FJ (1993): Evidence for a new variant CYP2D6 allele CYP2D6J in a Japanese population associated with lower in vivo rates of sparteine metabolism. Pharmacogenetics $\underline{3(5)}$, 256-63

You LY, Yu CN, Xie SG, Chen SQ, Zeng S (2007): Stereoselective glucuronidation of carvedilol by Chinese liver microsomes. J Zhejiang Univ Sci B $\underline{8(10)}$, 756-64

Zanger UM, Raimundo S, Eichelbaum (2004): Cytochrome P450 2D6: overview and update on pharmacology, genetics, biochemistry. M. Naunyn Schmiedebergs Arch Pharmacol $\underline{369(1)}, 23-37$

Zanger UM, Turpeinen M, Klein K, Schwab M (2008): Functional pharmacogenetics/genomics of human cytochromes P450 involved in drug biotransformation.

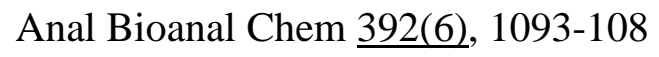

Zhou HH, Wood AJ (1995): Stereoselective disposition of carvedilol is determined by CYP2D6. Clin Pharmacol Ther 57(5), 518-24 
